\title{
lV.
}

\section{Beiträge zur Geschichte der Rezeption und der Symbolik der legitimatio per subsequens matrimonium. ${ }^{1}$ )}

\author{
Von
}

\section{Herrn Privatdozenten Dr. Ferd. Kogler}

in Innsbruck.

Einleitung . . . . . . . . . . . . . . . . . . S. 94

Die Rezeption der legitimatio per subsequens matrimonium . „ 100

Symbolische Formen der legitimatio per subsequens matrimonium " 141

I. Verwendung des bei der kirchlichen Trauung angewandten pallium oder velamen ecclesiae. . . . . „142

Il. Legitimation durch nachfolgende Ehe in der Form der Mantelsetzung. . . . . . . . . . . . . , 157

III. Andere Legitimationsformen . . . . . . . . . . " 170

\section{Einleitung.}

Die Legitimation durch nachfolgende Ehe ist ein Produkt der römischen Rechtsentwicklung. Dem germanischen Recht ist dieselbe ursprünglich fremd. ${ }^{2}$ ) Nach den germanischen Rechten gehörte das unecht geborne vom Vater an-

1) Vorliegende Arbeit wurde auf Anregung des Herrn Geheimrates Prof. Brunner unternommen, in dessen Seminar an der Universität Berlin ich im Wintersemester $1903 / 4$ arbeitete. Ich benutze gerne die Gelegenheit, Herrn Geheimrat Brunner für alle Anregung und alle Förderung, die er meinen Studien überhaupt und der vorliegenden Arbeit insbesondere zuteil werden ließ, auch an dieser Stelle meinen innigsten Dank auszusprechen. - Gleichzeitig oder wenigstens in nächster Zeit erscheint meine Studie über die legitimatio per rescriptum principis von Justinian bis zum Tode Karl IV. - ${ }^{2}$ ) Edict. Roth. 222 u. Liutpr. 106 enthalten keine legitimatio per subsequens matrimonium, wie Pertile, Storia del diritto Italiano ${ }^{2}$ III S. 391 Anm. 22 glaubt. Es handelt sich dortselbst nicht um vor, sondern um nach Eingehung der Ehe geborne Kinder. Ebensowenig enthält Roth. 155 eine Legitimation, wie Pertile a. a. O. S. 391 darstellt. 
erkannte Kind zur Familie des Vaters, hatte ihm gegenüber ein gewisses Erbrecht und nahm Anteil an den Rechten und Pflichten der väterlichen Sippe. Die unechte Geburt hatte weder eine geminderte Rechtsfähigkeit noch eine Standesminderung zur Folge. ${ }^{1}$ ) Bei dieser Sachlage war nach einem Institut, wodurch unehelichen Kindern die Rechte ehelicher gegeben werden, und insbesondere nach einer legitimatio per subsequens matrimonium kein Bedürfnis. Erst nach und nach hat sich unter dem entscheidenden Einfluß der Kirche, welche alle außerehelichen Geschlechtsverbindungen verpönte, die Rechtsstellung der unehelichen Kinder verschlechtert, bis man im deutschen Mittelalter bei deren Rechtlosigkeit angelangt war.

Anders lag die Sache bei den Römern. Diese kannten als Rechtsinstitut neben der vollgültigen Ehe noch ein zweites eheähnliches Geschlechtsverhältnis, den Konkubinat. Die aus diesem entsprossenen Kinder, die liberi naturales im technischen Sinne, gehörten nicht zur Familie und zum Stande des Vaters und hatten bis in die Zeit Justinians diesem gegenüber kein Erbrecht. Erst Justinian gab ihnen ein gewisses beschränktes Erbrecht nach ihrem Erzeuger, aber nur unter der Voraussetzung, daß derselbe weder eheliche Kinder noch eine rechtmäßige Gattin hinterläßt. ${ }^{2}$ )

Hier war das Bedürfnis nach einer Legitimation gegeben. Als temporäres Institut kannten eine legitimatio per

1) Über die rechtliche Stellung der Unechten in den germanischen Rechten vgl. Brunner, Die unechte Vaterschaft in den älteren germ. Rechten, diese Ztschr. 17. Bd. (1896); Ständerechtliche Probleme, diese Ztschr. 23. Bd. (1902) S. 198 ff. Maurer, Die unechte Geburt nach altnordischem Recht, Sitzungsberichte der Münchener Akad. philosoph.histor. Kl. Jg. 1883. Wilda, Von den unecht gebornen Kindern, Ztschr. f. deutsches Recht 15. Bd. (1855). Riv e, Zur Lehre von der Beurteilung der außerehelichen Verwandtschaft nach deutschem Recht, Ztschr. f. Rechtsgesch. 3. Bd. (1863). W. Sickel, Das Thronfolgerecht der unechten Karolinger, diese Ztschr. 24. Bd. (1903). Boden, Mutterrecht und The im altnordischen Recht. Berlin 1904. Einen kurzen Überblick über die ursprüngliche Stellung der Unechten und die Verschlechterung ibrer Lage durch den Einfluß der Kirche gebe ich in meiner Arbeit über die legitimatio per rescriptum principis. - ${ }^{2}$ ) Nov. 18 cap. 5 Nov. 89 cap. 13. 
subsequens matrimonium ${ }^{1}$ ) schon Verordnungen der Kaiser Konstantin, Zeno und Anastasius; zur dauernden Geltung verholfen aber wurde ihr erst durch die Gesetzgebung Justinians. Durch die nachfolgende Ehe der Eltern erhielten die im Konkubinat erzeugten Kinder, die liberi naturales, - denn nur diesen gegenüber war die Legitimation zulässig - vollständig die rechtliche Stellung der ehelichen Kinder.

Dieses Institut, von dem wir in nachjustinianischer Zeit bis zu Beginn des 12. Jahrhunderts keine Kunde mehr haben, fand seit Anfang des 12. Jahrhunderts, seit die aufblühende Rechtswissenschaft sich näher mit den justinianischen Rechtsquellen zu beschäftigen begann, zuerst in Frankreich und später auch allmählich in den meisten übrigen Ländern Aufnahme, wobei die von Justinian zum Beweis der Verwandlung des Konkubinats in eine Ehe vorgeschriebene Errichtung von instrumenta dotalia, da für Eingehung der Ehe ohnedies eine bestimmte öffentliche Form erforderlich war, in Wegfall kam. Ein entscheidender Wendepunkt trat insbesondere damit ein, daß Papst Alexander III. im Anschluß an das dritte lateranensische Konzil im Jahre 1179 die Legitimation durch nachfolgende Ehe auch für das kanonische Recht rezipierte und zwar gegenüber der Vorschrift Justinians mit der Modifikation, daß alle Arten unehelicher Kinder mit alleiniger Ausnahme der im Ehebruch erzeugten, der adulterini, durch die nachfolgende Ehe legitimiert werden:

Tanta est vis matrimonii, ut qui antea sunt geniti post contractum matrimonium legitimi habeantur. Si autem vir vivente uxore sua aliam cognoverit et ex ea prolem susceperit, licet post mortem uxoris eandem duxerit, nihi-

1) H. Wolf, Die legitimatio per subsequens matrimonium nach justinianischem Recht. Braunschweig 1881. Dieck, Beiträge zur Lehre von der Legitimation durch nachfolgende Ehe. Halle 1832. Glück, Erläuterungen der Pandekten II, $279 \mathrm{ff}$. Norma nn, De legitimatione secundum ius patrium tam antiquum quam hodiernum. Hafniae 1823. Ein Verzeichnis der größtenteils gemeinrechtlichen Abhandlungen über die Legitimation vom 16.- 18. Jahrh. findet sich bei M. Lipenius, Bibliotheca realis iuridica. Lipsiae 1742 Bd. I S. $338 \mathrm{f}$. 
lominus spurius erit filius et ab hereditate reppellendus, praesertim si in mortem uxoris prioris alteruter eorum aliquid fuerit machinatus, quoniam matrimonium legitimum inter se contrahere non potuerunt. ${ }^{1}$ )

Die Wirkung der nachfolgenden Ehe der Eltern für die Kinder sollte nach der kanonischen Vorschrift Alexander III. nicht etwa bloß auf das kirchliche Gebiet sich erstrecken, sondern auch für das weltliche Rechtsgebiet Geltung haben. Nach der kirchlichen Auffassung ist die Kirche eben die übergeordnete Einheit, in welche das weltliche Gemeinwesen, um als Teil der göttlichen Weltordnung gelten zu können, sich einfügen muß. Die Kirche jener Zeit beansprucht auch die Summe der weltlichen Gewalt und vindiziert sich demgemäß das Recht, auch über rein weltliche Angelegenheiten Gesetze zu geben oder die von der weltlichen Macht gegebenen Gesetze aufzuheben. ${ }^{2}$ ) Im vorliegenden Falle kommt für die Ausdehnung der von der Kirche zum Rechtssatz erhobenen legitimatio per subsequens matrimonium auf die weltliche Rechtssphäre aber noch der spezielle Grund in

1) Mansi, Conciliorum collectio XXII Spalte 388, Compilatio I lib. IV, tit. 18 cap. 6 u. cap. 6 X IV. 17. Den letzten Satz ${ }_{n}$ quoniam matrimonium legitimum inter se contrahere non potuerunt", welcher sich im Originaltext und noch in der compilatio I findet, ließ Raymund von Pennaforte in der Gregoriana weg, weil derselbe zu Mißverständnissen Anlaß geben konnte. So glaubt G. L. Boehmer, De legitimatione ex damnato coitu natorum (Exercitatio XX ad pandectas), daß die adulterini nur dann nicht legitimiert werden können, wenn das adulterium ein impedimentum dirimens bilde. Alexander III. wollte aber alle adulterini von der Legitimation ausschließen, er reibt nur dem einfachen adulterium den qualifizierten Fall an. - ") Vgl. Stutz, Kirchenrecht $\$ 28$, Holtzendorffs Enzyklopädie der Rechtswissenschaft 6. Aufl, hg. v. Kohler II S. 847 f. Freisen, Geschichte des kanon. Eherechtes ${ }^{2}$ S. 876 ff. Vgl. die im ersten Jahrzehnt des 13. Jahrh. verfaßte Glosse des Alanus bei Schulte, Literaturgeschichte der compilationes antiquae in den Sitzungsber. der Wiener Akad. 66. Bd. (1871) S. 89 f.: (Imperator) gladium habeat a papa, est enim corpus unum ecclesiae, ergo unum solum caput habere debet .... ergo papa iudex ordinarius est quoad spiritualia et quoad temporalia, potest $a b$ eo deponi imperator .... et quod dictum est de imperatore, dictum habeatur de quolibet rege vel principe, qui nulli subest, unusquisque enim tantum iuris habet in regno suo, quantum imperator in imperio. 
Betracht, daß die Kirche das ganze Mittelalter hindurch die Ehegesetzgebung unbestritten ausübte und infolgedessen für berechtigt galt, auch die Rechtswirkungen der Ehe für das bürgerliche Recht zu umschreiben. So sagt auch Antonius de Rosellis in seinem 1407 geschriebenen Tractatus de legitimatione 1): Legitimatio prestetur mediante actu spiritualis matrimonii et de ipso disponere est solius pape.

Man braucht übrigens über die Dekretale Alexanders III. nicht hinauszugehen, um zu sehen, daß dieselbe auch für das weltliche Recht Greltung haben sollte. Ist doch darin selbst bestimmt, daß die aus ehebrecherischen Verbindungen hervorgegangenen Kinder der Legitimation nicht teilhaftig und von der Erbfolge ausgeschlossen sein sollten. Aus dieser Normierung folgt e contrario, daß die andern Arten unehelicher Kinder, wenn sie durch nachfolgende Ehe der Eltern legitimiert wurden, erbfähig sein, also auch für das weltliche Rechtsgebiet als legitimi gelten sollten. Übrigens hat Alexander III., damit jeder Zweifel ausgeschlossen ist, selbst in einem speziellen Falle entschieden, dafo eine solche Legitimation auch hinsichtlich der hereditas paterna wirksam sein solle. ${ }^{2}$ )

Auf dem kirchlichen Rechtsgebiet regte sich, soweit wir sehen können, gegen die legitimatio per subsequens matrimonium keinerlei Widerspruch, war ja doch die oberste gesetzgebende Gewalt des Papstes in der Kirche in jener Zeit schon unbestritten anerkannt und galt überdies das römische Recht, dem dieses Institut entnommen war, als Recht der Kirche und teilweise auch des Klerus.

Aber der Klerus suchte dieses neue Institut auch hinsichtlich der bürgerlichen Rechtswirkungen überall zur Geltung zu bringen. Die profanen Rechtsquellen heben, wie wir noch sehen werden, wiederholt ausdrücklich hervor, dafo die legitimierende Kraft der Ehe durch die Einwirkung des "geistlichen Rechtes" in der weltlichen Rechtssphäre Eingang fand. In Italien, Frankreich und den nordischen Ländern scheint sich die Aufnahme ganz glatt ohne jedes

1) Darüber Schulte, Geschichte der Quellen u. Literatur des kan. R. II S. 303. - ${ }^{2}$ ) Comp. I lib. IV tit. 17 cap. 1 = cap. 1 X IV. 17. 
Widerstreben des Volkes vollzogen zu haben. In Deutschland und England aber lehnte sich das allgemeine Rechtsbewußtsein des Volkes entschieden gegen eine solche Neuerung auf. Die unter dem Einfluß der Kirche sich ausbildende Anschauung, da $\beta$ die Unechten eine geminderte Rechtsfähigkeit besitzen, war hier so tief eingewurzelt, daß man jetzt den kirchlichen Vorschriften, welche unter Umständen eine Besserung der Lage gewisser Unechter bezweckten, energisch widerstrebte. Zudem wuchs mit dem Erwachen des Nationalgefühls in Deutschland, das in dem eingeschobenen Satz des Sachsenspiegels (I. 3 \& 3 ), daß der Papst das Landund Lehnrecht nicht ändern dürfe, einen beredten Ausdruck fand, von selbst auch der Widerstand gegen das kanonische Recht, das im Laufe der Zeit, ob seines universellen Charakters, die nationalen Empfindungen immer schwächer berücksichtigte. ${ }^{1}$ ) Da dem Volke überdies die echtigende Kraft der Ehe etwas zu Abstraktes und Unfaßbares war, so sehen wir denn in England und Deutschland - allerdings mit verschiedeńem Erfolge - einen interessanten Kampf entbrennen zwischen den von den kirchlichen Organen begünstigten und getragenen neuen Rechtssätzen und dem im lebendigen Rechtsbewußtsein des Volkes fußenden alten Recht. In England war der Widerstand gegen das fremde Recht erfolgreich. Die Legitimation durch nachfolgende Ehe hat sich nicht Eingang zu verschaffen vermocht. In Deutschland hingegen mußte schließlich, als mit der Klerisei zum gemeinsamen Kampfe für das geschriebene Recht auch der gelehrte Juristenstand, dem bald auch die Rechtssprechung ausschließlich zufiel, sich verband, das Volksrecht immer mehr an Boden verlieren und konnte auf die Dauer der im römisch-kanonischen Recht enthaltenen legitimatio per subsequens matrimonium seine Anerkennung nicht mehr versagen.

Um aber die für die Kinder durch die nachfolgende Ehe der Eltern eintretende Rechtswirkung auch äußerlich zu dokumentieren und dem Volke begreiflicher erscheinen zu lassen, wurde diese Legitimation vielfach in bestimmte

1) Friedberg, Das kanon. u. Kirchenrecht. Deutsche Ztschr. f. Kirchenrecht III. F. 8. Bd. (1898) S. 12. 
symbolische Formen gekleidet, die sich in Italien, Frankreich und der Normandie, England, Deutschland und den nordischen Ländern gleichmäßig nachweisen lassen. Vorliegende Zeilen wollen nun zur Geschichte der Rezeption und der Symbolik der Legitimation durch nachfolgende Ehe einen kleinen Beitrag liefern. Sie wollen einmal zeigen, wie sich dieselbe, getragen vom Klerus und dem gelehrten Juristenstande, gegenüber dem alten Gewohnheitsrecht fast allüberall Eingang zu verschaffen wußte, und ferner den Formen nachgehen, in welche diese Legitimation gekleidet wurde. Dabei konnte eine Vollständigkeit der einschlägigen Quellenstellen bei einer Arbeit, die sich teilweise über Italien, Frankreich und die Normandie, England, die nordischen Länder und Deutschland erstreckt und zugleich über mehrere Jahrhunderte sich ausdehnt, weder erreicht werden noch auch beabsichtigt sein. Immerhin aber dürfte das in dieser Form zum erstenmal Gebotene hinreichend sein, um den allgemeinen Entwicklungsgang wenigstens in großen Zügen erkennen zu lassen.

\section{Die Rezeption der legitimatio per subsequens matrimonium.}

In Italien, wo Justinian nach der Vernichtung der Ostgotenherrschaft seine Gesetzbücher im vollen Umfange eingeführt hatte, war das Justinianische Recht nie ganz aus der Praxis und der kümmerlichen Rechtswissenschaft verschwunden ${ }^{1}$ ), aber seine Herrschaft war eine sehr beschränkte und insbesondere in Oberitalien, aber auch noch in Mittelitalien, mußte es dem siegreich vordringenden longobardischen Recht eine Position nach der andern überlassen. Die Nachrichten über die Geltung einzelner Institute des römischen Rechtes sind bis in das 12 . Jahrhundert hinein äußerst spärlich und es darf wohl mit Sicherheit angenommen werden, daß der Großteil der Justinianischen Rechtssätze und

1) Savig ny, Geschichte des röm. R. im M.-A. II S. 182 f. Conrat, Geschichte der Quellen und Literatur des röm. R. im früheren M.-A. S. 46 ff. Bethmann-Hollweg, Zivilprozeß des gem. Rechtes V S. $311 \mathrm{ff}$. Fitting, Zur Geschichte der Rechtswissenschaft im M.-A. diese Ztschr. 6. Bd. Rom. Abt. S. $94 \mathrm{ff}$. 
Einrichtungen überhaupt unbekannt geblieben oder vielmehr in Vergessenheit geraten ist. Von der legitimatio per subsequens matrimonium haben wir keine Kunde bis zur Glossatorenzeit. Erst die erwachende Rechtswissenschaft hat dieselbe aus dem Schutte der Vergessenheit wieder hervorgeholt.

Die zu Beginn der Glossatorenzeit (um 1125) wahrscheinlich im lombardischen Italien entstandene Epitome exactis regibus ${ }^{1}$ ) kennt wohl die der Legitimation verwandten Institute der Adoption und Arrogation ${ }^{2}$ ), definiert auch unter Hinweis auf die Institutionen Justinians den Begriff spurius ${ }^{3}$ ), von einer Legitimation aber weif sie noch nichts.

Das Dekret Gratians und die um die Mitte des 12. Jahrhunderts dazu verfaßten Summen des Paucapalea ${ }^{4}$ ), des Magister Rolandus, nachmaligen Papstes Alexander III. ${ }^{5}$ ), und des Magister Rufinus ${ }^{6}$ ), denen doch sonst das Justinianische Recht nicht unbekannt ist, kennen das Institut der Legitimation ebenfalls noch nicht.

Papst Alexander III. hat plötzlich im Jahre 1179 die Legitimation durch nachfolgende Ehe, ohne daß sich die frühere Kenntnis derselben in den juristischen Schriften nachweisen ließe, für das kanonische Recht anerkannt. ') Alexander III., der ehemalige Magister Rolandus, der in seiner Summe zum Dekret Gratians dieser Legitimation noch keine Erwähnung tut, hat seine Kenntnis davon

1) Ausgabe von M. Conrat, Berlin 1884. Dazu Fitting, a. a. O., welcher (S. $178 \mathrm{ff}$.) als Entstehungsort Nordfrankreich und als Entstehungszeit die zweite Hälfte des 12. Jahrhunderts annimmt, was schon aus dem Grunde unannehmbar sein dürfte, weil die französischen Quellen seit dem Dekrete Ivos von Chartres die legitimatio per subsequens matrimonium kennen ( $\mathrm{vgl}$. \&. $105 \mathrm{ff}$.), während dieselbe der epitome fremd ist. - $\left.{ }^{2}\right)$ II $\$ 12$ Filius adoptivus est, quem aliquis sibi adoptat in filium et accipit datum a patre, et econtra ipse, qui adoptat, pater adoptivus est, est auten adoptio gratuita quedam electio, qua quis aliquem sibi eligit in filium. Filius arrogatus est, quem sibi quis eligit in filium, quando est sui iuris. - ${ }^{3}$ ) II $\$ 17$ Spurius est filius incestis nuptiis natus, scilicet a Greca voce sporas, id est vulgo conceptus vel sine patre ut Instit. de nuptiis $(=1.12$ J. I, 10). - ${ }^{4}$ ) Ausgabe von Joh. Fr. v. Schulte, Gießen 1890. - ${ }^{5}$ ) Hg. von Thaner, Innsbruck 1874. - ') Hg. von Singer, Paderborn 1902 (Mangelhafte Ausgabe von Schulte, Gießen 1892). - 7) S. $96 \mathrm{ff}$. 
sicher der römischen Rechtswissenschaft entlehnt. Hiermit war für die Rezeption der legitimatio per subsequens matrimonium nicht nur in Italien sondern überhaupt der entscheidende Schritt getan. Die Dekretale Alexanders wurde von Bernhard von Pavia in seine um das Jahr 1191 verfaßte Extravagantensammlung, die sogenannte Compilatio prima ${ }^{1}$ ) aufgenommen und ist von da dann in den liber extravagantium Gregors IX. übergegangen. ${ }^{2}$ ) Dadurch wurde die Alexandrinische Norm endgültig fixiert und ist Gegenstand der Glossierung und der wissenschaftlichen Erörterung geworden, die allerdings nicht das Institut als solches in Frage stellten, sondern in der Regel mit den Wirkungen und Voraussetzungen desselben sich beschäftigten. Hier soll nur der zeitlich nächstfolgenden Quellenstellen italienischen Ursprungs gedacht werden und zwar mit Ausschluß der speziell mit dem Justinianischen Recht sich beschäftigenden Literatur, welche die im corpus civilis Iustiniani enthaltene Legitimation als etwas Gegebenes hinnahm und deren Anwendbarkeit lehrte.

Bernhard von Pavia tut in seiner gegen das Ende des 12. Jahrhunderts entstandenen Summe zur compilatio prima $^{3}$ ) der römischen Legitimationsarten einfach ohne jedwede weitere juristische Erörterung Erwähnung und beruft sich für die legitimatio per subsequens matrimonium auf Justinianisches und kanonisches Recht: Qui autem non sunt ab initio legitimi, fiunt quandoque legitimi pluribus modis: ut ecce solutus ex soluta filios genuit, deinde ipsam uxorem accepit praestans concubinae nomen uxoris, filii legitimi efficiuntur ut in Instit. de nuptiis $\S$ ultimo $[=\S 13$ J. I, 10] et infra eod. c. 1 et c. tanta $[=$ Comp. I lib. 4 tit. 18 , cap. 1 u. $6=$ c. 1 u. 6 X IV, 17]. Obwohl Bernhard hier sowohl auf das Justinianische Recht als auch auf die Dekretale Alexander III. sich beruft, so tradiert er eigentlich doch nur rein kanonisches Recht. Er erklärt alle ex soluto et soluta geniti, also entsprechend

1) Lib. IV tit. 18 cap. $6 . \quad{ }^{2}$ ) Cap. 6 X IV, 17. Über die Modifikation, die Raymund von Pennaforte vornahm, vgl. oben S. 97. 3) Bernardi Papiensis summa decretalium. Ausgabe von Laspeyres. Ratisbonae $1860 .{ }^{4}$ ) $\mathrm{Zu}$ compil. I lib. 4 tit. 18. 
der Bestimmung Alexander III. alle außerehelich erzeugten Kinder mit Ausnahme der adulterini, für legitimationsfähig, während Justinian nur die naturales im engeren Sinne, die ex concubina nati, dieser Wohltat teilhaftig werden ließ. Im Begriffe der liberi naturales hat sich allerdings infolge $\mathbf{A b}$ sterbens des Konkubinates eine Änderung vollzogen, der wir nun auch bei Bernhard begegnen. Unter liberi naturales im engern Sinne verstand man jetzt die Kinder derjenigen Erzeuger, zwischen welchen eine Ehe möglich wäre, oder aber auch die ex soluto et soluta geniti. ${ }^{1}$ ) Diese beiden Begriffe kommen sich zwar ziemlich nahe, decken sich aber durchaus nicht. Bernhard definiert die liberi naturales als geniti de illa, quae posset esse uxor. ${ }^{2}$ ) Als Wirkung der Legitimation bezeichnet er unter Berufung auf Novelle 89 cap. 3 : ut succedant in bona parentum. ${ }^{3}$ )

Die um die Wende des 12. und 13. Jahrhunderts entstandene sogenannte Ardizonische Rezension der liberi feudorum rechnet mit der Möglichkeit einer Legitimation, worunter auch die legitimatio per subsequens matrimonium inbegriffen ist, spricht aber den legitimierten Kindern ein Erbrecht in Lehen ab: Naturales filii, licet postea fiant legitimi ad successionem feudi nec soli nec cum aliis vocantur. $\left.{ }^{4}\right)$ Der Mailänder liber consuetudinum vom Jahre 1216 ) hingegen erklärt die legitimierten Kinder auch für lehensfolgefähig: Tantum filii naturales et legitimi, id est, qui ex legitimo matrimonio sunt procreati, ad successionem feudorum perveniunt, non ergo adoptivi filii, sed naturales facti postea

1) Näheres in meiner legitimatio per rescriptum. - 2) A. a. 0 . Potest ergo de filiis talis distinctio adhiberi: filiorum alii sunt naturales et legitimi, alii naturales tantum, alii legitimi tantum, alii nee naturales nec legitimi. Naturales et legitimi, ut qui de iustis nuptiis nascuntur; naturales tantum, ut geniti de illa, quae posset esse uxor; legitimi tantum ut adoptivi, nec naturales nec legitimi ut de incesto et nefario coitu nati. - s) Ibid.: Prodest autem filiis legitimos esse vel fieri, ut succedant in bona parentum ut in authent. quib. mod. natur. effic. sui $\S$ et quoniam. - ${ }^{4}$ ) Lib. II tit. $26 \S 11$. Iacobus de Axdizone vertritt in seiner vor Mitte des 13. Jahrh. entstandenen summa sive epitome iuris feudorum cap. 137 (de successione feudi) denselben Standpunkt. - 5) Liber consuetudinum Mediolani anni 1216. Herausgegeben von F. Berlan, Mailand 1868. 
legitimi ad successionem feudorum accedunt. ${ }^{1}$ ) Das dieser Textesstelle folgende Beispiel ${ }^{2}$ ) zeigt, daß der Verfasser des. Mailänder Rechtsbuches hauptsächlich und in erster Linie an die legitimatio per subsequens matrimonium gedacht hat.

Der im Jahre 1210 als Bischof von Ferrara verstorbene Kanonist Hugoccio $^{3}$ ) vertrat die Ansicht, daß die Legitimation durch nachfolgende Ehe ihre Wirkung nur hinsichtlich der Erbfähigkeit äußere, aber nicht auch in bezug auf den Empfang der Weihen. Demgegenüber betonte Alanus in seiner im ersten Jahrzehnt des 13. Jahrhunderts zur Compilatio I. verfaßten Glosse ${ }^{4}$ ), daß zu einer solchen Unterscheidung kein Grund vorhanden sei, da auch die Dekretale keine solche mache. ${ }^{5}$ )

Das aus dem Beginn des 13. Jahrhunderts stammende Florentiner Rechtsbuch ${ }^{6}$ ) kennt die legitimatio per oblationem curiae und die legitimatio per subsequens matrimonium. ${ }^{7}$ )

Tankred unterscheidet in seiner zwischen 1210 und 1214 geschriebenen summa de matrimonio ${ }^{8}$ ) Legitimationsarten secundum canones und solche secundum leges. $\mathrm{Zu}$ ersteren zählt er die legitimatio per subsequens matrimonium

1) Titulus 29 Berlan S. 70. - 2).Quid ergo, si aliquis ex ea, quae uxor esse poterat, filios substulit deinde eandem in matrimonium duxit dotalibus instrumentis confectis et ex ea postea alios filios procreavit, an primi an tantum secundi filii vel nulli succedunt, non ineleganter quaeritur. Dicimus, quod omnes tam primi quam secundi pariter ad successionem veniunt. Ebenda. - ${ }^{3}$ ) Schulte, Geschichte der Quellen u. Literatur des kan. Rechts I, $156 \mathrm{ff}$. - 4) Ebenda S. 188f. - s) Die Glosse des Alanus zu comp. I lib. IV tit. 18 cap. 6 bei Schulte, Literaturgeschichte der compilationes antiquae in den Wiener Sitzungsber. Bd. 66 (1871) S. 94: Dicit tamen Hug., quia proles haec legitima ad successionem, sed non ad promotionem, sed ego non distinguo, quia nec canon. Ähnlich wie Alanus die glossa ordinaria zu cap. $6 \mathrm{X}$ IV, 17: Sed numquid dices tales legitimos quoad ordines et honores? Videtur quod non, quia non sunt nati de legitimo matrimonio, sed credo, quod legitimi sunt quoad omnia, quia matrimonium omnia praecedentia purgat et sic proxima sive etiam praecedens causa turpitudinis sublata est. - $\left.{ }^{\circ}\right)$ Ausgabe von Conrat, Berlin 1882. - ${ }^{7}$ ) 1 II, 2 (De patria potestate): .... Naturales et legitimi sunt tantum in potestate patria, quales fiunt etiam curie dati et illi, qui ex aliqua suscipiuntur, cum qua posten contrahitur matrimonium. Conrat $\mathrm{S} .4 \mathrm{f}$. - ${ }^{8}$ ) Ausgabe von Wunderlich, Göttingen 1841. 
und die legitimatio per specialem indulgentiam papae, wobei er sich aber für die Legitimation durch nachfolgende Ehe nicht allein auf die Dekretale Papst Alexander III., sondern auch auf die Institutionen Justinians beruft. ${ }^{1}$ ) Als legitimationsfähig erklärt Tankred die liberi naturales im neueren ${ }^{2}$ ) technischen Sinne, als welche er diejenigen bezeichnet, qui de soluto et soluta nascuntur, quae posset ex uxor. $^{3}$ ) Die spurii, ut sunt illi, qui de adulterio vel incesto nati sunt ${ }^{3}$ ), sollen von der Legitimation ausgeschlossen sein.

Eine Anführung der Zeugnisse der späteren Literatur mag überflüssig erscheinen, denn in Italien regte sich gegen das nun in beiden Rechten enthaltene und vom Klerus und der Rechtswissenschaft getragene Institut der legitimatio per subsequens matrimonium, soweit wir sehen können, im allgemeinen kein Widerstand. Nur ein einziges Mal begegnet uns eine Spur eines Antagonismus seitens des Volkes. Papst Innozenz III. sah sich auf Klagen eines Vaters veranlaßt, der Gemeinde und dem Rate der Stadt Viterbo unterm 3. August 1207 aufzutragen, eine per subsequens matrimonium Legitimierte, welcher die Ehelichkeit bestritten wurde, als ehelich anzuerkennen und hinsichtlich ihrer Legitimität nicht zu kränken, cum secundum canonicas sanctiones favore subsequentis matrimonii proles de naturali prius suscepta concubitu legitima debeat reputari. ${ }^{*}$ )

Am frühesten hat die legitimatio per subsequens matrimonium in Frankreich Eingang gefunden. Hier war sie zu Beginn des 12. Jahrhunderts in der justinianischen Gestalt schon anerkannt.

1) Titel 38. Sequitur qualiter non legitimi legitimantur: Primus modus est per subsequens matrimonium, quoniam si quis habet filios naturales de aliqua et postea contrahit cum ea, filii iam uati legitimantur, sed si spurios habet ex ea, illi non efficiuntur legitimi ut habetur expresse extra I. qui filii sint legitimi 4. 18, tanta est vis 6 , conquestus 1 [= Compilatio I lib.IV tit. 18 cap. 6 u. $1=$ c. 6 u. $1 \mathrm{X} \mathrm{IV}, 17$ ]. Instit. de nuptiis $1,10 \S$ ultimo [\$13 J. I, 10]. Secundus est per specialem indulgentiam domini papae, ut extra III qui filii sint legitimi 4. 12, per venerabilem 2 [= Compilatio III lib. 4 tit. 12 cap. $2=$ cap. $13 \mathrm{X}$ IV, 17] et in alano e. t. sane quia apostolica sedes. Hi duo modi secundum canones reperiuntur. Sequuntur alii quidam secundum leges.

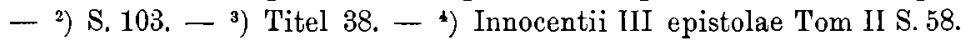
Potthast, Regesta pontificum nr. 3158. 
Schon das dem Bischof Ivo von Chartres zugeschriebene, jedenfalls aber nicht nach dessen Tode (1116) entstandene Dekret ${ }^{1}$ ) lehrte unter Hinweis auf die Institutionen Justinians die Anwendbarkeit dieses Institutes: Ut filii de concubina nati, quae postea in uxorem ducta est, legitimi liberi sint, priores sicut posteriores, sacrarum institutionum libro III titulo $\mathrm{I}^{2}$ )

$\mathrm{Ob}$ der Verfasser des decretum Ivonis die Legitimation durch nachfolgende Ehe etwa schon in Übung gefunden oder ob er ihr erst durch sein Werk Eingang verschafft hat, kann mit vollständiger Sicherheit nicht entschieden werden, sehr wahrscheinlich ist aber letzteres der Fall gewesen. Die Justinianische Novellengesetzgebung war zwar in Frankreich in der Gestalt der Epitome Juliani schon seit dem 9. Jahrhundert bekannt und findet sich seither, - allerdings sehr spärlich - benützt, so vom Abt Ansegis von Fontanella in seiner im Jahre 827 hergestellten Kapitulariensammlung, in den um 847 entstandenen Fälschungen des Benedikt Levita, von dem 882 verstorbenen Hinkmar von Rheims, von Abt Regino von Prüm $(† 915)$ in seinen libri duo de causis synodalibus et disciplinis ecclesiasticis, in der Sammlung des Abtes Abbo von Fleury $(\dagger 1.004)$, in dem zwischen 1012 und 1022 entstandenen Dekret des Bischofs Burchard von Worms u. a., aber nirgends findet sich eine Spur, daß etwa die Justinianische Bestimmung über die legitimierende Kraft der nachfolgenden Ehe schon in dieser Zeit rezipiert worden wäre. Hingegen aber wurde ihr nach Ivo von Chartres $(\dagger 1116)$ die Anerkennung nicht mehr versagt, so daß der Schluß naheliegt, da $\beta$ das decretum Ivonis, welches ja in ganz Frankreich ein ungeheures Ansehen genoB, hier bahnbrechend gewesen sei.

Die kurz danach in der Provence entstandenen Bearbeitungen des weltlichen Rechtes, nämlich das etwa in

1) Conrat, Geschichte der Quellen u. Literatur des röm. Rechtes im früheren M.-A. I S. $378 \mathrm{ff}$. - ${ }^{2}$ ) Decretum Ivonis pars 8 cap. 32 (bei Migne, Patrologia latina Bd. 161 Spalte 591). Im Anschluß an obige Stelle folgt als Beleg aus § 2 J. III, 1 der Satz: Si quis mulierem in suo contubernio copulaverit .. bis .. vel etiam nati ab hac luce subtracti fuerint. 
den Jahren $1120-1130$ verfaßte Tübinger Rechtsbuch ${ }^{1}$ ), das daraus stammende, nicht viel spätere Grazer Rechtsbuch $^{2}$ ) und die darauf fußenden gegen die Mitte des 12. Jahrhunderts schon vorhandenen Petri exceptiones legum Romanorum ${ }^{3}$ ) stellen die von den Eltern vor Eingehung der Ehe erworbenen Kinder den ehelichen vollkommen gleich.

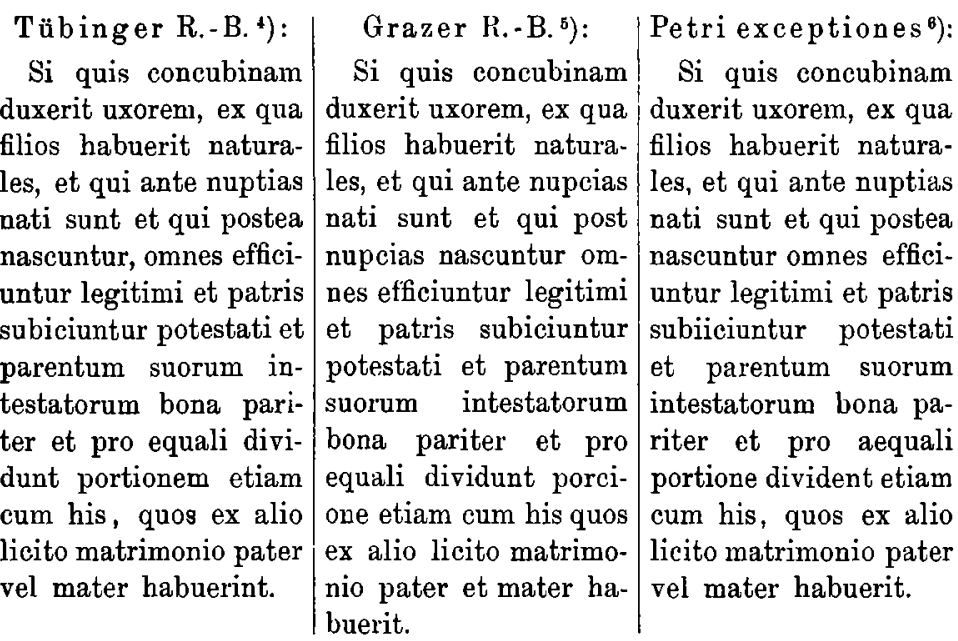

Stephan von Tournay ${ }^{7}$ ), der seine Summe zum Dekret Gratians $^{8}$ ) bald nach der Mitte des 12. Jahrhunderts schrieb, kennt ebenfalls die Justinianischen Legitimationsarten per rescriptum principis, per oblationem curiae und per sub-

1) Conrat a. a. O. S. 420, dem ich gegenüber Ficker, Über die Entstehungsverhältnisse der exceptiones legum Romanorum, Mitteilungen des Institutes für öst. Gesch.-Forsch. 2 Erg.-Bd. Fitting, a. a. 0 , bes. $127 \mathrm{ff}$. Savigny, Geschichte des röm. R. im M. - A. II S. $142 \mathrm{ff}$. Stintzing, Geschichte der populären Literatur des röm.-kan. R. S. $72 \mathrm{ff}$. Schupfer, Manuale di storia del diritto ital. ${ }^{3}$ I, $227 \mathrm{ff}$. u. a. hinsichtlich Charakter und Entstehungsverhältnisse dieser und der folgenden zwei Rechtsquellen folge. - 2) Conrat S. $490 \mathrm{ff}$. s) Conrat S. $516 \mathrm{ff}$. Ausgabe bei Savigny a. a. O. II S. $321 \mathrm{ff.} \mathrm{-} \mathrm{-)} \mathrm{Aus-}$ gabe von Conrat im Bulletino dell' istituto di diritto rom. III (1890) cap. 38 S. 107. - ${ }^{5}$ ) K. k. Univ.-Bibl. Graz Ms. III/37 vol. II (früher $40 / 8$ fol.) fol. $186^{\text {a. }}$ Die Kopie verdanke ich der Direktion dieser Bibliothek. Nach Stintzing S. 79 wäre es cap. 20a, nach Courat S. 492 cap. 20. - Liber I cap. 41 bei Savigny a. a. O. S. 343. — ${ }^{7}$ ) Vgl. darüber Schulte, Geschichte der Quellen u. Literatur des kanonischen Rechtes I S. $133 f .-{ }^{8}$ ) Ausgabe von Schulte, Gießen 1891. 
sequens matrimonium: Sicut naturales de concubina scilicet nati, qui nec servi nec legitimi heredes sunt nec patri succedunt, nisi cum et ipsi facti forte legitimi fuerint vel per principem vel quia curiae traduntur a patre vel quando pater matrem eorum dotalibus instrumentis confectis uxorem duxit. ${ }^{1}$ )

Der gleichfalls noch im 12. Jahrhundert im mittleren Frankreich verfaßte Brachylogus iuris civilis ${ }^{2}$ ) kennt alle Justinianischen Legitimationsarten und insbesondere läßt er die unehelichen Kinder durch die nachfolgende Ehe ihrer Eltern legitimiert werden. ${ }^{3}$ ) Während aber die vorher genannten, auf französischem Boden entstandenen Rechtsdenkmäler im engen Anschlufs an ihre Quellen noch immer von den filii de concubina nati, also von den liberi naturales im eigentlichen Sinne, als legitimationsfähigen Kindern sprechen, obwohl der Konkubinat schon lange abgestorben war, tritt uns auch im Brachylogus jene Begriffsveränderung entgegen, die eben eine Folge des Verschwindens dieses Institutes war und welche uns schon bei Bernhard von Pavia begegnet ist. $\left.{ }^{*}\right)$ Der Brachylogus bezeichnet dieser veränderten Sachlage gemäß als legitimationsfähig die von ihm als incogniti oder non cogniti benannten unehelichen Kinder, worunter er diejenigen versteht, quorum parentes iustas inter se nuptias contraxisse potuerunt. ${ }^{5}$ )

Als die Kirche die Legitimation durch nachfolgende

1) Zu cap. 12 C. 32 q. 2. - 2) Ausgabe von E. Böcking, Berlin 1829. Vgl. darüber Conrat S. $550 \mathrm{ff}$. Anderer Ansicht Schupfer a. a. O. S. $221 \mathrm{ff} .{ }^{3}$ ) Lib. I tit. 8 cap. 6 . $\$ 12$. Jure autem civili non cogniti sunt hi, quorum parentes iustas inter se nuptias contraxisse potuerunt. 13. Hi etiam civiles fieri possunt, si vel curiae dentur, 14. vel post nativitatem eorum inter parentes aliquo tempore dotalia instrumenta conficiantur, 15. vel super his preces imperatori porrigantur et princeps suam interponat auctoritatem, 16. vel si in testamento ut legitimos heredes instituerit, 17. vel si matrem eorum, usque quo die defunctus est, in contubernio habuerit. In Mißverstehung von l. 3 C. VII, 15 sieht das Rechtsbuch in der Fortdauer der Geschlechtsgemeinschaft mit der Konkubine bis zum Tode des Mannes eine Legitimation der Konkubinenkinder, während es sich dort um Erlangung der Freiheit handelt. - $)$ ) Oben S. 103. - 5) Den Ausdruck naturales gebraucht der Brachylogus im weiteren Sinne für alle unehelichen Kinder. Die naturales im neueren technischen Sinne heißt er aber incogniti oder non cogniti. 
Ehe für ihr forum rezipierte, war dieselbe in Frankreich schon allgemein anerkannt, es bedurfte hier nur mehr der Ersetzung der Justinianischen Normen durch die fast übereinstimmenden kanonischen, was ohne jede Schwierigkeit gelang. Die Quellen seit dem 13. Jahrhundert erkennen die echtigende Kraft der von den Eltern abgeschlossenen Ehe hinsichtlich der Kinder allgemein an ${ }^{1}$ ), ja deren Fassung lälit vielfach unzweifelhaft erkennen, daß die kanonischen Vorschriften vorbildlich und maßgebend gewesen sind. So bestimmte der der zweiten Hälfte des 14. Jahrhunderts angehörende Livre des droiz et des commandemens d'office de iustice $^{2}$ ) in teilweise wörtlicher Übersetzung der Dekretale Alexander III. ${ }^{3}$ ):

La force de mariage est si grant, que les enffans, qui sont nez devant le mariage, sont tenuz pour loyaux, quant le mariage est assemblé, combien que entre la nessanze desdiz enffans et cestui mariage autres mariages se fussent ensuiz entre la mère des diz enffans et autres hommes et entre le père et autre femme, par tant qu'ilz fussent soluz par mort ou par autre maniere. ${ }^{4}$ )

In England hingegen fand die Legitimation durch nachfolgende Ehe im weltlichen Recht keine Aufnahme. Die Prälaten ließen es zwar an Bemühungen, dieses Institut des kanonischen Rechtes auch im bürgerlichen Recht einzubürgern, nicht fehlen, die Barone setzten aber allen darauf abzielenden Bestrebungen energischen und erfolgreichen Widerstand entgegen.

Schon gegen Ende des 12. Jahrhunderts, also bald danach, als Alexander III. die römische legitimatio per subsequens matrimonium auch für das kanonische Recht rezipiert hatte, war nach dem Zeugnisse des dem Ranulphus de Glanvilla $(\dagger 1190)$ zugeschriebenen tractatus de legibus

1) Vgl. veben der folgenden im Text angeführten Stelle Bea umanoir, Coutumes du Beauvaisis weiter unten S. 151 f.; ferner Viollet, Histoire du droit civil Français S. 473; E. Glas son, Histoire du droit et des Institutions de la France VII S. 105f. - ${ }^{2}$ Ausgabe von C. I. Beautemps-Beaupre, 1865. Vgl. darüber Brunner in Holtzendorffs Enzyklopädie ${ }^{5}$ syst. Teil S. 308. - ${ }^{3}$ ) S. 96 f. - ) A. a. O. Tom. I Nr. 222 S. 398. 
et consuetudinibus regni Angliae tempore regis Henrici $\mathrm{II}^{1}$ ) (1154-1189) die Frage entstanden: Si quis, antequam pater matrem suam desponsaverit, fuerit genitus vel natus, utrum talis filius sit legittimus heres, cum postea matrem suam desponsaverit? Die Antwort lautete nach Glanvilla: Quidem licet secundum canones et leges Romanas talis filius sit legittimus heres, tamen secundum ius et consuetudinem regni nullo modo tamquam heres in hereditate sustinetur vel hereditatem de iure regni petere potest. ${ }^{2}$ )

Die kirchliche Partei arbeitete aber rührig und unverdrossen weiter, um dem kanonischen Recht zum Durchbruche zu verhelfen. Neuerdings wurde auf dem von König Heinrich III. am 23. Jänner 1236 in Merton abgehaltenen großen Reichstage vom König dieselbe Frage aufgeworfen, utrum videlicet quis natus ante sponsalia et matrimonium haberi possit pro legitimo sicut ille, qui post matrimonium natus fuit. ${ }^{3}$ ) Darauf antworteten die anwesenden Bischöfe einstimmig, quod omnes illi, qui nati fuerunt ante sponsalia vel matrimonium, ita erunt legitimi sicut illi, qui nati erunt post matrimonium, quoad dominum deum et quoad ecclesiam ${ }^{4}$ ) und sie baten den König und die Magnaten, quod ad hoc consensum preberent, quod nati ante matrimonium quoad omnia legitimi esse possent sicut illi qui post. Die Magnaten aber, soviel ihrer waren, erwiderten ebenso einstimmig, quod noluerunt leges Angliae mutare, quae usque ad tempus illud usitatae fuerunt et approbatae. ${ }^{5}$ )

1) Ausgabe bei Philipps, Englische Reichs- und Rechtsgeschichte, Berlin 1828, II. Band S. 335 ff. Vgl. Brunner in Holtzendorffs Enzyklopädie ${ }^{5}$ S. 339 . Pollock und Maitland, The history of English Law before the time of Edward I. Bd. I, S. $141 \mathrm{ff}$. vertreten die Ansicht, daß der Traktat von Glanvillas Sekretär Hubert Walter verfaßt sei. $\left.{ }^{2}\right)$ Lib. 7 cap. 15. - ${ }^{3}$ ) Dieses und das folgende in Henricus de Bracton, De legibus et consuetudinibus Angliae, lib. V, tract. 5 cap. 19 Ausgabe von Travers Twiss, London 1878-83, VI. Bd. S. $284 \mathrm{ff}$. 4) Weiter heißt es von den Bischöfen: nec voluerunt nec potuerunt sine preiudicio ecclesiasticae dignitatis respondere ad breve super huiusmodi inquisitione facienda de bastardia sic obiecta rescribere domino regi, videlicet utrum ante vel post, quia hoc esset in preiudicium s. ecclesiae ut dicebant. - ${ }^{5}$ ) Über den Reichstag von Merton vgl. auch Bractons Note Book, heransgegeben von F. W. Maitland, London 1887 ff. Vol. I S. $104 \mathrm{ff}$. 
Diese berühmte Entscheidung von Merton, die auch in den offiziellen Reichsstatuten überliefert ist ${ }^{1}$ ), kennzeichnet so recht den Gegensatz zweier verschiedener sich gegenseitig bekämpfender Rechtsanschauungen. Die Bischöfe ließen sich aber durch diesen Mißerfolg keineswegs entmutigen, sondern entfalteten jetzt nur eine um so größere Agitation zugunsten der Legitimation durch nachfolgende Ehe. Einen Niederschlag dieser Bewegung finden wir in zwei Briefen des Johannes Grosseteste, Bischofs von Lincoln, vom Jahre $1236^{2}$ ) an den einflußreichen Justiziar der königlichen Kurie William Raleigh (Wilhelm de Raleger), von welchem Grosseteste selbst sagt: quod in curia possis, quidquid volueris. ${ }^{3}$ )

Im ersten Brief ${ }^{4}$ ) stellt er den Satz, qua proles nota ante matrimonium subsequens post contractum matrimonium velut illegitima exhaeredatur, als eine lex ininqua et iniusta, iuri naturali et divino, canonico quoque et civili contraria hin und sucht des langen und breiten zu beweisen, quod proles nata ante matrimonium inter parentes eius contractum per matrimonium subsequens nanciscitur legitimationem et ius haereditarium in haereditate parentum, nisi forte alter vel uterque parentum aliud prius copulaverit matrimonium, quod ante generationem non fuerit solutum. Zum Beweise zieht Grosseteste nicht nur die einschlägigen Stellen des römischen und kanonischen Rechtes heran, sondern beruft sich auch auf die Schrift des alten und neuen Testamentes, die Schriften der Kirchenväter und die Vorgänge in der Natur, die exempla naturae. Ja er geht in seinem Eifer noch weiter, indem er den verteidigten Satz sogar als alt-

1) Statutes of the Realm 1, statutes 1: Ad breve regis de bastardia, utrum aliquis natus ante matrimonium habere poterit hereditatem sicut ille, qui natus est post, responderunt omnes episcopi, quod nolunt nec possunt ad istud respondere, quia hoc esset contra communem formam ecclesie, ac rogaverunt omnes episcopi magnates, ut consentirent, quod nati ante matrimonium essent legitimi sicut illi, qui nati sunt post matrimonium, quantum ad successionem hereditariam, quia ecclesia tales habet pro legitimis: et omnes comites et barones una voce responderunt, quod nolunt leges Anglie mutare que (ucusque) usitate sunt et approbate. $-{ }^{2}$ ) Roberti Grosseteste episcopi quondam Lincolniensis epistolae. Edited by H. R. Luard. London 1861. - s) Epistola 24 S. 96. - Epistola 23, S. 76 ff. 
englisches Gewohnheitsrecht hinzustellen sich bemüht, ohne sich dabei freilich auf mehr als auf die seniorum relatio berufen zu können:

- - cum, sicut notissimum est, iura etiam civilia natos ante matrimonium per subsequens matrimonium legitimos decernant et haeredes et ut seniorum relatione didici, consuetudo etiam in hoc regno antiquitus obtenta et approbata tales legitimos habuit et haeredes, unde in signum legitimationis nati ante matrimonium consueverunt poni sub pallio super parentes eorum extento in matrimonii solennizatione.

Von der Antwort des William Raleigh haben wir nur durch den darauf erflossenen zweiten Brief des Grosseteste ${ }^{1}$ ) indirekte Kunde. Raleigh verhält sich natürlich den Neuerungen des Grosseteste gegenüber ablehnend. Er gibt ihm allerdings den Bestand der Sitte, daß die vor der Ehe erworbenen Kinder bei der Trauung der Eltern mit diesen unter das ausgespannte Pallium gestellt werden, zu, spricht dieser Zeremonie aber unter Berufung auf das Zeugnis des Richard de Luci, Justitiars der curia regis unter Heinrich II. (1154-89) - natürlich nur für das weltliche Rechtsgebiet jede rechtliche Wirkung $a b$ :

bastardus sub pallio supra parentes nubentes extento positus inde surgit bastardus. ${ }^{2}$ )

Grosseteste weiß dieses Zeugnis nicht anders zu entkräftigen, als daß er es ins lächerliche zieht, beschwört aber im übrigen Raleigh noch einmal, ut tu leges et consuetudines legi divinae constitutioni ecclesiasticae contrarias coneris ad eorum concordiam commutare simul cum his a te

1) Epistola 24 S. 95 ff. Du Cange, Glossarium, sub verbo „pallio cooperire" stellt in Mißverstehung von Seldenus, Dissertatio ad Fletam cap. 9 S. 538 die Sache so dar, als ob der Brief des William de Raleigh an Grosseteste vorhanden wäre. - ${ }^{2}$ ) Grosseteste an Raleigh (Ep. 24): Praeterea ad confirmandam hanc legem, quod bastardus sub pallio supra parentes nubentes extento positus inde surgit bastardus, induxistis(!) testimonium Ricardi de Luci, cuius testimonium, quantam et qualem habeat comparationem ad testimonia divinae scripturae et canonicae contrarium testificantia, ,lippis patet et tonsoribus". 
efficaciter persuasis, penes quos est legum immutandarum et condendarum potestas.

König und Barone aber blieben nichtsdestoweniger unentwegt bei dem zu Merton aufgestellten Grundsatz. Auf einer am 16. Oktober 1236 abgehaltenen Reichsversammlung ${ }^{1}$ ) wurde nur eine alte Institution erneuert, deren Bestand für die Zeit König Heinrich II. (1154-1189) schon Glanvilla bezeugt ${ }^{2}$ ), worüber dann unterm 12. Oktober 1234 (die Iovis proxima post festum s. Dionisii) ein eigenes Gesetz erflossen ist $^{3}$ ) und welche schließlich auch Grosseteste in dem oben genannten Briefe erwähnt. ${ }^{4}$ ) Da nämlich der Kirche die Ehegerichtsbarkeit zustand, so wurde, wenn gegenüber je-

1) Bracton a. a. O. fol. $417 \mathrm{f}$.: Postea vero die Iovis proxime post festum s. Dionisii anno eodem coram ipso domino rege et subscriptis convocato consilio provisum fuit et concessum .... quod de caetero, cum bastardia obiecta fuerit alicui, de tali causa in curia domini regis, quod bastardus sit et ideo bastardus, quia natus ante sponsalia vel matrimonium contractum inter patrem suum et matrem suam, mittatur loquela ad ordinarium loci et fiat inquisitio per haec verba, utrum videlicet talis natus fuerit ante sponsalia sive matrimonium vel post, et rescribat ordinarius per eadem verba domino regi sine aliqua cavellatione ... In defectum curiae Christianitatis fiat inquisitio in curia domini regis, utrum ante matrimonium vel post ......-2) A. a. O.: Sed orta super hoc tamen contentione, utrum scilicet genitus an natus fuerit ante desponsationem an post, discutietur id, ut dictum est, coram iudice ecclesiastico et quod ab eo iudicatum fuerit, id domino regi vel eius iusticie scire faciet. Ita tamen, quod secundum, quod indicatum est in curia Christianitatis de matrimonio, scilicet utrum fuerit ille, qui hereditatem petit, natus vel genitus ante matrimonium contractum vel post, in curia regis supplebitur de adiudicanda vel abiudicanda ipsi hereditate, super qua contentio est, ita quod per iudicium curie hereditatem ipsam obtinebit vel clameum suum perdet. - ${ }^{\text {s) }}$ Bractons Note Book. Vol. I. S. 106 f. - 4) A. a. O. Epistola 23, fol. 89 f.: Iudices ad cumulum transgressionis suae et evidentiorem eius manifestationem etiam conceptos et natos in vero et de vero matrimonio voluerunt iudicare spurios et exhaeredandos, quando voluerunt ab episcopis inquiri et sibi rescribi, utrum is, contra quem proponeretur exceptio illegitimitatis, natus esset ante matrimonium solenniter contractum an post matrimonium solenniter contractum (cuius formae plura brevia a curia destinata adhuc penes me resident), cum multoties contrahatur clandestinum matrimonium sub paucorum testimonio sine solennitate; et deinde suscitata prole de huiusmodi matrimonio fiat in facie ecclesiae matrimonii solennizatio.

Zeitsclirift für Rechtsgeschichte. XXV. Germ. Abt. 
mandem die exceptio illegitimitatis oder bastardiae erhoben wurde, dem Bischof auch die Entscheidung der mit der Ehe zusammenhängenden Vorfrage überlassen, ob der Betreffende vor oder nach Eingehung der Ehe geboren sei. Aber nur darüber hatte sich die curia Christianitatis zu äufern, im übrigen aber sich jeder meritorischen Beurteilung der Legitimität oder Illegitimität zu enthalten. Auf der Basis dieses bischöflichen Spruches fällte dann die curia regis die Entscheidung, ob jemand hinsichtlich des weltlichen Rechtsgebietes als legitim oder illegitim zu achten sei und demgemäl auf die beanspruchte Erbschaft - um diesen Fall handelte es sich doch meistens - ein Recht habe oder nicht. Kam der Bischof diesen Bestimmungen nicht nach, so wurde auch über die Vorfrage, ob jemand vor oder nach Abschluß der Ehe geboren sei, in curia regis entschieden. ${ }^{1}$ )

Der Kirche wurde also, soweit es sich um die temporalia handelte, keinerlei entscheidende Einwirkung zuerkannt. Die Begründung dieser Maßregel zeigt uns ganz klar den Standpunkt, auf welchem König und Barone standen und auf Grund welcher Erwägungen man nicht der curia Christianitatis die Entscheidung überließ, ob jemand legitim oder illegitim sei:

Quia (quis) poterit esse legitimus secundum statuta ecclesiae quantum ad ordines et quantum ad dignitates et quantum ad leges et consuetudines Anglicanas bastardus. quantum ad successiones, - - - ad papam et ad sacerdotium quidem pertinent ea, quae spiritualia sunt, ad regem vero et ad regnum ea, quae sunt temporalia, iuxta illud „coelum coeli domino, terram autem dedit filiis hominum". Et unde ad papam nihil pertinet, ut de temporalibus disponat vel ordinet non magis quam reges vel principes de spiritualibus, ne quis eorum falcem immittat in messem alienam. Et sicut papa ordinare potest in spiritualibus quoad ordines et dignitates, ita potest rex in temporalibus de haereditatibus dandis vel haeredibus constituendis secundum consuetudinem regni sui.

1) Ein Formular für ein königl. Mandat, welches dem Bischof eine solche Voruntersuchung aufträgt, bei Glanvilla a. a. 0. lib. 7, cap. 14. und Bracton a. a 0 . 
Von einer Anerkennung der legitimatio per subsequens matrimonium für das weltliche Rechtsgebiet war aber keine Rede. Die Entscheidung von Merton ist vielmehr auch für alle Zukunft in dieser Frage die Rechtsgrundlage geblieben, denn bis auf den heutigen Tag hat England die legitimatio per subsequens matrimonium von sich fern gehalten ${ }^{1}$ ) und ist somit der einzige Staat mit germanischer Rechtsentwicklung, welcher dieses römisch-kanonische Institut nicht rezipiert hat.

Ähnlich wie in England war auch in der Normandie die causa bastardiae nach den noch in der ersten Hälfte des 13. Jahrhunderts entstandenen Coutumes ${ }^{2}$ ) der curia episcopi zur Entscheidung vorbehalten. Während aber in England nach dem Grundsatz "quis potest esse legitimus secundum statuta ecclesiae ... et quantum ad leges et consuetudines Anglicanas bastardus " der Bischof nur darüber sich zu äußern hatte, ob jemand vor oder nach Eingehung der Ehe geboren sei, Legitimität oder Illegitimität aber die curia regis beurteilte, entschied in der Normandie der Bischof, quia causa bastardie ad forum seculare non pertinet sed ad ecclesiasticum, kurzweg über Legitimität oder Illegitimität und die in der zweiten Hälfte des 13. Jahrhunderts entstandene summa de legibus Normannie in curia laicali ${ }^{3}$ ) stellte als Norm hin: quos iudex ecclesiasticus pro legitimis reputat, et laicus legitimos reputabit. Auf Grund des Ausspruches des Bischofs, gegen welchen noch eine Appellation an den Erzbischof möglich war, urteilte dann die curia regis secundum consuetudinem terre über die weltlichen Rechtsfolgen.

In Deutschland verhielt man sich lange Zeit gegenüber der legitimatio per subsequens matrimonium nicht minder

1) Glasson, Histoire du droit et des institutions de l'Angleterre III. S. 186 f. Viollet, Histoire du droit civil Français S. 473. Glasson, Histoire du droit et des institutions de la France VII. S. 106. - ${ }^{2}$ ) Le très ancien coutumier de Normandie herausgegeben von E. F. Tardif, Coutumiers de Normandie. Vol. I. Pars II. cap. 75 \$. 72. Vgl. über diese Coutumes auch Brunner in Holtzendorffs Enzyklopädie der Rechtswissenschaft ${ }^{5}$ syst. Teil S. 325 f. $-{ }^{3}$ ) Hg. von Tardif, Coutumiers de Normandie Vol. II. Distinctio 3, cap. 25 \& 2 S. 88 . Vgl. Brunner a. a. 0 : S. $326 \mathrm{f}$. 
ablehnend. Während die legitimatio per rescriptum principis schon seit der ersten Hälfte des 13. Jahrhunderts in Übung war ${ }^{1}$ ), hat jene vor dem Ende desselben nirgends Boden gewonnen, und wo in früherer Zeit das Institut der Legitimation überhaupt erwähnt wird, wie im Schiedsspruche zwischen dem Erzbischof Konrad und der Stadt Köln, dem sog. laudum Conradinum, vom 28. Juni $1258^{2}$ ) oder in den notae des Abtes Hermann von Niederaltaich $(\dagger 1275)^{3}$ ), ist kaum an die legitimatio per subsequens matrimonium zu denken. Schlieflich hat aber doch das römisch-kanonische Recht überall den Sieg davongetragen. Die Legitimation überhaupt und die durch nachfolgende Ehe insbesondere gehört zu jenen wenigen Instituten, die in Deutschland fast durchaus schon vor der allgemeinen Rezeption der fremden Rechte Eingang gefunden haben. Nur vereinzelt hat erst diese die Legitimation durch nachfolgende Ehe zur Anerkennung gebracht und nur ganz ausnahmsweise, z. B. im lübischen Rechte, sind ihr erst in einem noch späteren Zeitpunkt Rechtsfolgen für das bürgerliche Leben beigelegt worden. In der Zeit, in welcher die legitimatio per subsequens matrimonium erst um ihre Anerkennung kämpfte, forderte man bisweilen, daß zur Ehe die kaiserliche oder päpstliche Legitimation hinzutrete. ${ }^{4}$ )

1) Vgl. meine legitimatio per rescriptum. - 2) Lacomblet, Niederrhein. Urk.-B. II. S. 248: De illegitimis autem videtur nobis, quod illegitimi non debent assumi (in scabinos), nisi probitatis merita et sapientia reddant eis, quod natales abstulerunt et sint legitimati. Unrichtig verlegt Mittermaier, Grundzüge des gem. deutschen Privatrechts 6. Aufl. II. S. 258 Anm. 6 diese Frwähnung der Legitimation in das kölnische Weistum vom Jahre 1169. - 3) Boehmer, Fontes rerum Germ. III. S. 568: Ille qui dicitur ehuntmeister ... debet indicere parentibus pueri, ut redimant eum a servitute, ut possit legitimari et hereditatem habere. - *) Vgl. die unten S. 129 f. angeführten Stellen des Magdeburger-Breslauer system. Schöffenrechtes, des alten Kulm und der Magdeburger Fragen. Keine Legitimation durch kaiserl. Reskript schon durch nachfolgende Ehe legitimierter Kinder enthält die formula 12 des Collectarius perpetuarum formarum des Johannes de Geyluhusen, Ausgabe von Kaiser, Innsbruck 1900 S. 10, sondern nur eine Erklärung ad habundancioris cautele presidium, daß die vor der Ehe geborenen Kinder durch die Ehe ihrer Eltern legitim sind. 
Dem Sachsenspiegel ist jede Legitimation durch nachfolgende Ehe fremd. Eicke fordert für die Ehelichkeit eines Kindes nicht nur eheliche Geburt, sondern auch eheliche Zeugung und läBt demgemäß das Kind, das zwar in der Ehe, aber zu früh geboren wird, als unecht schelten: Svenne dat wif erst man nimt, wint se kint er erer rechten tiet, dat dat kind leven moge, man mach it beschelden an sime rechte, went it to vro geborn is. ${ }^{1}$ ) Wie fremd Eicke der Gedanke an eine Legitimation durch die heiligende Kraft der Ehe war, sieht man ferner daraus, daß er sogar Fälle kennt, in welchen man selbst, obwohl äußerlich eine Ehe besteht, nur unechte Kinder zeugen kann: Sve so enes mannes wif behuret openbare oder wif oder maget nodeget, nimt he se dar na to echte, echt kint ne wint he nimmer bi ere. ${ }^{2}$ )

Diese Grundsätze des Sachsenspiegels haben im Gebiete des sächsischen Rechtes lange Zeit die Herrschaft behalten, und nur sehr langsam und allmählich gelangte ihnen gegenüber im nördlichen Deutschland der Gedanke von der echtigenden Kraft der Ehe partikularrechtlich zum Durchbruch. Dabei beobachten wir die Erscheinung, daß oftmals, wenn wir das ganze Institut schon lange anerkannt und in Übung sehen, auf einmal eine jüngere Rechtsquelle je nach der Vorlage wiederum auf den älteren ablehnenden Standpunkt zurückgreift.

Ob die einzelnen Rechtsquellen die Legitimation durch nachfolgende Ehe anerkennnen, läßt sich fast durchaus nur daraus ersehen, ob sie den vor der Ehe geborenen Kindern ein Erbrecht zuerkennen oder nicht, denn über die Behebung der mit dem Makel der Unehelichkeit verbundenen Rechtlosigkeit äußern sie sich nicht. In der Regel wird nun die Gewährung eines Erbrechtes und die Behebung der Rechtlosigkeit Hand in Hand gegangen sein, so daß letzteres auch nur dann eintrat, wenn ersteres gegeben wurde. Im allgemeinen wird also der Schluß von der $\mathrm{Zu}$ - oder Aberkennung eines Erbrechtes auf die An- bezw. Nichtanerkennung der

1) Ld. R. I. A. 36 \$ 1 (Homeyer). - ${ }^{2}$ ) Ld. R. I. A. 37. Dieser Artikel gehört zu den durch Gregor XI. verworfenen 14 Sätzen des Sachsenspiegels. 
Legitimation durch nachfolgende Ehe zulässig und richtig sein, aber zwingend ist er durchaus nicht, denn gleichwie die legitimatio per rescriptum principis, wenn nicht ausdrücklich ein Erbrecht gewährt wurde, nur die Rechtlosigkeit behob ${ }^{1}$ ), so ist es auch sehr leicht denkbar, dab der nachfolgenden Ehe der Eltern wohl die Wirkung zugeschrieben wurde, daß sie die Rechtlosigkeit der vorher erzeugten Kinder tilge, ohne aber ein Erbrecht zu begründen.

Der Glossator des Sachsenspiegels, Johann von Buch, zeigt sich mit den römischen Legitimationsarten schon gut vertraut, hatte er doch in Bologna sich seine Wissenschaft geholt. Er sagt davon in seiner Glosse, deren Abfassungszeit um das Jahr 1325 anzusetzen ist (zu Ld. R. I 44):

War it gesat recht is jegen dat naturlike recht, dar hebben de keisere alle de list gevunden, de se mochten, und hebbet de settinghe yo entlinc gedrucket. Also hebben se ok hir gesat dre stucke, wo en unechte kint moge echte werden: De erste is of men it in des keisers hof gheve, ut in instit. rubr. de nuptiis c. aliquando [1.13. J. I. 10]. De andere, of de vader de moder na to echte neme, ut in auct. rubr. de filiis ante c. pervenit coll. III. [Novelle 19, praef.] De dridde, of it de moder nicht werd en were, so mach ene de keiser echt, ut in auct. rubr. quibus modis c. liceat coll. VI. [Nov. 74 cap. 1], dit vernym, of be anders nene erven hedde.

Diese Glosse wurde bisher, soweit man überhaupt Gelegenheit hatte sich damit zu beschäftigen, gründlich mißverstanden. Der Ausdruck, "list" wurde im verkehrten, bösen Sinne aufgefaßt und so die Legitimation als "listige Erfindung"

1) Vgl. meine legitimatio per rescriptum. - 2) Der erste Satz nach gütiger Mitteilung des Herrn Geheimrates Steffenhagen aus der Amsterdamer Handschrift (Homeyer, Deutsche Rechtsbücher Nr. 8). Das Weitere nach Grupen, De uxore Theodisca (Göttingen 1748) cap. VI. \$ 4 S. 263 aus dem oldenburgischen Kodex (Homey er, Rechtsbücher Nr. 660), wo der für das Verständnis unentbehrliche Vordersatz fehlt. In Mißverstehung des Wortes curia macht der Glossator aus der legitimatio per oblationem curiae eine Legitimation durch Hingabe an des Kaisers Hof. Dieses Mißverständnis begegnet wiederholt, so z. B. Jurisprudentia Frisica Titel $47 \S 6$, Ausgabe von Hettema II, S. 86, Ostfriesisches Landrecht lib. 2, cap. 7. Wicht S. 317. 
der Kaiser hingestellt. ${ }^{1}$ ) "List" bedeutet aber bei dem Glossator Klugheit ${ }^{2}$, so daß also der Sinn der Stelle ist: Die Kaiser haben alle mögliche Klugheit aufgewendet, um den Gegensatz zwischen Gesetzesrecht und natürlichem Recht auszugleichen. Es ist das ein Gedanke, den schon Justinian ausspricht, wenn er sagt: filios (naturales) restituere naturae et antiquae ingenuitati ... neque enim a principio, quando sola natura sanciebat homines, antequam scriptae provenirent leges, fuit quaedam differentia naturalis atque legitimi, sed antiquis parentibus antiqui filii mox, ut praecedebant, fieabant legitimi ${ }^{3}$ ) und der dann auch in den Pfalzgrafenpatenten Karls IV. wieder begegnet, worin den Pfalzgrafen das ius legitimandi et ad primevum statum naturae reducendi, quo omnes legitimi nascebantur, eingeräumt wird..) Der Glossator äußert sich über die Wirkungen der Legitimation nicht näher, offenbar will er ihr dieselben beilegen, mit welchen sie das römische Recht ausstattet, er beruft sich ja auch ausschließlich auf Belegstellen aus dem corpus iuris Iustiniani.

Ihrem wesentlichen Inhalte nach ist diese Buchsche Glosse in das unter Herzog Adolf I. von Kleve (1417-1448) abgefaßte Klevische Stadtrecht übergegangen, nur ist die vom Glossator mißverstandene Legitimation durch Hingabe an des Kaisers Hof als unpraktisch beseitigt:

Doch soe wordt wail een onecht kint echt in tween stucken. Dat ierste, off die vader die moeder dair nae toe echten nemen mochte, ind hi si dan neme. Dat ander is, off die moeder des nit weerdich en is, soe mach oen die keiser echt geven, in deen doch end soe veer hi anders geen erven en hed. ${ }^{5}$ )

1) So außer Grupen a. a. O. von neueren Wilda, Der reichsgrätl. Bentincksche Erbfolgestreit Zeitschr. f. d. R. IV. (1840) S. 287. Siegel, Das deutsche Erbrecht S. 32 Anm. 111. - ${ }^{2}$ ) Gütige Mitteilung Steffenhagens. - ${ }^{3}$ ) Novelle 74 cap. 1. Ähnliche Gedanken auch Nov. 89 pr. u. c. 1. - ${ }^{4}$ ) Vgl. die Pfalzgrafenpatente 1357 Aug. 15 bei Ficker, Forschungen IV. Nr. 524 S. 539 f. 1369 Juni 6 ebenda Nr. 527 S. 545 f. und die formula $32 \mathrm{im}$ collectarius perpetuarum formarum des Johannes de Geylnhusen hg. von Kaiser (Innsbruck 1900) S. 23 f. - 5) Steffenhagen, Der Einfluß der Buchschen Glosse auf die späteren Denk- 
Während Johann von Buch die Legitimation durchaus auf römischen Ursprung zurückführt, stellt die jüngere $\mathrm{Pe}$ trinische Glosse ${ }^{1}$ ) die legitimatio per subsequens matrimonium als ein Erzeugnis des kanonischen Rechtes hin und hebt ausdrücklich hervor, daß die oben ${ }^{2}$ ) mitgeteilten Bestimmungen des Sachsenspiegels Ld. R. I. 36 durch den Einfluß des "geistlichen Rechtes" modifiziert worden sind:

$\mathrm{Na}$ geistlikem rechte aver, eft leddeghe lude sik belipen und kindere teleden unde sik darna in deme echte vortruweden, dy kindere worden echte, de sus vor und tu vru untfangen edder geboren weren, sus besceideliken, efte in der tyd des byslapendes muchte twisschen den sulven luden hebben echte gheweset, als oft sy beide do leddich weren, ut extra, qui fi(lii) sint legi(timi) c. tanta $[=$ c. $6 \mathrm{X}, \mathrm{IV} .17] \cdot{ }^{3}$ )

Eine dem Schwabenspiegel ${ }^{4}$ ) entlehnte Extravagante zu Ld. R. I. 36 des Soester Kodex ${ }^{5}$ ) des Sachsenspiegels schließt sich nach Inhalt und Form der Vorlage vollkommen an und erkennt gleich dieser die Legitimation durch nachfolgende Ehe im vollen Umfange an:

Heft eyn man eyne vrowen to ledichliken dinghen unde heft se kindere by ome vele eder lüttek unde nympt he se dar na to der e, wo vele kindere se vore von ome hadde, er he se sek gheven let to der e, de sint allentsamen rechte e kint unde erven eghen unde len von vader under von moder under von anderen eren vrunden, also wol alse de kindere, de se na mit en ander winnen, do se sek to eyn ander to der e namen. Wil men on des vor wertliken gherichte nicht gheloven, so scolen se or elich

mäler. I. Das Klevische Stadtrecht. Sitzungsberichte der Wiener Akademie, phil.-hist. Kl. Bd. 129, 7. Abhdlg. S. 34.

1) Zu folgenden Handschriften Honeyer, Deutsche Rechtsbücher Nr. 84, 293, 301 und 703. - ${ }^{2}$ ) S. 117. - ${ }^{3}$ ) Steffenhagen, Die Entwicklung der Landrechtsglosse des Sachsenspiegels IlI. Wien 1882 S. 27 (= Wiener Sitz.-Berichte, phil.-histor. Kl. Jg. 1882, Bd. 101, S. 777. Homeyer, Extravaganten des Sachsenspiegels a. a. O. S. 241 u. teilweise auch Sachsenspiegel II. 2, S. 185. - ${ }^{4}$ ) Der unten S. 135 f. mitgeteilten Stelle Laß3berg 377. - ${ }^{5}$ ) Ho m e yer, Deutsche Rechtsbücher Nr. 623. 
recht vor geystliken richte beholden unde scolen des breve und ingheseghel nemen; so behalden se ore recht vor allen wertliken richte mit rechte. ${ }^{1}$ )

Der von den Glossen des Sachsenspiegels eingenommene römisch-kanonistische Standpunkt war aber noch lange kein allgemeiner.

Das zu Anfang des 14. Jahrhunderts entstandene Görlitzer Landrecht weiß von der Legitimation durch nachfolgende Ehe nichts. Es kennt nur die legitimatio per rescriptum principis und per rescriptum papae, spricht aber beiden jede rechtliche Wirkung ab. ${ }^{2}$ )

Das aus der zweiten Hälfte des 14. Jahrhunderts stammende Rechtsbuch nach Distinktionen steht grundsätzlich noch auf dem Standpunkt des Sachsenspiegels, daß die nachfolgende whe nach Land- und Weichbildrecht keine echtigende Kraft habe, zugleich erkennt es aber schon an, daß die päpstliche und kaiserliche (= römische) Gesetzgebung in diesem Punkt reformierend eingegriffen habe:

Had eyn man unde wip kinder, dy unrecht zcusammene komen sin, unde had daz wip sinth zcu der ee genomen, dy kinder, dy sy vor hatten, dy nemen keyn erbeteyl unde bliben unelich zcu lantrechte unde zcu wichbilde. Abir zcu bebistlichen geseccze zcweyget sich das unde ouch noch keyserrechte, also vor beschreben steth in deme capittele von der geborth. ${ }^{3}$ )

In dem „Kapitel von der Geburt" nun spricht der Verfasser von der Wirkung der Legitimation durch nachfolgende Ehe, welche darin besteht, daß die legitimierten Kinder ihre Eltern, nicht aber auch andere Verwandte beerben können:

2) Homeyer, Extravaganten des Sachsenspiegels. Abhandlungen der Berliner Akademie 1861 S. 240 f. Die bei Kraut, Grundriß zu Vorlesungen über deutsches Privatrecht. 6. Aufl. (von Frensdorf) $\$ 186$ Nr. 4 S. 437 als Glosse zu Ssp. I. 37 mitgeteilte Stelle, auf welche auch Stobbe, Handbuch des deutschen Privatrechtes 3. Aufl. (von Lehmann) IV. S. 441 Anm. 8, besonders hinweist, ist nach gütiger Mitteilung Steffenhagens eine Interpolation aus dem Schwabenspiegel in modernisierter Fassung, die sich schon in den Zoblschen Drucken und auch in Gärtners Ausgabe findet. - ${ }^{2}$ ) Kap. $32 \$ 6$ bei Homeyer, Sachsenspiegel II. 2, S. $184 \mathrm{f.}-{ }^{3}$ ) Buch 1, Kap. 24, Dist. 3. Ausgabe ron Ortloff, Sammlung deutscher Rechtsquellen. Jena 1836. S. 57. 
$\mathrm{Nu}$ werden ouch kinder geborn naturlich, welche nu dy sin: wo ein elich man adder eyn elich fruwe adder eyn dirne sich zcusammene mischen, so daz sy an alle gelobde von naturlicher libe mit enander kinder gewinnen, dy kinder heysszen naturliche kinder. Noch der kinder geburth nemen sich dy sint zcu der ee, dy kinder sint von gotes wegen unde von bebestlichen geseccze geet unde nemen erbeteyl an ores vater unde muter gude, $a b$ wol vater unde muter sterbet, daz des mannes nesten, noch der fruwen nesten den kindern keyn anerstorben gud von vater unde von mutter vorlegen mogen. Dyselben kinder mogen abir an ores eldervater adder an orer eldermuter gud keyn erbeteylunge gehaben. ${ }^{1}$ )

Einen eigentümlichen Standpunkt nehmen die von Wasserschleben veröffentlichten sächsischen Erbrechtsregeln aus dem 15. Jahrhundert ein, indem sie einesteils ebenso wie der Sachsenspiegel den zwar in der Ehe, aber zu früh geborenen Kindern jedes Erbrecht nach dem Vater absprechen, anderseits aber doch wiederum, abweichend vom Sachsenspiegel, die Anfechtung der Ehelichkeit solcher Kinder ausschließen, wenn sie vom Vater anerkannt werden und insbesondere, wenn sie erst 36 Wochen nach Abschluß der Ehe zur Welt kommen:

Ein kindt, das czu frue geborenn isth, das nympt vom vater kein erbteil. Idoch so es der vater ahn seynem leben annympt und das vor sein kinth erkennt, so kan es kein ander beschelden und forderlich, so es bey 36 wochenn getragen ist worden. ${ }^{2}$ )

Die beiden Sätze dieser Regel widersprechen sich direkt, indem der erste die zu früh geborenen Kinder von der Erbschaft nach dem Vater ausschließt, der zweite sie aber ehelich und mithin auch erbfähig sein läßt, denn die Anerkennung seitens des Vaters ist eine selbstverständliche Voraussetzung, ohne die weder die vor der Ehe geborenen Kinder per subsequens matrimonium der Eltern noch auch

1) Buch 1, Kap. 5, Dist. 4 Ortloff a. a. O. S. 21. - 2) Wasserschleben, Prinzip der Sukzessionsordnung S. 149 regula 35. 
die zwar in der Ehe aber zu früh geborenen Kinder die Rechte ehelicher Sprößlinge erhalten. Der erste Satz widerspricht auch einer in der gerade vorausgehenden Regel ${ }^{1}$ ) aufgestellten Norm, wonach der "vom keiser, babst ader von der ehe" geehelichte Sohn seinen Vater, wenn er gar keine Erben hinterläßt, beerbt, mithin die legitimatio per subsequens matrimonium, wenn auch im beschränkten Umfang, anerkannt wird. Daß sich die Bestimmungen der verschiedenen Regeln widersprechen, ist leicht erklärlich, da sie ja auf verschiedene Quellen zurückgehen ${ }^{2}$ ), aber der Widerspruch in derselben Regel 35 läBt sich nur dadurch beseitigen, daß man annimmt, der Verfasser habe von vornherein den aus der Vorlage herübergenommenen ersten Satz, daß das zu früh geborene Kind nach dem Vater keinen Erbteil nimmt, durch den zweiten Satz, daß es doch, wenn es vom Vater anerkannt wird, legitim sei, modifizieren wollen, was allerdings in der Form nicht ganz glücklich gelungen ist.

Die Landesordnung Herzog Wilhelms für die Fürstentümer Jülich und Berg vom Jahre 1554 läßt die durch nachfolgende Ehe legitimierten Kinder in gleicher Weise wie die ehelichen erben:

So auch man und weib für irer ehelicher versamlung natürliche oder leybliche kinder mit einander hetten unnd sich darnach in sacrament der heyligen ehe ergeben und dardurch soliche kinder ehelich machen theten, so erben dieselbe kinder gleich mit anderen nachfolgenden erben, welche in stainder ehe gezilt und rechte erben seindt. ${ }^{3}$ )

Das vom Frankfurter Syndikus Johann Fichard verfaßte Landrecht der Grafschaft Solms vom Jahre 1571, welches

1) Regula 34: Der verstorbene lest gahr keinen erben hinter yhm, alleine seynen geelichten sohnn vom keiser, habst ader von der ehe, derselbige nympt seines vaters gut mit rechte... Es nympt aber solch geelichet kinth sunst kein erbteil alleine von seyner mutter, wie oben gesagt ist. - ${ }^{2}$ ) Die genannte regula 35 beruft sich auf eine deutsche Rechtsquelle lib. 2 cap. 9 dist. 4, regula 34 auf lex 3 , $\S$ filium in autentico "qui nova esse sen". - ${ }^{3}$ ) Titel: "Van erbung unnd succession geehelichter kinder durch nachvolgende heyrath" (Im Druck Köln 1562 S. 71). 
wegen seiner Vortrefflichkeit auch in vielen anderen fränkischen Gebieten als Gesetz angenommen wurde, stellt die durch nachfolgende Ehe legitimierten Kinder hinsichtlich des Erbrechtes auf ganz gleiche Stufe wie die ehelichen:

Und wiewol diese unsere ordenung alleyn vonn gebornen ehelichen kindern meldung thut, so wollen wir doch (gleich wie auch die keyserliche recht) in derselben zahl auch die iehngen kindere, so der mann mit eyner ledigen weibs personen (die sich zu demselben allein gehalten) vor der ehe gezeugt, folgens aber offenlich geehlicht unnd zu kirchen geführet hat, dadurch dann solche kindere auch geehlicht worden, mit begriffen und gemeynt haben, also dass dieselben für rechte ehekindere gehalten unnd zugleich den andern inn der ehe erzeugten kindern erbvehig seyn sollen. ${ }^{1}$ )

Hartnäckig hielt man in Holstein und in der Landschaft Dithmarschen an der alten Rechtsanschauung fest.

In Holstein wurde nach einem im Jahre 1494 bei dem Neumünsterschen Goeding erflossenen Urteil der Kläger abgewiesen "sich des väterliken erwes na Holsten recht und landesgebrücke nicht to unnerwinnen, dewyle ehme syne moder tweene iare tovorne gebaren, alse dorch de hillige ehe geechtet sy ". ${ }^{2}$ ) Und ein Urteil desselben Gerichtes wies im Jahre 1.509 einen vor der Ehe erzeugten Sohn, welcher das Testament seines Vaters wegen Präterierung anfocht, ab und gewährte ihm nur einen Alimentationsanspruch gegenüber seinen ehelichen Brüdern. ${ }^{3}$ )

Das Dithmarscher Landrecht vom Jahre 14474) erwähnt eine Legitimation gar nicht und eine Beliebung vom Allerheiligentag 1488 lehnt die Wirkung der von den Eltern eingegangenen Ehe für die vorher erzeugten Kinder ausdrücklich $\mathrm{ab}$, indem sie bestimmt:

Effte ein mann ein kind tügede mit der fruwen, ehe se tho sinen echten bedde gekamen, dat kind mag des

1) 2. Teil, 25. Titel $\S 6$ „Von geehelichten kindern“. - 2) Dreyer, Nebenstunden S. 297. - ${ }^{3}$ ) Ebenda S. 301 Nr. 8. - 4) Ausgabe von Michelsen, Sammlung altdithmarscher Rechtsquellen, Altona 1842. 
vaders erwe nicht mächtig syn, wen gelike de moder to des mannes echten bedde gekamen. ${ }^{1}$ )

Die Landrechte von $1539^{2}$ ) und $1567^{3}$ ) gehen darüber wieder mit Stillschweigen hinweg.

Einen ähnlichen Gedanken wie der, welcher uns schon im Sachsenspiegel begegnet ist ${ }^{4}$ ), finden wir auch in der ungefähr aus derselben Zeit stammenden fünften friesischen Überküre $^{5}$ ): Eine Magd, mit welcher der Dienstherr in geschlechtlicher Gemeinschaft gelebt und Kinder gezeugt hat, kann niemals desselben rechtes Eheweib werden. Die vor Eingehung der eheähnlichen Verbindung erworbenen Kinder bleiben ebenso illegitim wie die in derselben erzeugten :

Wersa en mon nime en wif to quern and to ku uder en ti alsa dena thianeste, sa him gad were, end him thenna en kind gader wrde, end thet kind skenade and thet wif liavade, thet hise thenne afte nome, thet hiu ni thet kind ni machte nenne aftne stol besitta, ni thera kinda nen, ther hiu bi him tege. ${ }^{6}$ )

Der Umstand, daß hier eigens hervorgehoben ist, daß das bei der Dienstmagd erzeugte Kind auch nach Eingehung der vermeintlichen Ehe nicht den ehelichen Stul besitzt, zeigt deutlich, daß das Institut der legitimatio per subsequens matrimonium im 13. Jahrhundert in Friesland, wenn auch nicht anerkannt, so doch nicht ganz unbekannt war.

Im Laufe der Zeit ging auch hier unter dem Einflufs der Kirche ein Wandel der Rechtsanschauungen vor sich. Das im Jahre 1515 aufgezeichnete ostfriesische Landrecht bemerkt zu dieser Bestimmung der fünften Überküre:

1) Dreyer, Nebenstunden S. 297. - 2) Ausgabe bei Michelsen a. a. O. - ${ }^{3}$ ) Druck in Cronhelms Corpus statutorum provincialium Holsatiae. - ${ }^{4}$ ) S. 117. - 5) Heck, Der Ursprung der gemeinfriesischen Rechtsquellen. Neues Archiv 17. Bd. 1892 S. 569 ff. setzt die Entstehung der Überküren in die Zeit Heinrichs IV. (nach 1085). Die eherechtlichen Bestimmungen der Überküre 4 und 5 sind aber jedenfalls jüngere Zusätze, die wahrscheinlich erst dem 13. Jahrhundert angehören. Schröder, Rechtsgeschichte S. 672 . Vgl. auch Richthofen, Untersuchungen zur friesischen Rechtsgeschichte I. S. 202 ff. - ') Hunsegoer Text. Richthofen, Untersuchungen I. S. 238 (Richthofen, Friesische Rechtsquellen S. 100). 
De vyfte overkoer is thegen insette der hilgen kercken na unsen goetduncken, daer umme wart dat nu nicht geholden. ${ }^{1}$ )

Diese Derogierung kann sich allerdings nur auf die angegebene ursprüngliche Fassung der fünften Überküre beziehen, denn der Wortlaut, welchen das ostfriesische Landrecht selbst von der fünften Überküre gibt, ist gegenüber der ursprünglichen Gestalt ganz wesentlich modifiziert und mit den kirchlichen Normen vollkommen übereinstimmend, indem hier angenommen wird, daß die Kinder mit der Magd im Ehebruche erzeugt sind und daß die rechtmäßige Gattin zur Zeit der versuchten Eingehung der Ehe mit der Magd noch lebt. ${ }^{2}$ )

Diese veränderte Rechtsanschauung kommt nun auch darin zum Ausdruck, daß das ostfriesische Landrecht die von solchen Eltern, zwischen denen kein trennendes Ehehindernis besteht, erworbenen Kinder durch die nachfolgende Ehe der Erzeuger echt werden läßt und dieselben den nach Eingehung der Ehe gewonnenen Kindern vollkommen gleich stellt, dabei ist es gleichgiltig, ob die Eltern in der Zeit zwischen der außerehelichen Zeugung und der Eingehung der Ehe etwa anderweitig verheiratet waren:

Wan ein mann hefft geteelt ein unechte kint by einer frouwen, de he mit sick im huise hadde all eine concubina, off eine ander frouwe buten dem huise nicht

1) Richth ofen, R.-Qu. S. 101 A.4. Wicht, Ostfriesisches Landrecht lib. III. cap. 101 S. 837: De viefte averkoer is tegen insettinge der hilligen kercken und gebruick důsser landen, darumme salt also nicht geholden werden. - 2) Ostfries. Ld. R. lib. III. cap. 100 (Wicht a. a. O. S. 827): Woir ein mann ein maget eder wyff wint tho sinen koyen und tho alsodaenen denst, alse der maget behorlich is, und he dan by de denstmaget schlepe und se ein kint van em in averspill teelde, wan dat kint dorna grot werde und eme de moeder des kindes dair na belevede und wolde se danne tho echte nemen, so muchte noch dat kint noch gene kinder, de se van em teelde, echte werden und de moeder muchte oek den echten stoell nicht besitten. Dat is waer, wan dat echte wyff noch levede und de kinder werden also vortan gewunnen in averspill, dan dat wort nicht tho gelaten darumme, dat se moegen gearbeidet hebben na den doet des echten wyfes: quia sunt machinati in mortem alterius. 
alse eine concubina, dairmede he up desillve tyt muchte staen in echtschup, alse de frouwe dat kint van em untfenck, und de mann nimpt darna desúlve frouw to echte ..., so is datsi̊lve kint so echte, als de kinder, so dairna in echtschup geteelet werden. .... Hefft oek de mann middeler tyt ein echte wyff genoemen und dat wyff stervet, darna nimpt de mann dat unechte wyff, dar he tho voeren kinder by hadde, tho echte, so sinnen de kinder echte. ${ }^{1}$ )

Das Erbrecht von Fivelgo und Hunsingo erkennt die echtigende Kraft der Ehe vollkommen an, indem es den geechtigten Kindern neben den echten ein Erbrecht gewährt:

Item soe syn daer mennigerleie kynderen, die doch alle gader arffenisse moeghen untfangen. In den erstenn soe syn daer echte kynderen, de echte geboren synn; ten anderen die geechtiget worden, als mantellkynder, dat sint kynderen, die van twe vrye luiden syn geboren, welcke olders daer nae malkanderen truwen end echtigen nae zeede end ghewoente. ${ }^{2}$ )

Die Iurisprudentia Frisica ${ }^{3}$, ein aus dem Ende des 15. Jahrhunderts stammendes Rechtsbuch, das einheimisches friesisches und römisches Recht zu einem Ganzen zu verarbeiten suchte, unterscheidet zwischen der Legitimation nach geistlichem und nach kaiserlichem Recht und reiht die legitimatio per subsequens matrimonium unter das geistliche Recht ein:

Dit is riucht: Dat de natuerlicke sonen moghen aefft wirda twyrahanda wys ney da gastlicke riucht. In 't arst, so aefftiget hij da frowa, deer hij da natuerlike kynden bij crijn haet; so sint da kynden aefft, deer hij eer teyn haet ende eeffter tiucht bij der frowa. ${ }^{4}$ )

1) Lib. II. cap. 20, Wicht S. 330 f. - 2) Richthofen, Friesische Rechtsquellen S. 325 f. $\$ 16$. Wir kommen auf diese Stelle noch in anderem Zusammenhange zurück. - ${ }^{3}$ ) Ausgabe von Hettema, Iurisprudentia Frisica of Friesche regtkennis, Leeuwarden 1834. - ${ }^{4}$ ) Titel 47 §5. Hettema a. a. O. II. S. 86. Die zweite Art nach ${ }_{n}$ geistlichem

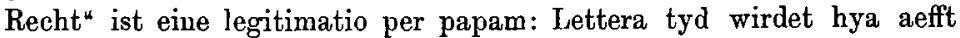
bij des paus wyeld, als er dij paus mey dispenseret (ebenda). Titel 47 $\S 5$ führt die Legitimationsarten „nach des Kaisers Recht“ an. 
Obwohl der Verfasser des Rechtsbuches die legitimatio per subsequens matrimonium zu einem Institut des kanonischen Rechtes zählt, folgt er doch hinsichtlich der Frage, welche Kinder legitimiert werden können, ebenso wie das ostfriesische Landrecht nicht ganz dem kanonischen Recht, indem er nur Kinder, die von Eltern erzielt werden, zwischen welchen im Zeitpunkt der Zeugung eine Ehe möglich wäre, naturales im neueren technischen Sinne, für legitimationsfähig erklärt, während das kanonische Recht alle außerehelich erzeugten Kinder mit alleiniger Ausnahme der adulterini dieser Wohltat teilhaftig werden läßt:

$\mathrm{Da}$ sonen, deer sint teyn twiscka twa, deer neen aefft bygaen moghen ende naet aeff moghen hya wirda, ner neen gued mogen hya ontfaen. ${ }^{1}$ )

In Nordfriesland hingegen wurden die vor Eingehung der Ehe erworbenen Kinder erst sehr spät als ehelich angesehen. Am 28. März (Dienstag nach Judica) 1542 bestätigte König Christian III. als höchste richterliche Instanz ein Urteil des nordfriesischen Fünfhardengerichts, daß eine vor der Ehe geborene Tochter nach ihrem Vater kein Erbrecht habe, weil das Kind "unrecht und 10 iahren to forn, ehe sin vader sine moder geehelichet, gebarn" sei. ${ }^{2}$ ) Auch noch im älteren Nordstrander Landrecht der fünf Nordstrander Harden vom Jahre $1558^{3}$ ) sind unechte Kinder erblos, auch wenn die Eltern sich nachher verehelichen:

Unechte kinder nah dissem landtrechte sind erfloss, wenn ock schon de modder darna mit demsůlvigen, dar se dat kind mit gehatt, sick voorehelicken wurde.4)

1) Titel $47 \S 15$ a. a. O. S. 92 . Die niederländische Übersetzung: De zonen, die geteeld zijn door twee, die geen en echt mogen aangaan, die mogen niet gewettigd worden of geen goed mogen zij ontrangen. Titel $47 \S 7$ definiert natürliche Kinder , als een man bij eenre frowa tiucht" und setzt sie 1. den ,aefftlyck ende natuurlyck" Kindem 2, den "spurii“, den "hor natuurlyck ner aefftlyck, als da deer sint teyn in da wrhuur, jeffta twiska twa, deer neen aefft mogen bygaen " und 3. den „filii adoptivi ${ }^{4}$ entgegen. $-{ }^{2}$ ) Dreyer, Nebenstunden S. 299 f. $-{ }^{3}$ ) Vgl. darüber Stemann, Geschichte des öffentlichen und Privatrechtes des Herzogtums Schleswig II, S. 162. - ${ }^{4}$ ) Artikel 43, Dreyer, Sammlung vermischter Abhandlungen I, S. 507. 
Erst das neuere Nordstrander Landrecht ${ }^{1}$ ) vom Jahre 1572 erkennt den vorehelichen Kindern ein Erbrecht zu. ${ }^{2}$ ) Ähnlich wie das Landrecht widerstrebten auch die Stadtrechte Norddeutschlands und voran das Magdeburger Recht, in dem die stadtrechtliche Umbildung des Sachsenspiegels am reinsten zum Ausdruck kam, dem Eindringen der legitimatio per subsequens matrimonium.

Die von Nicolaus Wurm $(\dagger 1383)$ verfaßte Blume von Magdeburg ${ }^{3}$ ) schließt sich noch ganz an die Fassung des Sachsenspiegels an. Nach ihr erben die erst nach Ablauf von 7 Monaten nach Eingehung der Ehe geborenen Kinder und erst die nach "achtehalbin mondin" gebornen kann man nicht mehr als unehelich schelten. ${ }^{4}$ )

Das Magdeburg-Breslauer systematische Schöffenrecht aus der Mitte des 14. Jahrhunderts ${ }^{5}$ ) lehnt die echtigende Wirkung der Ehe ab. Selbst wenn die vorehelich erworbenen Kinder nach der Ehelichung der Eltern vom Kaiser oder Papst per rescriptum legitimiert werden, so beerben sie ihre Eltern doch nicht, wenn eheliche Kinder vorhanden sind:

Eyn man siczcze mit eynir vrauwin, di nicht syn elich weip ist, und gewinne kindir mit er und lizse em di selbe vrauwin treuwin und gewunne ouch mit ir kindir und di erstin kindir wurdin elich gemacht von dem bobiste adir von dem keysir; der man sturbe dornoch, zo mochtin di erstin kindir mit den lecztyn keyn teil genemyn. ${ }^{6}$ )

1) Stemann II S. 162 f. $-{ }^{2}$ ) Stemann II S. 247 f. - ${ }^{3}$ ) Hrsg. von H. Böhlau, Weimar 1868. - 4) Particula II, cap. 74 (entsprechend Sachsenspiegel Ld. R. I, 36): So wen ein man irst weip genymt, gewint eer eyn kint mit ir ee rechte czeit, daz lebindig blybit: stirbit der vater sint, iz mag kein erbe gesein in dez mannes gute und man mag daz kint bescheldin an seynem rechte. Und sotan sache sol man rechinen uf daz kurcze, alz ob sy irin man hab gehabit sebin mondin, so teilt man dem kinde daz erbe zcu, odir achtehalbin, so hot mans vor ein elich kint. Wen worum? Waz in dem sebindin mondin odir in dem achtin geborin wirt, were unmogelich lebendig zcu blybin. Und diz kumt czu von dez rechtis gunst. Übereinstimmt auch II, cap. 73 mit S. Sp. I, 37: Swer so eins mannes weip behurt odir mayt odir weip notzcogit, nymt er sy darnach czu der ee, eekint gewinnet er nymer by ir. - ${ }^{5}$ ) Ausgabe von P. Laband. Berlin 1863. - ${ }^{\circ}$ ) 4. Buch, 2. Teil, 55. Kap. Laband S. 167.

Zeitschrift fiir Rechtsgeschichte. XXV. Germ. Abt. 
Die Fortbildung des Magdeburg-Breslauer systematischen Schöffenrechtes, wie es uns im sogenannten „alten Kulm" "1) vorliegt, schließt sich vollinhaltlich an die Vorlage an. ${ }^{2}$ )

Auch die gegen Ende des 14. Jahrhunderts (zwischen 1386 und 1400) entstandenen Magdeburger Fragen ${ }^{3}$ ) erkennen die legitimatio per subsequens matrimonium nicht an. Einmal fordern sie, damit die vor der Ehe erzeugten Kinder mit den ehelichen Erbe nehmen können, in der den beiden vorgenannten Rechtsquellen entsprechenden Stelle den Hinzutritt der kaiserlichen oder päpstlichen Legitimation per rescriptum ${ }^{4}$ ) und sprechen überdies noch ausdrücklich der nachfolgenden Ehe der Eltern eine erbrechtliche Wirkung für die vorher erzeugten Kinder ab:

$\mathrm{Ab}$ eyn man wip adir mayt beslefft, dy sache wirt offinbar, der selbe dy dornoch nympt zcu der ee unde kinder mitenander gewynnen, der man und dy vrouwe sterbin. Ab dy kinder ir erbe unde gut sullen nemen adir nicht? Hiruff sprechen wir scheppin zeu Magdeburg recht: Besleffit eyn man wip adir mayt, dy do ledig ist, mit irem willen unde nympt sy dornoch zcu der e, gewynnen sy kinder in der e mittenander, dy kinder nemen irer beider erbe noch irem tode. Haben si abir kinder mittenander vor der e gehat, dy mogen ires erbis nicht nemen. ${ }^{5}$ )

1) Ausgabe von Leman, Das alte kulmische Recht. Berlin 1838. - ${ }^{2}$ IV, 97, Leman S. 134: Eyn man sitze myt eynir vrouwen, dy nicht syn elich wib ist und gewynne kynder myt yr und lisse ym dyselbe vrouwe truwen und gewynne ouch kyndir myt yr. Und dy irsten kynder wurden elich gemacht von deme bobiste adir von deme keyser. Der man der sturbe dornoch, so mochten dy irsten kyndir nicht teyl genemen myt den letzten kinden. Eine Schwankung der Rechtsanschauung, indes nur hinsichtlich der legitimatio per rescriptam, macht sich aber darin geltend, daß ein Teil der Handschriften das letzte

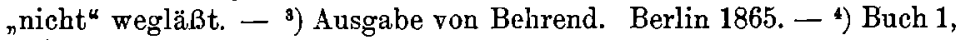
cap. 14, dist. 9, Behrend S. $135 \mathrm{f}$ : : Eyn man bekindet sich mit syner amyen, die nicht syn elich wip ist unde lesset sy ym dornoch truwen unde gewynnet ouch mit ir kinder, dy ersten kindere werden elich gemacht von dem babiste adir keiszer; der man stirbet. Ab dye ersten mit den leczten teil sulle nemen? Hiruff sprechen wir scheppin zcu Magdeburg recht: Dy ersten kinder sullen mit den leczten teil nemen. - s) Buch 1, cap. 14, dist. 3, Behrend S. 132. 
Erst in einem Spruch der Schöffen von Magdeburg ${ }^{1}$ ) aus der ersten Hälfte des 15. Jahrhunderts sehen wir die legitimatio per subsequens matrimonium voll anerkannt. Den legitimierten Kindern wird gleiches Erbrecht zugesprochen, wie den ehelichen.

Vollständig eingelebt hatte sich aber diese Rechtsanschauung bei den Schöffen von Magdeburg noch lange nicht, denn noch ungefähr ein Jahrhundert später im Jahre 1532 ließen sie nach Görlitz ein gegenteiliges Urteil ergehen:

Hat eyner eyne iungfraw geschwengert, ap ehr dan gleych dieselbe darnach zcur ehe genohmen und alsso in stehnder ehe das kindt zur welt gebracht - szo mag doch dasselbige geborne kyndt nach vorordnunge sechssischer rechte vor ehelich nicht geacht und gehalten werden unnd kann alsso aus mangel seyner ehelichen geburt die erbliche gerechtigkeit seynes vorstorben vadters im rechte nicht nehmen ader erfordern. ${ }^{2}$ )

Auch ein Dresdener Schöffenurteil aus dem Jahre 1553 steht noch ganz auf dem ablehnenden Standpunkt der Magdeburger Fragen:

Beschlefft ein man ein weib oder magd, die da ledig ist, mit iren willen und nimpt si darnach zu der ehe, gewinnen sie kinder in der ehe miteinander, die kinder nemen irer beider erb nach irem tode. Und haben sie aber kinder miteinander vor der ehe gehabt, die mögen ires erbes nicht gewinnen. ${ }^{3}$ )

1) Wasserschleben, Sammlung deutscher Rechtsquellen I S. 248 cap. 108. Lörsch und Schröder, Urkunden zur Geschichte des deutschen Privatrechtes ${ }^{2}$ Nr. 329 S. 240. - 2) Th. Neumann, Magdeburger Weistümer (Görlitz 1852) Nr. 71 S. 224. - ${ }^{3}$ ) Dreyer, Nebenstunden S. 289. Lörsch und Schröder, Urkunden zur Geschichte des deutschen Privatrechtes ${ }^{2}$ Nr. 342 S. 250 ff. enthalten aus Bodmanns Rheingauischen Altertümern eine angebliche Entscheidung des Oberhofs zu Eltville aus dem 15. Jahrhundert, worin die legitimatio per subsequens matrimonium sogar für einen adulterinus anerkannt und demselben allerdings in einem Falle, in welchem keine ehelichen Kinder vorhanden sind - ein Erbrecht nach Vater und Mutter zugesprochen wird. Allein der ganze Oberhof zu Eltville hat gar nicht bestanden und die Oberhofentscheidungen sind eine Fälschung Bodmanns. Vgl. Herbert Meyer, Das sog. Rheingauer Landrecht, eine Fälschung Franz Josef Bodmanns. Diese Ztschr. XXIV. (1903) S. $333 \mathrm{ff}$. 
Die um die Mitte des 14. Jahrhunderts aufgezeichneten Statuten von Goslar verwerfen die Legitimation durch nachfolgende Ehe gleichfalls:

Heft en man unde en wif kindere, die onecht sin, to samene, al en sic de na to echte nemen, de kindere, de se vore hadden, er se sic to echte nemen, ne nemet doch nen erve unde blivet onechte kindere. ${ }^{1}$ )

Das Statut der Stadt Werle von 1392 räumt der Legitimation durch nachfolgende Ehe, wenn eheliche Kinder vorhanden sind, ebenfalls keinen Platz ein:

Een kind vor der echte geteelet (= gezeugt) mag neen erve upbo̊ren mit dem kinde in der echte geteelet. ${ }^{2}$ )

Aus dem Umstand, daß hier den legitimierten Kindern ein Erbrecht neben ehelichen ausdrücklich abgesprochen wird, darf man wohl schließen, daß ihnen ein solches in Ermangelung ehelicher Sprößlinge zustand. In welchem Umfang, muß3 freilich dahin gestellt bleiben.

Die gegen Ende des 14. Jahrhunderts entstandenen Eisenacher Rechtsbücher des Stadtschreibers Johannes Rothe lassen die durch nachfolgende Ehe legitimierten Kinder nach Vater und Mutter, aber nicht nach den übrigen Verwandten erben $^{3}$ ):

Dy ferde geburt heissit eyn naturliche elich gebort und sint, wo eyn ledig man und eyn ledig wip adir eyn elich man adir elichiz wip sich zcusammen mischin und so doch daz geschet an alle gelobede von naturlichir liebe und di kinder mit eynandir gewunnen, di kindir heissin naturliche kinder noch der gebort. Nemen si sich darnach zcu der e, di kindir werdin von gotis gnadin und von bebistlichin gesetzce ${ }^{4}$ ) geeed und nemen eris vatir gud und er muter, wan er vatir und er muter gesterbin, daz dez mannes nehistin erbin noch der frawin den kindirn er

1) Die Goslarischen Statuten hrsg. von Göschen, Berlin 1840 S. 13. - $\left.{ }^{2}\right)$ Dreyer, Nebenstunden S. 296. - ${ }^{3}$ ) Eisenachisches Rechtsbuch I. 1 bei Ortl off, Sammlung deutscher Rechtsquellen Jena 1836, I. Bd. S. 648. Damit stimmt das zweite Rechtsbuch (Purgoldts) I. 38 bei Ortloff a. a. O. II. S. 35 inhaltlich überein. - ${ }^{4}$ ) Purgoldts R.-B. schiebt danach ein "adder von dem keyser zcu lehinguthin". 
irstorbin gud von vatir und von muter nicht vorteilen mogin. Abir ${ }^{1}$ ) an eris eldirvater und eldermuter gud en mogen si keyne erbeteylunge gehabin.

Daß die Legitimation in ihrer römischrechtlichen Gestalt im Anschluß an die Buchsche Sachsenspiegelglosse in dem zwischen 1417-1448 abgefaßten Klevischen Stadtrecht anerkannt ist, wurde schon in anderem Zusammenhange hervorgehoben. ${ }^{2}$ )

Nach den Statuten von Küstrin vom Jahre 1429 beerben die vor der Ehe erzeugten Kinder mit den ehelichen nur die Mutter, aber nicht den Vater:

Kronskindere moghen gein erve upboren, id en si van orer moder wegen. Eft ock de vader ore moder tor echte nam, so en scolen se doch mit die brodere und sustere dat vaders gut nicht deilen, sondern to orer becostinge hebben, wat de brodere willen. ${ }^{3}$ )

Wahrscheinlich darf man auch hier aus dem Ausschluß der vorehelichen Kinder vom Erbe des Vaters, wenn echte Kinder vorhanden sind, e contrario schließen, daß sie beim Mangel derselben den Vater beerben können.

Die "erneuwerte reformation" der Stadt Frankfurt a. M. vom Jahre 1578 reiht die per subsequens matrimonium legitimierten Sprößlinge unter die ehelichen Kinder:

Es werden aber under die zahl der ehelichen kindere von rechts wegen gerechnet auch die ienigen, welche ob si wol im ehestandt von iren eltern nit entpfangen und geboren, sonder volgends erst durch derselben offentliche eheliche vermåhelung seynt geehlicht worden, also dass auch die kindere, so sie die eltern fürter in solchem ehestandt mit einander zeugen, kein mehrer gerechtigkeyt als die vorgemeldte erste haben, dann, wie die recht sagen, so haben die letste eheliche kindere den ersten geehlichten dess zu dancken, dass sie ehelich geborn seynt und ire eltern umb lieb willen der ersten kinder sich selber geehlicht haben. ${ }^{4}$ )

1) Druck hat „adir". Purgoldts R.-B. hat richtig nabir". - 2) Oben S. 119. - ${ }^{3}$ ) Pa uli, Abhandlungen aus dem lübischen Recht. III. Teil, S. 27. - ) 5. Teil, 1. Titel, $\$ 4$. 
Ebenfalls sehr schwer und spät verschaffte sich die Legitimation durch nachfolgende Ehe in Lübeck und dessen Tochterstädten Eingang.

Ein Urteil des Lübecker Oberhofes vom Jahre 1505 nach Reval sagt ${ }^{1}$ ), „dass ein wanbörtig ${ }^{2}$ ) gebohrnes kind der erfolgten ehe seiner eltern ungeachtet seiner geburt wegen kein erbe nehmen könne."

Im Jahre 1534 bestätigt der Rat der Stadt Lübeck ein Stralsundisches Urteil, wonach ein vor der Ehe erzieltes Kind nach Lübischem Rechte an dem väterlichen Erbe keinen Anteil nimmt:

Nachdeme ire kindt... nicht aus dem eelichen brauthbetthe sondern vor der berömpten ee geborn, so soll daselb kindt nach statrecht erbe zu nemen, unbequem seyn. ${ }^{3}$ )

Auf demselben ablehnenden Standpunkt steht das lübische Recht noch gegen Ende des 16. Jahrhunderts. Erst im 17. gelangte die legitimatio per subsequens matrimonium allmählich zur Anerkennung. ${ }^{4}$ )

Rascher fand die Legitimation durch nachfolgende Ehe in Süddeutschland unter dem Einfluß des Schwabenspiegels oder vielmehr eines jüngeren Zusatzes zu demselben Eingang.

Der Spiegel deutscher Leute, welcher die legitimatio per rescriptum principis und per rescriptum papae anerkennt ${ }^{5}$ ), steht in bezug auf die legitimatio per subsequens matrimonium allerdings noch ganz auf dem Standpunkt des Sachsenspiegels. Auch nach ihm kann man die Ehelichkeit eines zwar in der Ehe, aber zu früh gebornen Kindes anfechten:

Swenne ein weib erste man nimt, gewinnet si ehint e ir rechten zeit, man mag daz chint beschelten an seinem rechte, wan ez ze fri geporn ist. ${ }^{6}$ )

1) Dreyer, Nebenstunden S. 298 und Einleitung zur Kenntnis der Lübeckschen Gesetze, Verordnungen und Rechtsurkunden I, 3, S. 276. 2) Wan =Mangel, Gebrechen. Vgl. Schiller und Lübben, Mittelniederdeutsches Wörterbuch „wan" V, 582. - $\left.{ }^{3}\right)$ Dreyer, Nebenstunden S. 301 N. 10. - 4) C. W. Pauli, Abhandlungen aus dem lübischen Rechte. III. Teil S. 30. - ${ }^{5}$ ) Ausgabe von Ficker, Artikel 45. - ${ }^{8}$ ) Artikel 40. 
Ferner übernimmt der Spiegel deutscher Leute von Eicke auch den Satz:

Swer eines mannes weib behůret oder ledich weip oder maget notzoget, nimt er sei dar nach ze e, êe chint gewinnent si nimmer bei einander. ${ }^{1}$ )

Auch noch der Schwabenspiegel erkennt nur das im Ehebettę erzeugte Kind als ehelich an und läßt das zu früh nach Eingehung der Ehe oder zu spät nach Auflösung derselben geborne Kind als unehelich schelten, wobei er als Frist bei Knaben die Zeit von 41, bei Mädchen - wohl in Anlehnung an das römische Recht - die Zeit von 40 Wochen festsetzt ${ }^{2}$ ), und dieselbe Bestimmung übernimmt das Rechtsbuch Ruprechts von Freising. ${ }^{3}$ )

Aber schon ein jüngerer, noch dem 13. Jahrhundert angehörender Zusatz des Schwabenspiegels erkennt die legitimierende Kraft der nachfolgenden Ehe in vollem Umfange an, indem er den per subsequens matrimonium legitimierten gleich den ehelichen Kindern ein Erbrecht gegenüber allen Verwandten - sogar in Lehen - einräumt (Laßberg 377):

Hat ein man eine frouwe ze ledeclichen dingen unde hat kint bi ir vil oder lútzel unde nimet er si dar nach ze rehter e, swaz si kinde sampt hetten zun e, e das si einander ze e nemen, diu sint ellủ sampt rehte e kint und erbent eigen unde lehen von vater unde von miter unde von andren iren frúnden alse wol alse diu kint, die si dar nach gewinnent, so si einander ze e genomen hant. Wil man in dez vor weltlichen nút gelouben, so suln si ir elich reht vor geistlichen gerihte behalten unde

1) Artikel 41. $-{ }^{2}$ ) Laßberg 40: Swenne ein wip erste man nimt, gewinnet si kint vor ir rehten zit, man mac daz kint beschelten an sinem rehte. Gewinnet ein wip kint nah ir mannes tode nach ir rehten zit, daz mac man och wol beschelten an sinem rehte, wan ez zespete chomen ist. Disiu zweier slahte chint, der (din) rechtvertigen wil sint si degen kint, so sol man ir zil raiten zeminsten ein und vierzic wochen, diu ein woche ist in zegenaden dar zo gesezzet, der megede kinden an ein vierzec wochen. Ditze gerihte sol vor der phafheit geschehen und mac diu kint uber chomen, daz si zespate oder ze vrú komen sint, si erbent ir vaters gưtes niht, si erbent oh můter gútes niht, ez erbent ie die nehsten mage. - ${ }^{3}$ ) Ausgabe von Maurer I. cap. 33. 
suln dez brieve unde ingesigel nemen, so behabent si ir reht vor allem weltlichem gerihte mit rehte.

Aus dem letzten Satz dieser Stelle ergibt sich nun allerdings der Schluß, daß die weltlichen und geistlichen Gerichte unter Umständen die Wirkung der nachfolgenden Ehe der Eltern für die Kinder verschieden beurteilt haben ${ }^{1}$ ), indem der Spiegler die Möglichkeit in Betracht zieht, daß der weltliche Richter der legitimatio per subsequens matrimonium seine Anerkennung versage, und die Rechtsuchenden für diesen Fall an das geistliche Gericht verweist, in dessen Händen die Ehegerichtsbarkeit lag, und den weltlichen Richter an den Ausspruch des geistlichen Gerichtes bindet. Wir finden hier denselben Gedanken, welchem wir in der um dieselbe Zeit wie der Schwabenspiegel entstandenen summa de legibus Normannie in curia laicali begegnen: quos .. iudex ecclesiasticus pro legitimis reputat, et laicus legitimos reputabit. ${ }^{2}$ )

Siege ${ }^{3}$ ) hat den Satz "wil man in dez vor weltlichen (gerihte) nut gelouben etc." nur auf die unmittelbar vorausgehenden Worte "so si einander ze e genomen" bezogen und demgemäß darzutun versucht, daß die Anrufung des geistlichen Gerichtes nur zu dem Zwecke erfolgen soll, um den $A b s c h l u B$ der Ehe zu beurkunden. Diese Interpretation ist aber sicher unrichtig schon um deswillen, weil in einem Teil der Handschriften der Zwischensatz "so si einander ze e genomen" ganz fehlt.")

Das nicht viel später als der Schwabenspiegel entstandene Wiener Stadtrechtsbuch ${ }^{5}$ ) räumt den durch nach-

1) Schon von Eichhorn, Deutsche Staats- u. R.-Gesch. ' II S. 617 f. Wilda, Der reichsgräflich Bentincksche Erbfolgestreit. Ztschr. f. deutsches Recht IV. Bd. (1840) S. 288 und Brackenhöft in Weiskes Rechtslexikon, Artikel: Intestaterbe, Intestaterbfolge etc. nach deutschem Rechte V. Bd. S. 736, hervorgehoben. - ${ }^{2}$ ) Siehe oben S. 115. - ${ }^{3}$ ) Das deutsche Erbrecht S. 34. - ${ }^{4}$ ) Vgl. die unten S. 159 abgedruckte Fassung dieses Kapitels aus der Züricher (Ende des 13. oder Anfang des 14. Jahrhunderts) und Wien-Ambraser (1462) Hs, - ${ }^{5}$ ) Ausgabe von H. Schuster, Das Wiener Stadtrechts- oder Weichbildbuch, Wien 1873. Dasselbe entstand nach Schuster S. 36 zwischen 1276 bis 1296, jedenfalls aber vor 1325 . 
folgende Ehe legitimierten Kindern nach den Eltern vollkommen gleiches Erbrecht ein, wie den ehelichen:

Nimpt ein man ein hausvraun, die er vor beslaffen hat, und hat auch chind mit ir zwai oder dreu, ee daz er seu genomen hat, und darnach und er seu genimbt, so gewint si awer chinder mit ihm, und chaufent auch die weil erib und aigen, und darnach sterbent si paideu vater und mueter, und die lesten chind wellent den ersten chinden nicht tailez lazzen darumb, daz si ir mueter gewan pei irm vater, ee das er si nam zu ainer chonen, und jechend des, si sein nicht ee chind, so welle wir daz, das dieselben chind geêt sein von dem, das ir vater und ir mueter eleich an einander genomen habent, und darumb habent seu als gueten tail an dem erib, daz ir vater und ir mueter habent, als die lesten. ${ }^{1}$ )

Die Reformation der Stadt Nürnberg vom Jahre 1522 räumt den durch nachfolgende the legitimierten Kindern ein vollkommen gleiches Erbrecht ein wie den ehelichen mit Ausnahme der Folge in Lehen:

So man unnd weyb vor irer eelicher versammung natürliche oder leybliche kinder miteinander hetten und sich darnach eelich versameten, so erben dieselben kinder gleich mit andern nachvolgenden erben, so die erbschafft auff ir selbs ruet, on geschefft oder ander verding, doch hindan gesetzt freye manlehen, der recht sich gebürt durch lehenrecht ausszetragen. ${ }^{2}$ )

Diese Bestimmung ging dann über in die nverneute reformation" der Stadt Nürnberg aus dem Jahre $1564 .{ }^{3}$ )

Die Tirolischen Landesordnungen von 1532 und 1573 die von 1526 schweigt darüber - erkennen die Legitimation

1) Artikel 92. Auf den Widerspruch zwischen diesem Artikel und Artikel 93, welcher die legitimatio per subsequens matrimonium nicht anerkennt, hat schon Schuster a. a. O. S.39 aufmerksam gemacht. Der Widerspruch dürfte auf verschiedene Vorlagen zurückzuführen sein. 2) Titel 14, Gesetz 3. - ${ }^{3}$ ) Titel 34, Gesetz 5: Wann ain ledige mansperson mit ainem ledigen weibspild kinder erzeügt het und nachmaln dieselbig weibs person eelichet, so werden die kinder, so davor ledig geborn, durch solche ee für rechte eeliche kinder gehalten und mit den andern in der ee erzeugten kindern zu erben zugelassen. 
durch nachfolgende Ehe zwar nicht direkt, aber doch indirekt an, indem sie verbieten, daß ein Adeliger auf seine unehelichen Kinder seinen adeligen Namen und sein adeliges Wappen übertrage, „außgenommen er hab dann dieselben uneelich gebornen kinder mit vermählung und bestättung der heiligen ee gegen irer muetter geelichet. "1)

Der Landesbrauch der vorarlbergischen Herrschaft Blumenegg vom Jahre 1609 stellt die durch nachfolgende Ehe legitimierten Kinder erbrechtlich den ehelichen vollkommen gleich :

So wellen wir demnach, sezen auch und ordnen hiemit, das so wol geehelichte als ungeehelichte kinder, so außerhalb deß ehestands erzeugt worden (es seyen gleich andere eheliche kinder vorhanden oder nit) von aller väterlichen und müeterlichen erbschafft ausgeschlossen sein sollen, allein den fal außgenommen, wann sollich unehelich geborne kinder mit vermehlung und bestetung der heiligen ehe gegen irer muetter geehelicht werden, alßdan wollen wir, daß si in allen erbgerechtigkaiten andern gleich anfencklich ehelich gebornen kindern gleich seyen. ${ }^{2}$ )

Bezüglich der Lehenfolge der durch nachfolgende Ehe legitimierten Kinder kann ich mich begnügen, auf C. F. Diecks Abhandlung „Über die Lehenfolgefähigkeit der Mantelkinder" zu verweisen ${ }^{3}$ ), wo die einschlägigen Quellenstellen bis zu Beginn des 19. Jahrhunderts zusammengetragen sind. ${ }^{4}$ )

Verhältnismäßig schnell fand die Legitimation durch nachfolgende Ehe in den nordischen Ländern Aufnahme, wenngleich nicht in der reinen Gestalt des kanonischen Rechtes, sondern in einer den Rechtsanschauungen des Volkes angepaßten Form. ${ }^{5}$ )

1) Buch 3, Titel 37. - 2) 37. Jahresbericht des Vorarlberger Museumsvereines über das Jahr 1898, Seite $105 \mathrm{f}$. - ${ }^{3}$ ) C. F. Dieck, Beiträge zur Lehre von der Legitimation durch nachfolgende Ehe. Halle 1832. I. Abhandl. - 4) Nachzutragen wäre jetzt insbesondere das Urteil des deutschen Reichsgerichtes in Zivilsachen vom 13. Dezember 1884 Bd. XII Nr. 60 S. $239 \mathrm{ff.}$ - 5) Für das folgende ist zu vgl. Maurer, Die unechte Geburt nach altnordischem Rechte. Münchener Sitzungsberichte Jg. 1883 S. 68 ff. Wilda, Von den unecht gebornen Kindern. Ztschr. f. R -Gesch. XV (1855) S. 279 ff. 
In den norwegischen Rechtsquellen seit dem 13. Jahrhundert ist dieses Institut schon anerkannt.

Nach den Frostuthingslög ${ }^{1}$ ), die in der uns erhaltenen Gestalt aus der Mitte des 13. Jahrhunderts stammen, sollten vor der Ehe erzeugte Kinder durch die nachfolgende Ehe nur dann die Rechte ehelicher Kinder bekommen, wenn nach der Heirat noch ein lebendes Kind geboren wird. Eine solche Legitimation sollte nicht nur gegenüber dem Vater, sondern auch allen übrigen Verwandten gegenüber volle Rechtswirkung haben.

Dieser Rechtssatz wurde vom sogenannten Christenrecht König Sverris unverändert übernommen.

Eine eigentümliche Behandlung erfuhren die von Verlobten erzeugten Kinder, die Brautkinder.

Nach den Frostuthingslög und dem älteren Stadtrecht sollten Brautkinder als eheliche gelten, wenn der Vater unter Umständen stirbt, welche erkennen lassen, daß der Vollzug der Ehe von ihm beabsichtigt war.

Hier hat unzweifelhaft der bekannte kanonische Rechtssatz hereingespielt, daß ein Verlöbnis durch Hinzutreten der copula carnalis in eine Ehe sich verwandle, ohne aber vollständig zum Durchbruch zu gelangen.

Das sogenannte Christenrecht König Sverris gibt dieser Bestimmung über die Brautkinder nur eine allgemeinere Fassung und nähert sich dadurch völlig dem genannten Satz des kanonischen Rechtes, es stellt nämlich die Regel auf, daß Brautkinder schlechthin gleich den ehelich gebornen erben sollen, wenn ihr Vater vor der Hochzeit verstorben ist.

Auch die beiden Christenrechte des Königs Magnús Hákonarson (1263-1280), dem die Nachwelt den Beinamen Lagaboetir d. i. Gesetzverbesserer beilegte, lassen die Brautkinder ohne weiteres gleich den ehelichen erbfähig sein, auch wenn die Hochzeit nicht erfolgt, ohne daß dabei etwa der Tod des Vaters Voraussetzung wäre. Da sie sich dabei auf das gemeine Recht der Christenheit berufen, so lassen sie offenbar gleich diesem die sponsalia de futuro durch

1) Über die nordischen Rechtsquellen vgl. Maurer in von Holtzendorffs Enzyklopädie der Rechtswissenschaft ${ }^{5}$ (syst. Teil) S. 349 ff. 
Hinzutritt der copula carnalis in sponsalia de praesenti sich verwandeln.

Durch die Geburt von Brautkindern werden nach den Christenrechten des Königs Magnus ferner auch solche Kinder legitimiert, welche von den Brautleuten vor ihrer Verlobung miteinander gewonnen wurden. Hier zeigt sich gegenüber den kanonischen Grundsätzen eine bedeutende Abweichung, indem nach diesen die sponsalia de futuro schon durch copula carnalis in sponsalia de praesenti sich verwandeln und demgemäß schon dadurch die vor der Verlobung gewonnenen Kinder legitimiert werden, während die Christenrechte des Königs Magnus sich nicht mit der bloßen copula zufrieden geben, sondern darüber hinaus erst die Geburt von Brautkindern maßgebend sein lassen. ${ }^{1}$ )

Die neueren von König Magnus im Jahre 1268 gegebenen Gulathingslög erklären die vor der Ehe erzeugten Kinder neben den ehelichen Sprößlingen als rechte Erben, wenn der Erzeuger die Mutter nach Gottesrecht heiratet. ${ }^{2}$ )

In den schwedischen Westgöthalagen und Uplandslög begegnet die Legitimation durch nachfolgende Ehe gleichfalls.

Nach den dem 13. Jahrhundert angehörenden Westgöthalagen hat schon die öffentlich eingegangene Verlobung für die vorher erworbenen Kinder Legitimation zur Folge. ${ }^{3}$ )

Die aus dem Jahre 1296 stammenden Uplandslög erkennen die echtigende Kraft der Ehe im vollen Umfange an, und zwar auch dann, wenn die Eltern nach der außerehelichen Geburt ihrer Kinder etwa eine andere Ehe eingegangen waren. Aber nicht nur die erfolgte Eheschließung wirkt legitimierend, sondern auch eine öffentlich eingegangene Verlobung hat dieselbe Wirkung. ${ }^{4}$ ) Zwischen den sponsalia de praesenti und den sponsalia de futuro wurde demgemäß nicht strenge unterschieden. Die von Brautleuten erzeugten Kinder werden kurzweg als rechte Ehekinder angesehen. Die copula carnalis ersetzte hier offenbar, wie im kanonischen Rechte, den eheschließenden Akt.

Von der dänischen Quellengruppe lehnen das aus den ersten Jahrzehnten des 13. Jahrhunderts stammende schonische

1) Unrichtig Maurer a. a. O. S. 71/72. - ${ }^{2}$ ) Wilda a. a. O. S. 279. 3) Wilda S. 279. - 4) Wilda S. 280. 
Recht ${ }^{1}$ ) und die ältere ungefähr in derselben Zeit entstandene Bearbeitung des seeländischen Rechtes, welche unter dem Namen König Waldemars segelt, das ganze Institut der Legitimation durch nachfolgende Ehe ausdrücklich ab. Hingegen erkennen das von König Waldemar II. im Jahre 1241 erlassene jütländische Gesetzbuch und die jüngere noch der ersten Hälfte des 13. Jahrhunderts ańgehörende Bearbeitung des seeländischen Rechtes, welche mit König Erich in Verbindung gebracht wurde, dasselbe in vollen Umfange an. ${ }^{2}$ )

Das von König Magnus in den Jahren 1271-73 für Island gegebene Gesetzbuch, die sogenannte Járnsída, bezeichnet es als eine im ganzen Land gesetzlich eingeführte Bestimmung, daß eine rechtsgültig eingegangene Verlobung alle von den Brautleuten vor oder nach derselben erzeugten Kinder legitim mache.

Diese Bestimmung ist dann in das gemeine Landrecht und Stadtrecht übergegangen und durch eine besondere Verordnung vom 14. Juni 1314 auch dem von König Eiríkr Magnússon in den Jahren 1280-81 den Isländern gegebenen Gesetzbuch, dem Jónsbók, einverleibt worden und zwar mit dem aus dem kanonischen Recht genommenen Zusatz, daß diese Vorschrift auf die im Ehebruche erzeugten Kinder keine Anwendung finden soll. Dieser Zusatz ist dann im neueren isländischen Christenrecht so weit gefaßt, daß darunter alle von solchen Personen Gezeugte zu verstehen sind, zwischen welchen ein impedimentum dirimens besteht.

\section{Symbolische Formen der Legitimation durch nachfolgende Ehe.}

Die Rechtsanschauung des Volkes konnte sich mit der bloß abstrakten Wirkung der Ehe für die Kinder nicht abfinden, es erkannte ja grundsätzlich abstrakte Verhältnisse im Rechtsleben nur dann an, wenn sie in gewissen äußeren

1) Andreae Sunonis [1201-22 Erzbischof von Lund] iuris Scanici expositio 24: Non prodesse hoc potest filio naturali ..., quod ipsius pater putativus matrem suam duxerit in uxorem. Schlyter, Corpus iuris Sueo-Gothorum antiqui Vol. IX pag. 259. - ${ }^{2}$ ) Wilda S. $280 \mathrm{f}$. 
sinnlichen Tatsachen hervortraten. ${ }^{1}$ ) So wollte es auch hier einen sichtbaren Ausdruck der rechtlichen Wirkung der von den Eltern abgeschlossenen Ehe für die Kinder haben. Die Kirche konnte dieser Rechtsanschauung des Volkes sehr leicht Rechnung tragen, ohne ihren Rechtssätzen Abbruch zu tun. Und tatsächlich kam sie denn auch entgegen und ließ sich zu einer Art Kompromiß herbei, indem sie die legitimatio per subsequens matrimonium in eine bestimmte, dem Volksgeist angemessene Form kleidete. Naheliegend war es, die bei der kirchlichen Traung selbst beobachteten Zeremonien auf irgend eine Weise nun auch zur Versinnbildlichung der rechtlichen Wirkung der nachfolgenden Ehe der Erzeuger für die früher erzeugten Kinder zu gebrauchen. Unter den kirchlichen Zeremonien war aber wieder eine ob ihrer rechtlichen Bedeutung vor allen andern zu diesem Zwecke geeignet, nämlich der Gebrauch eines Tuches oder einer Decke (pallium, velamen, französisch poile drap oder voile), welches nach dem eheschließenden Akte, meist bei der auf die Trauung folgenden Brautmesse oder eines Teiles derselben, vielfach auch während der Benediktion über die Brautleute ausgespannt wurde oder womit dieselben ganz oder teilweise bedeckt wurden.

Es gilt nun zunächst, den Bestand und Umfang dieses kirchlichen Brauches nachzuweisen und sodann zu zeigen, wie derselbe für die Legitimation dienstbar gemacht wurde.

Ein velamen, mit dem die feminae virgines bei der Benediktion verhüllt wurden, erwähnen schon der alte Tertullian $\left.(\dagger 220)^{2}\right)$ und Isidor von Sevilla $\left.(\dagger 636) .{ }^{3}\right)$ Aber beide sprechen nur von einer velatio der Braut und verstehen unter dem velamen offenbar den Brautschleier. Auch der hl. Ambrosius († 379) spricht von einem obnubere caput suum seitens der Braut im alten Testamente und denkt dabei wohl ebenfalls an den Brautschleier. ${ }^{4}$ )

1) Vgl. Zallinger, Wesen und Ursprung des Formalismus im altdeutschen Privatrecht. Wien 1898. S. 5. - 2) De virginibus velandis bei Migne, Patrologia latina Bd. II Spalte $935 \mathrm{ff}$, insbesondere cap. 17 Spalte $960 \mathrm{f}$ - ${ }^{3}$ ) De ecclesiasticis officiis lib. II cap. 8 \$11. Migne, Bd. 83, Spalte 807 und lib. II cap. $20 § 6$ ebenda Spalte 811 . Letztere Stelle unten S. 148 Anm. 1. - ) Bei Gratian c. 8. C. 30 q. 5. 
Jedenfalls nicht im Sinne von Brautschleier versteht Papst Nikolaus J. $(858-867)$ das velamen, wenn er sagt, daB beide Brautleute, sofern nicht eines davon einmal verheiratet war, das velamen coeleste empfangen gemäß dem Vorgange im Paradiese, als Gott die ersten Menschen mit den Worten segnete: crescite et multiplicamini. ${ }^{1}$ )

Können wir aus der Äußerung Nikolaus I. immerhin noch nicht genau ersehen, welche Funktion dieses velamen hatte, so lassen uns Quellen seit Beginn des zweiten Jahrtausends nicht mehr im Zweifel, daß damit eine Decke gemeint ist, welche über die Brautleute ausgespannt wird oder womit sie bedeckt werden. Wir können diese Sitte gleichmäßig für England, die Normandie und Frankreich, Italien und die nordischen Länder nachweisen.

Nach einem alten englischen Rituale von Salisbury (dem ordo Sarisburiense), das in den südöstlichen Gebieten Englands diesseits des Trent im Gebrauch war, wurde über die Brautleute, wenn beide das erstemal heirateten, während der auf die Trauung folgenden Brautmesse ein Tuch gespannt, welches vier Kleriker an den vier Ecken hielten: Prosternat se sponsus et sponsa in oratione ad gradum altaris extento super eos pallio, quod teneant quatuor clerici per quatuor cornua in superpelliciis nisi alter eorum prius fuerit desponsatus et benedictus quia tunc non habeatur pallium super eos nec dicatur sacramen-

Die Stelle unten S. 147 Anm. 3. Fre is en, Geschichte des can. Eherechtes ? S. 137 und Dieckhoff, Die kirchliche Trauung S. 31 erwähnen, daß von einer coniugalis velatio auch in einem Briefe des Papstes Siricius an Bischof Himerius vom Jahre 385 die Rede sei. Ich finde in diesem Schreiben (Mansi, Conciliorum collectio III S. 655. Jaffe, Regesta pontificum ${ }^{2}$ Nr. 255 S. 40) nur eine coniugalis violatio(!).

1) Antwort Nikolaus I. auf die Frage der consules Bulgarorum, wie Hochzeiten gefeiert werden sollen: ambo ad nuptialia foedera perducuntur et primum quidem in ecclesia domini cum oblationibus, quas offerre debent deo per sacerdotis manum, statuuntur sicque demum benedictionem et velamen coeleste suscipiunt ad exemplum videlicet, quo dominus primos homines in paradiso collocans benedixit eis dicens: "crescite et multiplicamini". Mansi, Collectio conciliorum XV, $401 \mathrm{f}$. Decretum Gratiani c. 3, C. $\mathrm{XXX}$ q. 5 . 
talis benedictio. ${ }^{1}$ ) Aber auch für die nordwestlich des Trent gelegenen Gebiete Englands bezeugt uns ein Rituale der Kirche von York (der ordo Eboracensis) denselben Brauch: Missa dein celebratur illis (Brautleute) genuflectentibus sub pallio super eos extento, quod teneant duo clerici in superpelliceis. ${ }^{2}$ )

Dieselbe Sitte weiß der in den Diensten des Erzbischofs Theobald von Canterbury stehende Johann von Salisbury (Johannes Saresberiensis) ${ }^{3}$ ) in seinem um die Mitte des 12. Jahrhunderts abgefaßten Werke Policraticus sive de nugis curialium et vestigiis philosophorum zu berichten:

Inolevit etiam consuetudo, ut, quos in commercium carnis ecclesiae iungit auctoritas, pallio velentur altaris aut alio ab ecclesia constituto, ut torus, qui Christo conciliante construitur, sic in fide castitatis fragilitatis suae maculas protegat, ut totius sit probri aut confusionis ignarus. ${ }^{4}$ )

Dieselbe Zeremonie bezeugt uns ferner Robert Grosseteste, Bischof von Lincoln, in den schon erwähnten ${ }^{5}$ ) zwei Briefen vom Jahre 1236, die uns noch in der Folge beschäftigen werden.

In Frankreich und in der Normandie begegnen wir seit Beginn des 11. Jahrhunderts derselben Sitte. Das Pallium wird hier aber nicht immer über die Brautleute ausgespannt, wie wir das in England durchaus gefunden haben, sondern oftmals werden die Nupturienten mit demselben geradezu zugedeckt.

Das Pontifikale des monasterium Lyrense (Lire, Lira im Departement Eure) ${ }^{6}$ ) von der Wende des 11. und 12. Jahrhunderts berichtet:

Post sanctus prosternant (sponsus et sponsa) se in orationem extento pallio super eos, quod teneant quatuor homines ad quatuor cornua. ${ }^{7}$ )

1) Bei Seldenus, Uxor Ebraica (Londini 1646) lib. 2, cap. 27 S. 274. - 2) Seldenus a. a. O. S. 278. - 3) Darüber Wattenbach, Deutschlands Geschichtsquellen ${ }^{6}$ II, S. 483. - ${ }^{4}$ ) Lib. VIII cap. 11 (Ausgabe Lugduni Batavorum 1639 S. 577 bei Migne, Patrologia latina Bd. 199 Spalte 749). - ') Oben S. 112. - ') Siehe Uly sse Chevalier, Repertoire des sources historiques du moyen age II Spalte 1705 "Lire". 7) Martene, De antiquis ecclesiae ritibus. Rotomagí 1700. S. 619. 
Ein Missale der Kirche von Rouen (missale insignis ecclesiae Rotomagensis) von ungefähr 1300 meldet:

Antequam (sacerdos) faciat fractionem prosternantur uterque ante altare et extendatur super eos pallium, si non fuerint alias coniugati seu alter eorum fuerit coniugatus, quia eo casu non fieret.

Nach einem Gebet wird das Pallium wieder entfernt und der Priester schreitet in der Lesung der Messe weiter. ${ }^{1}$ )

Ein um das Jahr 1000 geschriebenes Missale von Rennes (missale Redonense) berichtet, daß der Priester den Brautleuten während der auf die Trauung folgenden Messe ante altare sub pallio vel alio quolibet opertorio, sicuti mos est, die Benediktion erteilt. ${ }^{2}$ )

Nach dem ungefähr aus dem Jahre 1300 stammenden Pontifikale der Kirche von Auxerre (pontificale ecclesiae Autissiodorensis) wird nach der Trauung eine Messe gelesen, cum autem dictum fuerit „libera nos, quaesumus, domine ab omnibus malis etc.", antequam dicatur „pax domini" sponsus et sponsa prostrati ante altare pallis cooperiantur. ${ }^{3}$ )

Dasselbe berichtet ein Pontifikale der Kirchen von Lyon und Tarantaise ${ }^{4}$ ) von ungefähr 1400: Antequam dicatur „pax domini“ sponsus et sponsa prostrati ante altare pallio cooperiantur. ${ }^{5}$ )

Mit dem Pontifikale von Lyon stimmt ein Missale der Kirche von Paris von ungefähr 1400 wörtlich überein. ${ }^{6}$ )

An ein vollständiges Zudecken der Brautleute ist bei diesem pallio cooperire nicht zu denken. Aus dem Pontifikale der Kirche von Arles (pontificale ecclesiae Arelatense) von ungefähr 1300 ersehen wir genauer, wie diese Vela-

1) Martene a. a. O. S. 629. - ${ }^{2}$ ) Martene a. a. O. S. 616: Sponsus autem et sponsa candelas ardentes in manibus tenentes et offertorium missam audientes offerunt et antequam ,pax domini“ dicatur, ante altare sub pallio vel alio quolibet opertorio, sicuti mos est, eos benedicat. - ${ }^{3}$ ) Martene a. a. O. S. 226. - ${ }^{4}$ ) Pontificale Lugdunense, quod etiam usui fuit ecclesiae Tarantasiensi. - s) Martene a. a. O. S. 631. --) Missale insignis ecclesiae Parisiensis annorum circiter 300 (so im Jahre 1700) quod olim usui fuit Ludovico cardinali Borbonio ....: Antequam dicatur "pax domini“, sponsus et sponsa prostrati ante altare pallio cooperiantur. Martene a. a. O. S. 636.

Zeitschrift für Rechtsgeschichte. XXV. Germ. Abt. 
tio vor sich ging: Velet eos sacerdos ita: virum super scapulas, puellam super caput, et ponat iugalem ${ }^{1}$ ) super humeros eos. ${ }^{2}$ )

Eine teilweise Bedeckung der Brautleute mit dem velamen war auch in Italien üblich.

In einem zu Venedig 1576 gedruckten offiziellen Sacerdotale ad consuetudinem Romanae ecclesiae aliarumque ecclesiarum wird auch über die Schultern beider Brautleute ein velum gegeben: Velum unicum induitur sponsorum scapulis. ${ }^{3}$ )

Nach dem Archiepiscopale, welches Kardinal und Erzbischof Gabriel Palaeotti 1590 für seinen Kirchensprengel Bologna herausgab, cingit parochus sponsorum colla candido aliquo velo. ${ }^{4}$ )

In den nordischen Ländern hat sich das Ausspannen einer Decke über die Nupturienten besonders lange erhalten.

Johannes Loccenius $(\dagger 1667)$ berichtet noch in der ersten Hälfte des 17. Jahrhunderts in seinen Antiquitates SueoGothicae als lebenden Brauch, daß über die Neuvermählten bei der Benediktion von Jünglingen und Jungfrauen ein velamen ausgespannt wird: Copulatione facta ad aram sistitur uterque sponsus et sponsa, ubi consecratio vel benedictio expanso a iuvenibus et virginibus super capita novorum nuptorum velamine fit. ${ }^{5}$ )

Es scheint übrigens, daß diese Zeremonie der Velation ein ganz allgemeines Institut war. Robertus Bellarminus ${ }^{6}$ ) $(\dagger$ 1612) führt die Bedeckung der Brautleute mit dem velamen unter den Zeremonien an, die gewöhnlich bei der Eheschliefoung beobachtet zu werden pflegen ${ }^{7}$ ) und das

1) Iugale definiert Du Cange als velum, quo velantur coniuges, cum matrimonio ineunt, und unser iugalis als velum, quo conteguntur sponsus ac sponsa, com matrimonio coniuguntur. - ${ }^{2}$ ) Martene a. a. 0 . S. 624. $-{ }^{3}$ ) Seldenus, Uxor Ebraica lib. 2, cap. 26 S. 269. Nur findet sich hier ein sinnstörender Druckfehler indem "spatulis" statt ${ }_{n}$ scapulis" steht. - 4) Seldenus a. a. O. lib. 2, cap. 26 S. 262. - 5) Antiquitatum Sueo-Gothicarum libri tres. lib. 2, cap. 25 (tertia editio Upsala 1670 S. 156). - ${ }^{3}$ Schulte III, S. 459 f. $-{ }^{7}$ ) De matrimonii sacramento (in seinen Disputationes de controversiis Christianae fidei adversus huius temporis haereticos. Tom. III, controversia V, liber III) Ingolstadt 1605. Cap. 33. In matrimonio igitur hae caeremoniae observari 
concilium Limanense vom Jahre 1582 nimmt benedictiones nuptiales und velationes einfach für identisch an. ${ }^{1}$ )

Für Deutschland aber habe ich trotzdem den Bestand dieses Institutes nicht nachweisen können.

Was hatte nun der Gebrauch dieses pallium oder velamen, das über die Eheleute ausgespannt wurde oder womit die Eheleute bedeckt wurden, für eine Bedeutung?

Edmund Martene ${ }^{2}$ ) vertritt in seinem im Jahre 1700 erschienenen Buche de antiquis ecclesiae ritibus die Ansicht, daß diese Zeremonie ein signum pudoris sei. Allein Martene weiß zwischen den verschiedenen Arten der velamina nicht gehörig zu unterscheiden. Er spricht zwar einerseits von dem velum oder velamen als Tuch, welches über die Brautleute ausgespannt wird, gründet aber andererseits seine Ansicht von der Bedeutung desselben doch wieder nur auf Quellenstellen, welche von dem velamen als dem Brautschleier sprechen, wovon der heilige Ambrosius sagte, quod pudoris gratia se puellae obnuberent ${ }^{3}$ ), und in dem Isidor von Sevilla einerseits unter Berufung auf den ersten Brief des Apostels Paulus an die Korinther cap. 114) ein Zeichen

solent: Primo benedicuntur novi sponsi in ecclesia a sacerdote, secundo offertur pro eis obiatio eucharistiae, tertio velamine obnubuntur etc.

1) Du Cange, Glossarium sub verbo velatio: benedictiones nuptiales, quas velationes rocant. $-{ }^{2}$ ) A. a. 0. S. $608 \mathrm{f}$ : : Dum cantetur benedictio, velum purpureum in signum pudoris super sponsum et sponsam expandebatur ut docent nostri libri rituales. - ${ }^{3}$ ) Decretum Gratiani c. 8. C. 30 q. 5: Nec illud otiosum, quod cum veniret Rebecca, vidit Isaac ambulantem et cum interrogasset, quis esset, cognito, quod ipse esset, cui duceretur uxor, descendit et caput suum obnubere coepit docens verecundiam nuptiis praeire debere. Inde enim et nuptiae dictae, quod pudoris gratia se puellae obnuberent. - ${ }^{4}$ ) Übersetzung der Vulgata: . . Omnis viri caput Christus est, caput autem mulieris vir, caput vero Christi deus. Omnis vir orans aut prophetans velato capite deturpat caput suum. Omnis autem mulier orans aut prophetans non velato capite deturpat caput suum, unum enim est, ac si decalvetur, nam si non velatur mulier tondeatur. Si vero turpe est mulieri tonderi aut decalvari, velet caput suum. Vir quidem non debet velare caput suum, quoniam imago et gloria dei est, mulier autem gloria viri est .... Vos ipsi iudicate, decet mulierem non velatam orare deum? Nec ipsa natura docet vos, quod vir quidem, si comam nutriat, ignominia est illi, mulier vero, si comam nutriat, gloria est illi, quoniam eapilli pro velamine ei datae sunt?... 
sah, daß die Frau in die Gewalt des Mannes komme und anderseits ein Zeichen der jungfräulichen Scham ob der kommenden Dinge. ${ }^{1}$ )

Am nächsten dürfte der Erklärung dieser Zeremonie doch Johann von Salisbury kommen, wenn er den Zweck derselben dahin auffaßt, ut torus, qui Christo conciliante construitur, sic in fide castitatis fragilitatis suae maculas protegat, ut totius sit probri aut confusionis ignarus. ${ }^{2}$ )

Damit stimmen auch die Worte Papst Nicolaus I. überein, daß die Brautleute das velamen empfangen ad exemplum videlicet, quo dominus primos homines in paradiso collocans benedixit eis dicens: „crescite et multiplicamini“".3)

Dieses Pallium oder Velamen ist offenbar eine Versinnbildlichung des torus matrimonialis. Es ist in der ganzen Zeremonie ein von der Kirche übernommener Rest des alten Beilagers erhalten, das ja ursprünglich öffentlich in formaler Weise abgehalten wurde. Diese Auffassung findet sich schon bei dem großen französischen Juristen Antoine Loisel $\left.(\dagger 1617)^{4}\right)$, in dessen berühmtem Werke Institutes coutumieres $^{5}$ ) lib. I, cap. 4: Le poêle, qui se mettait et qui se met sur les noveaux mariés, représente le lit coniugal. ${ }^{6}$ )

Dieser Charakter der Zeremonie läßt es auch begreiflich erscheinen, daß die velatio sponsorum kein spezifisch christliches Institut ist. Die Kirche hat den Gebrauch dieses Palliums vielmehr dem jüdischen Rechte entlehnt. Nach

1) Isidorus Hispalensis, de eccles. officiis lib. II, cap. 20, § 6: Feminae, dum maritantur, velantur scilicet, ut noverint, se per haec viris suis esse subiectas et humiles, unde et ipsum velamen vulgo mavortem vocant, id est Martem, quia signum maritalis dignitatis ac potestatis in eo est, caput enim mulieris vir est (I. Corr. XI), licet et proinde velentur, dum nubunt, ut verecundiam muliebritatis agnoscant, quia iam sequitur inde, quod pudeat. Unde Rebecea, cum ad sponsum duceretur, simul ut cum ipsa conspexit, salutationem vel oscula non sustinuit, sed statim sentiens, quod esset futura, pallio caput velavit. 2) S. oben S. 144. - ${ }^{3}$ ) Oben S. 143. - Darüber Brunner in Holtzendorff's Enzyklopädie der Rechtswissenschaft. System. Teil, 5. Aufl. S. 322. - ${ }^{5}$ ) Ausgabe von Dupin und Laboulaye, Paris 1846. - ${ }^{\text {B) }}$ In genaunter Ausgabe I. Bd. S. 87. Von neueren bekennt sich zur gleichen Ansicht Glasson, Histoire du droit et des institutions de la France VII, S. 106 Note 1. 
dem Buche Ruth III. 9 wurden die Brautleute mit einer Decke, Pallium, bedeckt. ${ }^{1}$ ) Die Bedeckung mit einem Mantel, amictus, erwähnt auch Ezechiel VI. $8 .^{2}$ )

Ein Schriftsteller aus der Mitte des 17. Jahrhunderts ${ }^{3}$ ) bezeugt uns die velatio sponsorum bei den Juden ganz in derselben Weise, in welcher wir sie in der christlichen Kirche angewendet sahen, noch für seine Zeit als lebenden Brauch: Hodierni iudaei $\tau \tilde{\omega} \nu \pi \alpha \tau \varrho o \pi \alpha \varrho \alpha \delta \omega ́ \tau \omega \nu$ tenacissimi solemnem habent copulam et peculiarem benedictionis locum, in quo novos sponsos sub erecto velo quatuor perticis suffulto collocant, ja nach dem Vorbilde von Ruth III 9 werden auch noch heutzutage in Deutschland bei den Juden Braut und Bräutigam während der Gebete der Umstehenden bei der Trauung mit einem Tuche oder Talit bedeckt. ${ }^{4}$ )

Der Gebrauch dieses Palliums oder Velamens ecclesiae wurde nun in der Kirche auch benützt, um die rechtliche Wirkung der von den Erzeugern abgeschlossenen Ehe für die Kinder äußerlich zum Ausdruck zu bringen und er war dazu auch sehr geeignet. Die Kinder wurden nämlich nun der Zeremonie der Trauung zugezogen und nun selbst mit den beiden Eltern unter das pallium gestellt. Wir können den Bestand dieser Sitte für England, Frankreich und die Normandie und Oberitalien nachweisen. Die ältesten sicheren Belege für das Bestehen dieser Form der Legitimation durch nachfolgende Ehe stammen aus der ersten Hälfte des 13. Jahrhunderts aus England.

Robert Grosseteste bezeugt in dem oben ${ }^{5}$ ) genannten Brief vom Jahre 1236 den Bestand dieser Sitte: In signum

1) Übersetzung der Vulgata: Et ait illi: quae es? Illaque respondit: ego sum Ruth ancilla tua, expande pallium tuum super famulam tuam, quia propinquus es. Pallium ist im ganzen Kapitel in der Bedeutung von Decke gebraucht. $-{ }^{2}$ ) Vulgata: Et transivi per te et vidi te et ecce tempus tuum, tempus amantium, et expandi amictum meum super te et operui ignominiam tuam. Et iuravi tibi et ingressus sum pactum tecum, ait dominus deus, et facta est mihi. - ${ }^{3}$ ) Joa chim Hildebrand, De nuptiis veterum Christianorun. Helmstadt 1661 (Nicht paginiert). - ${ }^{4}$ ) D u schak, Das mosaisch-talmudische Eherecht. Wien 1864, S. 46. Frankel, Grundlinien des mosaisch-talmudischen Eherechtes. Breslau 1860, S. 30 ff. Mayer, Die Rechte der Israeliten, Athener und Römer, Leipzig 1866, II S. $330 \mathrm{ff.}-{ }^{\text {5) }}$ S. 111. 
legitimationis nati ante matrimonium consueverunt poni sub pallio super parentes eorum extento in matrimonii solennizatione.

Obwohl im übrigen Grossetestes Nachrichten, wie wir gesehen haben ${ }^{1}$ ), nicht sehr zuverlässig sind, da er ja mit einer gewissen Tendenz arbeitete und unter anderm auch behauptete, daB in England die Legitimation durch nachfolgende Ehe immer Rechtens gewesen sei, so können wir doch diesen Punkt nicht anzweifeln. Einmal ist es kaum denkbar, daß Grosseteste seine Nachricht bloß aus der Luft gegriffen hätte, und ferner gibt ja William Raleigh den Bestand dieser Sitte ausdrücklich zu, nur spricht er ihr jede rechtliche Wirkung für das weltliche Recht $a b^{2}$ ): bastardus sub pállio supra parentes nubentes extento positus inde surgit bastardus.

An dem Bestand dieses Institutes dürfen wir demnach nicht zweifeln. Da aber in England eine legitimatio per subsequens matrimonium für das weltliche Rechtsgebiet niemals anerkannt war, so blieb natürlich die Wirkung der von Grosseteste berichteten legitimatio per pallium auf das kirchliche Gebiet beschränkt. In dieser Form und in diesem Umfange war sie aber noch im 15 . Jahrhundert in Übung. ${ }^{3}$ )

Für das 13. Jahrhundert ist uns das Institut der Legitimation durch nachfolgende Ehe in der Form der Stellung der vorher gebornen Kinder unter das Pallium der Kirche auch für Frankreich und die Normandie sicher bezeugt.

1) S. 111 f. - ${ }^{2}$ ) S. 112. - ${ }^{3}$ ) Dreyer, Nebenstunden S. 290, Anm. b. Die dort bezogenen älteren Werke vou John Brydall und Robert Sharrock waren mir nicht zugänglich. Johannes Seldeuus, Dissertatio ad Fletam, cap. 9, schreibt: Caeterum ritum eundem ipsum [= legitimatio per pallium] sub Richardo secundo, quando autoritate parlamentaria legitimi facti sunt liberi Joannis Gandavensis ducis Lancastriae e Catharina uxore tertia ante matrimonium suscepti, idque in ipsis comitiis adhibitum alicubi legisse me memini. Aber hierin hat ihn sein Gedächtnis wohl sehr getäuscht, denn bei der Legitimation der Kinder des Herzogs von Lancaster im Jahre 1397 handelte es sich um keine legitimatio per subsequens matrimonium, sondern per rescriptum regis. Von der Anwendung des Palliums ist keine Rede. Näheres in meinem Aufsatz zur Geschichte der legitimatio per rescriptum principis. 
Philipp Beaumanoir ${ }^{1}$ ), „der glänzendste Vertreter der französischen Jurisprudenz des Mittelalters", der für Frankreich ungefähr dieselbe Bedeutung hat, wie Eicke von Repgow für Deutschland, berichtet uns, daß nach den Coutumes $d u$ Beauvaisis ${ }^{2}$ ) nicht nur der vom Bräutigam empfangene nasciturus, welchen die Braut im Mutterleibe trägt, durch die Heirat der Eltern ehelich wird, sondern auch die schon vor der Ehelichung gebornen Kinder, wenn oder vielmehr weil sie bei der Trauung mit dem Vater und mit der Mutter unter das Pallium der Kirche (le paile oder le drap de sainte Eglise), welches über die Brautleute ausgespannt zu werden pflegt, gestellt werden. Solche Kinder erben und werden beerbt vollkommen gleich, wie in der Ehe geborne und erzeugte Kinder:

$\$ 579$ (= Deugnot XVIII, 2) Car, quant uns hons a compaignie a une fame hors de mariage et il l'espouse aprés ou tans qu'ele est grosse, l'enfes q'ele a ou ventre devient loiaus par la vertu du mariage. Voire s' il en i avoit pluseurs enfans nes avant qu'il l'espousast, et la mere et li enfant, a l'espouser, estoient mis dessous le paile ${ }^{3}$ ) de sainte Eglise, si devenroient il loiaus oir et seroient aherité, comme loiaus oir en toutes manieres de descendemens ou d' escheoite de coste.

$\$ 600(=$ Deugnot XVIII, 23) L'en ne doit pas douter que quant uns hons hors du lien de mariage a compaignie a une fame et en a enfans, et il l'espouse puis qu' enfant sont né ou ou tans qu'ele est grosse, se li enfant sont mis dessous le drap, - liqueus dras est acoustumés a metre sur ceus qui se marient solemnement en sainte Eglise, ne soient loiaus puis qu'il i sont mis aveques le pere et aveques la mere le mariage fesant; et puis lors ne sont pas li enfant bastart, ains sont oir et pueent estre aherité si comme loiaus enfant né en mariage. Et par ceste grace que sainte Eglise et coustume consentent a teus manieres

1) Darüber Brunner in Holtzendorffs Enzyklopädie der Rechtswissenschaft (system. Teil) ${ }^{5}$ S. 312, $-{ }^{2}$ ) Statt der alten Ausgabe von Deugnot, Paris 1842, jetzt eine neue von Salmon, Paris 1899. - ${ }^{3}$ ) Variante: le drap. 
d'enfans avient il souvent, que li pere espousent les meres pour la pitié des enfans, si que meins de maus en sont fet.

Die historia Normannorum des Guilelmus Gemeticensis ${ }^{1}$ ), welcher nach seiner eigenen Aussage ${ }^{2}$ ) unter Richard III. von der Normandie (1026-1028) lebte, erzählt uns nun freilich, daß schon bei der Vermählung des Normannenherzogs Richard I. (943-996) mit Gunnor oder Gonnor, die nicht vor dem Jahre 968 stattfand $^{3}$ ), die vorher mit ihr gezeugten Kinder bei der Trauung zugleich mit ihren Eltern unter das Pallium genommen und so legitimiert worden wären:

Genuit itaque (Richardus comes) ex Gunnore filios tres et totidem filias, ut in libro, qui de gestis eiusdem ducis scriptus est, superius invenitur. Cum vero idem comes quendam filium suum nomine Robertum vellet fieri archiepiscopum Rotomagensem, responsum est ei a quibusdam, hoc nullatenus secundum scita canonum posse, ideo quod mater eius non fuisset desponsata. Hac itaque causa comes Richardus Gunnorem comitissam more Christiano sibi copulavit, filiique, qui iam ex ea nati erant, interim, dum sponsalia agerentur, cum patre et matre pallio cooperti sunt, et sic postea Robertus factus est archiepiscopus Rotomagensis. $\left.{ }^{4}\right)$

Danach scheint es also, daß der Brauch, die Brautkinder bei der Trauung unter das Pallium zu stellen und so zu legitimieren, schon in das 10. Jahrhundert zurückreicht.

Sieht man aber genauer zu, so findet man, daß dieser Bericht sowohl für die Zeit des Wilhelmus Gemeticensis, noch mehr aber für die Zeit Herzog Richard I. ein Anachronismus ist.

Es handelt sich hier nämlich - wir können sagen glücklicherweise - um die Wirkung der Legitimation durch nachfolgende Ehe für das kirchliche Gebiet: Robert kann erst Erzbischof von Rouen werden, nachdem die Erzeuger sich geehelicht haben. Für das kirchliche Gebiet hat aber

1) Bei Duchesne, Historiae Normannorum scriptores antiqui (Lutetia Parisiorum 1619) S. 312 f. - ${ }^{2}$ ) Lib. VI cap. 1. $-{ }^{3}$ ) Lappenberg, Geschichte von England II S. 34. - ${ }^{4}$ ) Lib. 8 cap. 36. 
diese Legitimation erst Papst Alexander III. (1159-1181) im Anschluß an das III. luateranensische Konzil (1179) anerkannt und aus dem Justinianischen Recht rezipiert. Obiger Bericht kann also frühestens erst gegen das Ende des 12. Jahrhunderts entstanden sein. Der Verfasser, der natürlich nicht Wilhelmus Gemeticensis sein kann ${ }^{1}$ ), hat einfach Rechtsinstitute seiner Zeit auf frühere Verhältnisse übertragen. ${ }^{2}$ )

In Frankreich war diese Form der Legitimation sehr verbreitet. Man hielt allgemein an dem Satz fest: Enfans nés avant le mariage, mis sous le poile, sont légitimés ${ }^{3}$ ) und bezeichnete die legitimatio per subsequens matrimonium kurzweg als pallio cooperire oder als mettre les enfans sous le poile oder sous le drap. ${ }^{4}$ ) Noch gegen Ende des 17. Jahrhunderts haben wir von der Anwendung dieser Legitimationsart Kunde. Nach den Ritualbüchern der Bistümer Toul und Verdun vom Jahre 1691 wird es noch immer so gehalten, daf die vor der Ehe geborenen Kinder bei der Benediktion ihrer Eltern unter die voile gegeben werden. Allerdings erregte dieser Brauch schon Anstoß. Die Vorführung einer größeren Zahl vorehelicher Kinder mag nicht sehr erbauend gewesen sein und gab Ärgernis. Vielleicht sah man darin auch eine Profanierung kirchlicher

1) Daß das Ende des 7. und das 8. Buch spätere Zutaten sind, hat man übrigens schon lange erkannt. Vgl. Potthast, Wegweiser durch die Geschichtswerke des europäischen M.-A. ${ }^{2}$ I, $556 \mathrm{f}$. und die dort angeführte Literatur. $\mathrm{Zu}$ den bisherigen Gründen könnte man noch den im Text angeführten neuen hinzufügen, welcher zugleich für die Zeit der Einschiebung einen terminus a quo gibt. - ${ }^{2}$ ) Bei Dudo von St. Quentin, Historia Normanniae ducum, bei Duchesne a. a. O. und Migne, Patrologia latina Bd. 141 S. 609 f. findet sich die ganze Geschichte der Gunnor gar nicht erwähnt. Der in der 2. Hälfte des 12. Jahrhunderts schreibende normannische Dichter Wace erwähnt in seinem Roman de Rou (hrsg. von H. Andresen, Heilbronn 1877-79) III. Teil, Vers $611 \mathrm{ff}$. wohl die Heirat Richards mit Gonnor, von Kjndern aus vorehelicher Liebe erzählt er nichts. $-{ }^{3}$ ) Loysel, Institutes coutumières I. 40, Ausgabe von Dupin und Laboulaye, Paris 1846, I S. 87. - ${ }^{4}$ Vgl. Du Cange, Glossarium, verb. pallio cooperire. Allerdings darf man unter dem pallium oder poile nicht wie es so häufig geschieht (z. B. Warnkönig und Stein, Französische Staats- und Rechtsgeschichte $^{2}$ II S. 177) den Mantel der Braut verstehen. 
Zeremonien, denn die Ritualien fügen bei, daß das nur geschehen soll, wenn es ohne Ärgernis (sans scandale) möglich ist:

Quoique l'epoux ait deja eté marié, quand il epouse une vierge ou une fille, qui n'est point convaincue de s'etre abandonée a d'autre qu' a lui, on observe les memes ceremonies qu' aux premieres noces et s'ils ont eu des enfans on les mettra sous le voile, si cela se peut faire sans scandale. ${ }^{1}$ )

In Oberitalien war die Legitimation durch nachfolgende Ehe in derselben Form gleichfalls üblich, ja sie scheint sogar das Regelmäßige gewesen zu sein, denn die im Jahre 1586 aufgezeichneten Coutumes von Aosta ${ }^{2}$ ) sehen sich veranlaßt, ausdrücklich zu bestimmen, daß die liberi naturales durch nachfolgende Ehe der Eltern legitim werden, auch wenn diese Zeremonie nicht beobachtet werde:

Enfans naturels sont légitimé par le mariage de leurs parens, encore que du tems de la solennisation ils ne soient mis sous même drap et couverte. ${ }^{3}$ )

In Deutschland läßt sich diese Legitimationsform nirgends nachweisen, was ja begreiflich ist, da sich auch der Gebrauch des Palliums oder Velamens bei der kirchlichen Trauung nicht nachweisen lält.

Das über die Legitimationsform durch das Pallium Gesagte illustriert in interessanter Weise das beigegebene Bild, welches Joh. Mich. Friedr. Lochner in seiner 1747 erschienenen Dissertation de antiquo ritu legitimandi liberos illegitimos per pallium veröffentlichte. ${ }^{4}$ ) Dieses Bild nahm Lochner

1) Bei Grupen, De uxore Theodisca, cap. VI $\$ 12$ S. 282. - ${ }^{2}$ ) Vgl. darüber Pertile, Storia del diritto Italiano ${ }^{2}$ II, 2 S. 93. - ${ }^{3}$ ) La coutum d'Aoste I. 20, 31. Diese Stelle auch bei Pertile a. a. $0 .{ }^{2}$ III S. 391 Nr. 20. - ") Davon hat es danu Karl Gottl. Knorr in seinen rechtlichen Abhandlungen und Gutachten (Halle 1757) Nr. 1 "Nachricht von den Mantelkindern " und ferner Hommel, Jurisprudentia numismatibus illustrata nec non sigilis, gemmis aliisque picturis vetustis varie exornata, Leipzig 1763, S. 214 abgedruckt. Die genannte Dissertation Lochners wird überall, wo sie zitiert ist, Christian Gottlieb Schwarz als Autor zugeschrieben. Der genaue Titel heißt: Exercitatio academica de antiquo ritu legitimandi liberos illegitimos per pallium. quam praeside Christiano Gottlib. Schwarzio com. palat. caes, 


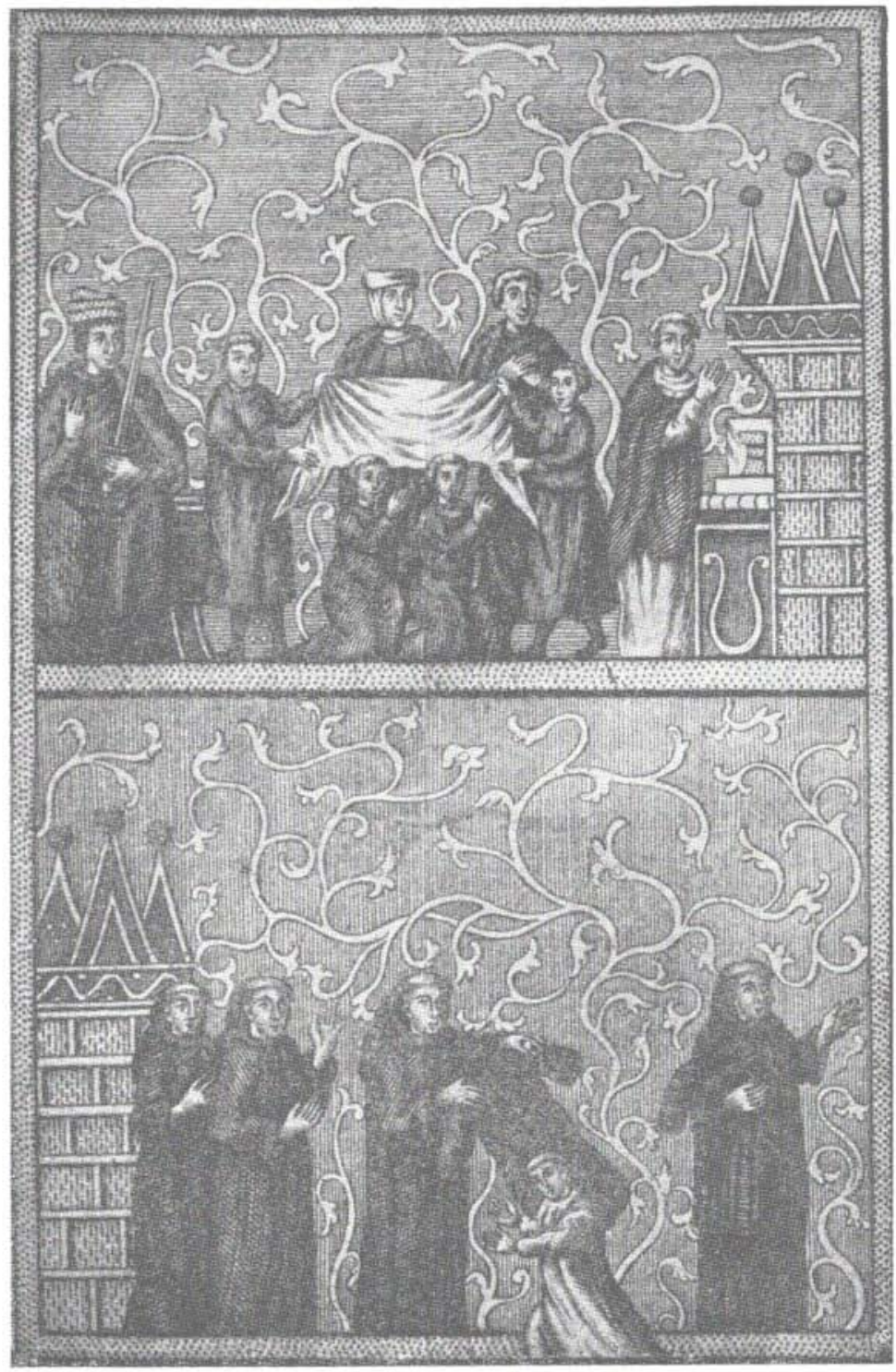

Symholische Datrstellung der Jegitinationsarten: per rescriptum principis, per subsequens matrinsonium land per oblationem monasterio (= curiace coelesti 
aus einem handschriftlichen Corpus juris Justiniani, der nach seiner Angabe aus dem Anfang des 14. Jahrhunderts stammt. In demselben war das Bild zu Novelle 74, welche eben die Legitimation regelt, eingepickt. Eine Kontrolle der Lochnerschen Angaben ist nun allerdings dadurch sehr erschwert, dab uns das Originalbild fehlt und wir auf einen Schluß von der Kopie auf das Original angewiesen sind. Wie mir aber Kunsthistoriker ${ }^{1}$ ) versichern, erscheint die Altersangabe Lochners durchaus glaubwürdig. Das Bild stammt sicher aus dem Anfang des 14, vielleicht noch aus dem Ende des 13. Jahrhunderts und zwar weist der ganze Charakter desselben auf Italien oder Frankreich als Entstehungsort hin. Als fast sicher ist anzunehmen, daß es nicht einer deutschen Schule angehört. Dieses Resultat stimmt sehr gut mit den Ergebnissen unserer Untersuchung überein, wonach wir die legitimatio per pallium ecclesiae wohl in Frankreich und Italien, nicht aber in Deutschland nachweisen können.

Nach diesem Bild ist der Vorgang gegenüber dem Inhalt der behandelten Quellen insofern modifiziert, als mit dem Tuch nicht die Kinder samt ihren Eltern, sondern nur erstere allein überdeckt werden. Allein diese oder ähnliche Abweichungen mögen sich im Laufe der Zeit ja sehr leicht ergeben haben, zudem wenn etwa das Ausspannen eines Tuches über die Nupturienten als allgemeine Sitte außer Übung gekommen ist und das Tuch nur noch im Fall der Isegitimation angewendet wurde.

Neben der besprochenen legitimatio per subsequens matrimonium bringt unser Bild auch noch die legitimatio per rescriptum principis, dargestellt durch die sitzende Figur des Kaisers, und die an Stelle der legitimatio per oblationem curiae herausgebildete legitimatio per oblationem monasterio ( $=$ curiae coelesti) zur Verarischaulichung.

Da dieses kirchliche Pallium cin Symbol des torus matrimonialis war, so ist auch der Gedanke, welcher dieser

acad, seniore et prof. publ. 3. Junii a. s. r. 1747 in circulo academico ventilandam proponit Johannes Michael Fridericns Lochnerus, phil. et iur. cultor.

1) Ich verdanke fachmännische Gutachten den Herren Prof. H. Semper in Innsbruck und Maler Philipp Schumacher in Berlin. 
Form der Legitimation durch nachfolgende Ehe zugrunde liegt, leicht erfafobar. Dadurch, daß die Kinder unter das Pallium gestellt wurden, sollte gewissermaßen fingiert werden, daß sie einem legitimen Ehebett entsprossen, daß sie in stehender Ehe erworben wären. So schrieb auch schon Otto Everhard in seiner 1730 gedruckten iurisprudentia symbolica:

Non alia quaerenda est origo solennitatis in legitimatione per subsequens matrimonium ubivis fere usitatae, ut liberi naturales ex concubina nati in ipsis nuptiarum solennitatibus cum patre et matre pallio operiantur, ut $a b$ iis ex legitima coniunctione procreati aut ritu civitatis a patre adoptati intelligantur.')

Neben dieser symbolischen Zeugung glaube ich aber in dem Zuziehen der Kinder zur öffentlichen Trauung noch ein anderes Moment erblicken zu dürfen, nämlich auch einen Ausdruck des Publizitätsprinzipes, indem dadurch einerseits die Echtigung der Kinder öffentlich dokumentiert werden und andererseits dem Publikum Gelegenheit geboten sein sollte, eventuell Einsprache zu erheben, wenn die Vaterschaft vielleicht nicht unbestritten war.

Neben dieser Legitimation per pallium ecclesiae haben wir seit dem 13. Jahrhundert auch Nachricht von dem Bestande einer andern Legitimationsform, die sich nicht an kirchliche Zeremonien anschlieft bzw. nicht aus denselben erwachsen ist. Danach wurden die vorehelichen Kinder bei der Trauung ihrer Eltern anstatt unter das über die Brautleute gedeckte oder gespannte Tuch unter den langen weiten Mantel der Mutter, seltener des Vaters, gestellt und so legitimiert.

Die langen weiten Mäntel waren ein wesentlicher Bestandteil der früheren Tracht und durften insbesondere bei festlichen Gelegenheiten nicht fehlen. ${ }^{2}$ )

1) Everhardus Otto, Exercitatio III. de iurisprudentia symbolica, Traiecti ad Rhenum 1730, cap. 4, pag. 278. - 2) Vgl. Sanders, Wörterbuch der deutschen Sprache "Mantel". Grimm, Deutsches Wörterbuch „Mantel ${ }^{\star}$. Schiller und Lübben, Mittelniederdeutsches Wörterbuch "Mantel" und "Hoicke". 
Die oben ${ }^{1}$ ) erwähnte Verheiratung Herzogs Richard mit Gonnor berichtet uns auch der im Jahre 1244 verstorbene flandrische Dichter Philipp Mousket (oder Mouskes) in seiner Reimehronik und tut dabei auch der Legitimation der vorehelichen Kinder der Nupturienten Erwähnung:
Li dus, ki les enfans ama, Gunnor adonque espousa
Et li fil, ki ia furent grant, Furent entr' au III en estant
Par desous le mantiel la mére
Furent fait loial cil troi frere. ${ }^{2}$ )

Hier haben wir die erste Quellenstelle, welche anstatt des kirchlichen Palliums den Mantel der Mutter (le mantiel la mere) als Legitimationsform nennt. Die Anwendbarkeit auf Herzog Richard I. ist allerdings auch hier ausgeschlossen, weil für das 10. Jahrhundert von dem Bestehen einer legitimatio per subsequens matrimonium in der Normandie noch keine Rede sein kann. Aber unzweifelhaft hat zur Zeit Mouskets eine solche Sitte bestanden. Wahrscheinlich hat der Dichter aus der Fortsetzung der historia Normannorum des Guilelmus Gemeticensis ${ }^{3}$ ) geschöpft und den Inhalt der Quelle seinen Anschaungen entsprechend umgeformt.

Für Deutschland ist uns nur die Legitimation durch nachfolgende Ehe in der Form der Stellung der Kinder unter den Mantel eines Elternteils beglaubigt.

Zwei Handschriften des Schwabenspiegels, die Züricher schon aus dem Ende des 13. oder Anfang des 14. Jahrhunderts ${ }^{4}$ ) und die Wien-Ambraser aus dem Jahre $1462^{5}$ ) geben die oben mitgeteilte Stelle über die Anerkennung der legitimatio per subsequens matrimonium ${ }^{6}$ ) in folgender Fassung:

1) Oben S. 152. - $\left.{ }^{2}\right)$ Philippe Mouskes, Chronique rimée, publiée par le Baron de Reiffenberg, Brüssel 1836 - 38. Bd. II Vers 14941 bis 46. Obige Stelle entstellt auch bei Du Cange, Glossarium ,pallio cooperire". - 3) Oben S. 152. - +) Home yer, Rechtsbücher Nr. $731=$ Laß Berg, Schwabenspiegel Nr. 196. - ") Homeyer Nr. $681=$ Laßberg 159. - - Laßberg. Artikel 377, oben S. 135. 
Wie unelich kind elich werdent. ${ }^{1}$ )

Es haut ain man lediglichen kinde by ainer frơwen, der sye lûtzel oder vil, und nympt er die selben frówen ze rechter e, die kind sint zehande rechte ekind alb wol, alß die sie hernach gewinnet. So sprechent saimlich lûtte die ungelerten: er sûlle sie zü im hullen under den mantel, al er ir mitter elichen neme, oder sûllen sie mit der gûrtel umb vahen zů im. Des ist nicht. Wa die kind sint, so sint sie ekind es syen sûne oder dochtter und erbent aigen und lehen zů allem rechte mit ain ander ieren geschwistergiten. Wer in das uff weltlichem gerichte versagt, so habent sie es uff gaistlichem gericht, so můß es das weltlich stâtte haben.

Wir ersehen aus dieser Stelle, daß der Gebrauch, die in voreiliger Liebe erzeugten Kinder zum Zeichen ihrer Legitimierung bei der Trauung unter den Mantel - und zwar hier des Vaters - zu hüllen oder mit dem Gürtel und zwar beider Elternteile - zu umfangen, im Volke allgemein verbreitet war, $\mathrm{da} \beta$ es aber eben auch nur ein Volksgebrauch war, für den "sumlich ungelehrten lute" eintraten, der aber von den juristisch Gebildeten, die sich mit der abstrakten Wirkung der Ehe schon abgefunden hatten, als eine überflüssige Formalität angesehen wurde, diesen Gedanken des Spieglers haben wir schon in den Coutumes von Aosta gefunden. ${ }^{2}$ )

1) Da der Druck dieses Kapitels aus der älteren Züricher Handschrift von Finsler, Über eine Hs. des Schwabenspiegels in Falcks Eranien zum deutschen Recht I. Bd., 2. Lieferung (1826) S. 61 augenscheinlich fehlerhaft ist, mir aber eine Kollationierung deshalb nicht möglich war, weil die Hs. auf der juristischen Bibliothek in Zürich nicht aufgefunden werden konnte, so muß ich den Text nach dem jüngeren Wiener Kodex, Hofbibliothek Hs. $\frac{2904}{\text { Jur. CIV Nr.166 }}$ (Olim Ambras 141) fol. 148' und 149, geben. Der Druck dieser Hs. von Lahr in Senckenbergs corpus iuris Germ. Tom. II S. $456 \mathrm{f}$. hat dieses Kapitel nicht. Das entsprechende cap. 378 hat eine andere Fassung. Scherz gibt die entscheidende Stelle teilweise als Anmerkung zum 366. Kapitel des schwäbischen Landrechtes (= Laßberg 3i7) in Johannes Schilters Thesaurus antiquitatum Teutonicarum Tom. II pag. 211 aus der WienAmbraser Hs - ${ }^{2}$ ) S. 154. 
Das mit dem Gürtel Umfangen kommt im großen und ganzen auf dasselbe hinaus wie das unter den Mantel Hüllen, nur werden hier die Kinder dem Körper noch viel inniger genähert, als bei der Mantelhüllung, denn der Gürtel hielt nicht die äußere, sondern die innerste Bekleidung über den Hüften zusammen. ${ }^{1}$ )

Der in der ersten Hälfte des 15. Jahrhunderts tätige $J_{0-}$ hannes Rothe ${ }^{2}$, "der Vater der thüringischen Landeshistoriographie", erzählt uns in seiner Chronik zum Jahre 1289, daß Landgraf Albrecht der Unartige mit Kunegund von Eisenberg sich vermählte und daß diese den noch bei Lebzeiten von Albrechts erster Gemahlin Margarethe erworbenen Sohn bei der Trauung unterm Mantel hielt, damit er einen ehelichen Namen bekomme:

Hyndennach alsso lantgrave Albrecht seynen sson Apetzin, den her vonn Kunnen von Isenberg erkregen hatte, unde om seyne eliche wirthynne frawe Margarethe, der iungen herren muter, zu Franckenfort gestorben was, do liess her om dieselbe Kunne zu Warpergk zu der ee geben unde die hatte den kebissson die weile under yrem mantil, uf das her eynen elichen namen erkrigen mochte. ${ }^{3}$ )

Von Rothe hat diese Nachricht dann wahrscheinlich der um ein halbes Jahrhundert spätere monachus Pirnensis Johannes Lindner ${ }^{4}$ ) entlehnt. Er berichtet in seinem Onomasticon:

Kunegunda (ader Kunne) von Eisenberck, lantgrafen Albrechten in Duringen beislefferyn (1286), gewan mit ir einen son Apecz, gab ym in schilt einen bunten lawe mit einen helm auf das houpt gestôrczt, lies die hernach ym vorelichen, hilt den bastard underm mantel, gab ym ein das sloz Tenneberg. ${ }^{5}$ )

An diesem Bericht ist nun allerdings verdächtig, daß die Legitimation durch nachfolgende Ehe in der Form der

1) Vgl. Grimm, Rechtsaltertümer ${ }^{4}$ I S. $215 \mathrm{f},-{ }^{2}$ ) Lorenz, Deutschlands Geschichtsquellen ${ }^{8}$ II S. $103 \mathrm{ff}$ - - ${ }^{3}$ ) Ausgabe von R. von Liliencron. Jena 1859 (3. Bd. der Thüringischen Gesch.-Quellen) cap. 546 S. 458. - ${ }^{+}$) Nach Jöcher, Allg. Gelehrtenlexikon II. Teil, Spalte 2452 geb. um 1450, trat 1474 in das Dominikanerkloster Pirna. - 5) Mencke, Scriptores rerum Germ. II Spalte 1487. 
Mantelsetzung hier bei einem adulterinus in Anwendung gekommen sein soll, dem sowohl Kaiser Justinian wie Papst Alexander III. diese Wohltat versagt hatten.

Allein es ist trotzdem nicht ausgeschlossen, daB im vorliegenden Falle diese Zeremonie, wenn auch nicht mit ihren Rechtswirkungen, so doch in ihrer Form tatsächlich gehandhabt wurde. Denn der fragliche adulterinus Apetz war nach dem Zeugnisse desselben Johannes Rothe schon vorher durch König Rudolf legitimiert worden. ${ }^{1}$ ) Dasselbe berichtet uns das auf den verschollenen Annalen des St. Thomasklosters fußende Chronicon terrae Misnensis ${ }^{2}$ ), welches in seinem ersten für uns in Betracht kommenden Teil nach 1463 niedergeschrieben ist. ${ }^{3}$ ) Apetz war also bei der Vermählung seiner Erzeuger schon im Besitz ehelicher Rechte. Es ist nun durchaus nicht undenkbar, daß man, um jedes Mißverständnis auszuschließen, die Mantelsetzung trotzdem angewendet hat, um die Ehelichkeit des Apetz neuerlich zu dokumentieren. Eine darüber hinausgehende Bedeutung hätte dieselbe in unserem Falle allerdings nicht gehabt. Aber selbst, wenn der Bericht Rothes nicht auf Wahrheit beruhen sollte, beweist er doch, daß jhm die Legitimation durch nachfolgende Ehe in der Form, daß die Kinder unter den Mantel der Mutter gestelit wurden, ein bekanntes Inistitut war, das er dann freilich auf unpassende Verhältnisse übertragen hätte.

In Lübeck war es noch gegen Ende des 16. Jahrhunderts üblich, daß die Brautkinder bei der Trauung unter die hoiken $=$ Mäntel ${ }^{4}$ ) der Brautleute gesetzt wurden, allerdings erregte diese Sitte schon AnstoB. Der Lübeckische

1) Unde so liez er den selbin kebis son Apetzin yn dem andern iare domoch [1287] den konnig elichin. Der gab ym an synen schilt den bunten Doringischin leuwin mit eyme helme uber daz hoibet gestrutzt zcu eine unterscheide der unelichin gebort. Mencke a. a. O. II Spalte 1748. - - ${ }^{2}$ ) Lorenz a. a. O. II S. $116 \mathrm{f} . \quad{ }^{3}$ ) Albertus ... vocavit filium suum Albertum natum de concubina scilicet de Künnen von Ysenberg, quem legitimare sibi fecit, dedit sibi quam plura castra .... Mencke a. a. O. II Spalte 327. Hier kann nur eine legitimatio per rescriptum gemeint sein. - 4) Schiller und Lübben, Mittelniederdeutsches Wörterbuch II S. 281.

Zeitschrift für Rechtsgesehichte. XXV. Germ. Abt. 
Superintendent Andreas Pochenius hebt in einem Berichte vom 19. März 1582 an den Stadtrat von Lübeck über eine Kirchenvisitation zu Möln diese hoikensetzung mit besonderem Miffallen hervor:

De geselle und de frowe, wo ick vanne gemeldet, ist dat unechte kind under den hoiken holdende getrouwet, se vele upschenk gemaket und mannigen christliken personen ärgerlich to sehen gewesen. Ick hebbe solches den pfarrer verweten. ${ }^{1}$ )

Eine Dithmarsische Chronik berichtet uns diese Sitte gleichfalls noch für eine sehr späte Zeit, lange nach der Reformation:

Hermannus Emmo oder Emme, so der kerken Hemme im pawestdohme gedehnet, ist, nachdem he de Luthersche lehre angenamen, bi dem pastorat darsulvest gebleven und heft siene meiersche gefriet und nachdem se thovor etlike kindere thosamen getüget, sint deselven, als se tosamen copeleret, der meiersche under den hoyken gestahn und vor ehelik geachtet. ${ }^{2}$ )

Nach dem Zeugnisse des Georg Schulz ${ }^{3}$ ) wurde dieser Brauch in einigen Orten Deutschlands noch in der ersten Hälfte des 17. Jahrhunderts in der Weise beobachtet, dalo die Kinder, sofern sie vermöge ihrer körperlichen Entwicklung dazu fähig sind, bei der Trauung neben der Mutter stehen und dieselbe am Kleide halten:

De consuetudine tamen in nonnullis imperii locis hoc observari solet, ut liberi, si eius aetatis sint, matri in ipsa copula sacerdotali quam proxime adstent eamque vestitu teneant. ${ }^{4}$ )

1) Dreyer, Nebenstunden S. 292. - 2 ) Dreyer a. a. O. S. 291. Schiller und Lübben a. a. O. S. $282 \mathrm{f}$. aus dem (mir nicht zugänglichen) Schleswig-Holsteinschen Anzeiger 1752 fol. 825. - " s) Synopsis institutionum imperialium. Witeberge 1630. - 4) Lib. I tit. 10 (de nuptiis) Anmerk. k S. 33. Diese Stelle wurde von späteren Juristen einfach abgeschrieben und in der Weise entstellt, daß die Worte "si eius aetatis sint", die sich doch nur auf die körperliche Entwicklung der Kinder beziehen, erweitert wurden in si eius aetatis sint, qua intelligere possunt, quid agatur“. So von A. W. Lauterbach († 1678), Collegium theoretico-practicum ad Pandectas (entstanden um die Mitte des 17. Jahrhunderts). Neue Ausgabe Tübingen 1744. Lib. I tit. $6 \S 20$. 
Da G. Schulz seine Notiz nicht von einem Vormann entlehnt ${ }^{1}$ ), sondern aus eigener Anschauung niedergeschrieben zu haben scheint, so ist kein Grund vorhanden, an der Wahrheit zu zweifeln.

In Brabant ist uns für das 13. Jahrhundert eine ähnliche Formalität bezeugt, wenn es gilt, den rechtmäßigen Abschluß einer Ehe und demgemäß die Ehelichkeit der Kinder zu beweisen. Nach der Keure ${ }^{2}$ ) von Terhulpen vom 3. Juni $1230^{3}$ ) hat der überlebende Ehegatte, wenn die Ehe angefochten wird, den rechtmäßigen Abschluß der Ehe mit zwei Nachbarn vor dem Altare zu beteuern, indem er den aus dieser Ehe stammenden Säugling auf dem linken Arm trägt oder, wenn das Kind schon laufen kann, unterm linken Rockschoß (sub ora palli sui sinistra) hält:

Si vir duxerit mulierem et ille sit altioris sanguinis, in illa fecerit ius ecclesiasticum, et si vir moriatur et parentes viri dicant, quod virum legitime non duxerit, illa, si puerum habet, qui lactens sit, debet illum adportare super brachium suum sinistrum ad sinistrum coram altari et debet ibi comparare eum duobus vicinis suis idoneis, quod vir suus eam legitime duxerit et ius ecclesiasticum compleverit. Si infans talis sit aetatis, quod propriis viribus ambulare possit, sub ora pallii sui sinistra illum adducet. De viro

Stryck ( $\uparrow 1710)$, Usus modernus pandectarum, 4. Ausgabe Halle i. M. 1722, zu Digest I tit. 6 (De his qui sui vel alieni iuris sunt) $\S 10$. Von Lauterbach übernahm die gleiche Stelle R.F.Telgmann, Commentatio iuris feudalis de genuia significatione vasalli eiusque iure exinde fluenti. Braunschweig und Leipzig 1728 , cap. 3 § 24 A.b. S. 96, von diesem J. M. F. Lochner in der oben S. 154 angegebenen Dissertation S. 24. G. F. Wagner, Disputatio de legitimatione per subsequens matrimonium. 1652, cap. 25 hat die Stelle von Schulz noch in ihrer ursprünglichen Gestalt.

i) Wenigstens nennt er keinen Autor. Die Nachschreiber des. Schulz nennen gewissenhaft ihre Quellen. - 2) Über Keuren im allgemeinen vgl. Warnkönig, Flandrische Staats- und Rechtsgeschichte I, S. $387 \mathrm{ff}$, bes. $390 \mathrm{ff}$. - ${ }^{3}$ ) Les gestes des ducs de Brabant, par Jean de Klerk, d'Anvers publiés par J. F. Willems Tom I. (= De Brabantsche Yeesten) Brüssel 1839 S. 632 . Actum Lovanii et datum a. d. 1230 feria secunda post octavam pentecostes. Diese Keure ist bestätigt vom Hz. von Lothringen. 
autem similiter fiet. Post hanc probationem factam dominus dux illos tueri debet et rim omnem sicut et caeteros omnes debet reprimere.

In Schweden und wohl überhaupt in den nordischen Ländern wurde das vor der Ehe geborne Kind zum Zeichen seiner Legitimierung bei der Trauung der Eltern in sinu et sub pallio patris gestellt, also nicht unter den Mantel der Mutter. ${ }^{1}$ )

Trotzdem die Nachrichten der Quellen über die Mantelsetzung bei der Legitimation durch nachfolgende Ehe sehr spärlich sind, muß diese Sitte doch einstens eine größere Verbreitung gehabt haben, denn die per subsequens matrimonium legitimierten Kinder werden ganz allgemein, auch ohne Beziehung auf die Mantelsetzung, als Mantelkinder, mantellati, bezeichnet.

Das Erbrecht von Fivelgo und Hunsingo definiert Mantelkinder als Kinder, die von zwei Leuten geboren, welche Eltern hernach nach Sitte und Gewohnheit zusammen heiraten. ${ }^{2}$ )

Die oben ${ }^{3}$ ) erwähnte Sachsenspiegelglosse aus dem 15 . Jahrhundert fügt der Stelle über die Legitimation durch nachfolgende Ehe, ohne zu erwähnen, daß die Kinder etwa unter den Mantel der Mutter gestellt werden, hinzu: Und dusse heite wy mantel kindere.

Nach der vom Frankenberger Schöffen Johann Emerich im Jahre 1493 niedergeschriebenen Samlung der alten Rechte und Gewohnheiten der Stadt Frankenberg (in Hessen) soll der Schöffe "van unberuchtigen frommen aldern syn beyderteil eelich geborn, keyn mantelkynt".4)

In einer Konstitution vom 3. Jänner 1593 verordnete Herzog Heinrich Julius von Braunschweig, daß es keineswegs gestattet sein solle "die ausser der ehe erzeugte oder mantelkinder per subsequens matrimonium oder in andere wege, wenn es uns oder andern lehen-

1) I. Ihre, Glossarium Suigothicum, Upsala 1769, Tom. II Spalte 619: Skỏtsåtubarn, infans, qui ante nuptias natus sub actu consecrationis matrimonalis in sinu et sub pallio patris collocatus legitimabatur. Hier ist das pallium patris unzweifelhaft der Mantel des Vaters. 2) Die Stelle oben S. 127. - ${ }^{3}$ ) Seite 120. - 4) Friedrich Christaf Schmincke, Monumenta Hassiaca, Kassel 1748, II. Teil S. 681. 
herren oder auch den echt und recht gebornen agnaten und mitbelehnten oder auch löblichen von unsern voreltern, vorfaren und uns erlangten und confirmirten privilegien zum nachteil geschehen wolte, zu le gitimieren. $\left.{ }^{1}\right)$

Im Gandersheimischen Landtagsabschied vom 10. Oktober 1601 erklärte dann der Herzog, vorerwähnte „wegen der mantel- und per subsequens matrimonium legitimirten kinder" erlassene Konstitution getreulich einzubalten und "dieselben kinder oder einige spurios" zu neuen oder adeligen Lehen nicht zuzulassen. ${ }^{2}$ )

In England ist für die per subsequens matrimonium für das kirchliche Rechtsgebiet legitimierten Kinder gleichfalls die Bezeichnung mantle children in Gebrauch gewesen ${ }^{3}$ ), und ebenso wurden in Frankreich die durch das mettre sous le poile oder sous le drap oder durch das pallio cooperire legitimierten Kinder mantiellati, mantellati ${ }^{4}$ ) genannt.

In England und Frankreich, wo es an einem eigenen Namen für die per pallium ecclesiae legitimierten Kinder gebrach - wenigstens ist uns nichts davon bekannt scheint man den Ausdruck "Mantelkinder" von Deutschland rezipiert zu haben, obwohl er auf das Institut des pallio cooperire und dem mettre sous le poile nicht paßte.

Niederdeutsche Quellen bezeichnen die legitimatio per subsequens matrimonium kurzweg als "dat onder de huik wettigen" und die so legitimierten Kinder als "mantelkinderen", "enfans de mạteau".5)

1) Telgmann, Commentatio iuris feudalis, cap. $3 \S 24$ S. 98. Willich, Churfürstl. Braunschweig-Lüneburgische Landesgesetze und Verordnungen I S. $636 \mathrm{f} . \quad{ }^{2}$ ) Willich a. a. O. Telgmann a. a. 0. Stellen über mantellati in dieser allgemeinen Bedeutung aus dem Saalbuch der St. Thomaskirche zu Straßburg bei Brinckmeier, Glossarium diplomaticum II 169; Carpentier, Glossarinm, verb. mantellatus. Jüngere Belege aus den Jahren 1780 und 1819 bei Dieck, Beiträge zur Lehre von der Legitimation dareh nachfolgende Ehe, S. 288/89. $\left.{ }^{3}\right)$ Pollock and Maitland, The history of english law before the time of Edward I., Cambridge 1895, II. Bd. S. 395. - ") Bige on, De la legitimation par acte du souverain S. 69. Übereinstimmend Du Cange und Carpentier: Mantellatus dicitur filius ante matrimonium natus, qui in ipsis nuptiarum sacris solemnibus cum patre et matre pallio cooperitur legitimationis gratia. - $\left.{ }^{5}\right)$ Noordewier, Nederduitsche regtsoudheden (Utrecht 1853) S. 41. Raepsaet, Analyse historique 
Diese Legitimationsform ist nicht aus kirchlichen Zeremonien erwachsen, sondern gründet sich auf alte einheimische Rechtsgebräuche. Sie ist hervorgegangen aus einer bei den Völkern des Morgen- uud Abendlandes weit verbreiteten Adoptionsform, die wir zunächst kennen lernen müssen.

Diodorus Siculus erzählt, daß Hera auf Bitten ihres Gemahls Zeus den jungen Herakles in der Weise adoptierte, daß sie zu seinem Bette herantrat, den Knaben sich an den Leib legte und dann, um einen wahren Geburtsakt nachzuahmen, denselben unter ihren Kleidern zur Erde nieder ließ. Daran knüpft er die wichtige Bemerkung, daß die Barbaren diese Sitte auch noch heutzutage bei der Adoption beobachten:

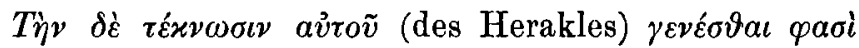

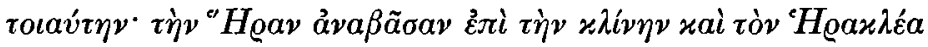

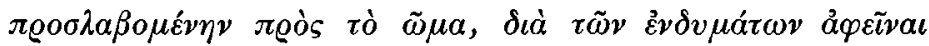

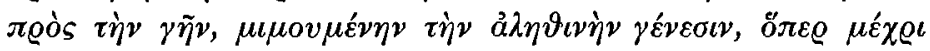

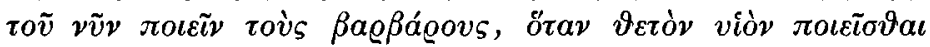
Bov́ $\lambda \omega \nu \tau a u .{ }^{2}$ )

Diese Nachricht des Diodorus Siculus wird uns auch durch eine Reihe anderer Quellenstellen bestätigt.

Auf dieselbe Weise wurde nach dem Bericht Alberts von Aachen (Albertus Aquensis) ${ }^{3}$ ) auf dem ersten Kreuzzug Balduin, der Bruder Gottfrieds von Bouillon, vom Fürsten von Edessa adoptiert:

Dux ... Baldewinum sibi filium adoptivum fecit, sicut mos regionis illius et gentis habetur, nudo pectori suo illum astringens et sub proximo carnis suae indumento semel hunc investiens fide utrimque data et accepta. Sic utrisque firmatis paternitate et filiatione. ${ }^{4}$ )

et critique de l'origine et des progrès des droits civils, politiques et religieux des Belges et Gaulois Bd. III (= Raepsaet, Oeuvres complètes Bd. V) Nr. 316 S. 42. Stallaert, Glossarium van verouderde rechtstermen, kunstwoorden en andere uitdrukkingen uit Vlaamsche, Brabantsche en Limburgsche oorkonden II, S. 189. Allerdings unterscheiden alle genannten Autoren zwischen Pallium der Kirche und Mantel nicht gehörig.

1) Ausgabe von Petrus Wesselingius, Amsterdam 1746. - ${ }^{2}$ ) Lib. IV, 39 (Tom. I pag. 284). - ${ }^{3}$ ) Vgl. Watten bach, Deutschlands Geschichtsquellen 'II S. $178 \mathrm{ff.}-{ }^{4}$ ) Albertus Aquensis, Historia Hierosolimi- 
Guibert, Abt von Nougent-sous-Couci ${ }^{1}$ ), erzählt über dieselbe Adoption des Balduin:

Adoptionis autem talis pro gentis consuetudine dicitur fuisse modus: Intra lineam interulam, quam nos vocamus camisiam, nudum intrare eum faciens sibi adstrinxit et haec omnia osculo libato firmavit. Idem et mulier post modum fecit. ${ }^{2}$ )

Die Beobachtung derselben Sitte berichtet für die 2 . Hälfte des 13. Jahrhunderts der griechische Geschichtsschreiber Georg Pachymeres († nach 1308) ${ }^{3}$ ) bei der Adoption des Bulgarenfürsten Sphentisthlab durch die bulgarische Carin Maria, eine Nichte des 1282 verstorbenen Michael VIII. Paläologus, wobei zugleich die Verbrüderung mit Marias Sohn Michael zum Ausdruck kam:

Res palam in ecclesia celebrata sic est: Post adhibitos a sacerdote solemnes in talibus occursus benedictiones et ritus caeteros, magno allucente funalium numero Maria regium diducens pallium, ambos hine atque inde ulnis admovit Michaelem pusionem ac senem Sphentisthlabum. ${ }^{4}$ )

Nach dem Zeugnisse des spanischen Historiographen Surita $(\dagger 1580)$ ging auch in Arragonien im 11. Jahrhundert die Adoption in derselben Weise vor sich:

Adoptionis ius illorum temporum instituto more rite sancitum tradunt, qui is inoleverat, ut quae adoptaret per stolae fluentes sinus eum, qui adoptaretur, traduceret. ${ }^{5}$ )

Unter gleichbedeutenden Zeremonien erfolgte in Spanien gegen Ende des 10. Jahrhunderts die Adoption des unechten Königssprossen Mudarra durch seine Stiefmutter Sanctia.

tanae expeditionis lib. 3 cap. 21 bei Bongars, Gesta dei per Francos. Tom. I S. 222.

1) Vgl. Wattenbach a. a. O. II S. 218. 247. - 2) Guibertus, Gesta dei per Francos lib. 3 cap. 13 bei Bongars a. a. O. I S. 496 . 3) Georgii Pachymeris Michael Palaeologus sive historia rerum a Michaele Palaeologo gestarum. Ausgabe Griech. und Lat. Venedig 1729. Diesen Bericht des Pachymeres übernimmt gegen Ende des 16. Jahrhunderts Maurus Orbini, Il regno de gli Slavi, Pesaro 1601 pag. 464. 4) Lib. VI cap. 2 (a. a. O. S. 242). Vgl. auch dazu Jireček, Geschichte der Bulgaren S. 276. - ${ }^{5}$ ) Indices rerum ab Aragoniae regibus gestarum lib. I (zum Jahr 1034) in Ausgabe 1578 S. 23 in Hispania illustrata T'om. III S. 18. 
Der im Jahre 1624 verstorbene Jesuit Johann Mariana berichtet darüber folgendes:

Eius adoptionis hic ritus fuit, rudis quidem sed insignis gentique solennis: Quo die (Mudarra) nostra sacra suscepit et balteo militari donatus a Garsia Ferdinando comite Castellae est, novercae (Sanctiae) amplissimi indusii manica acceptus, collari etiam indusii capiti inserto additoque osculo in familiam transiit. Ex eo more vulgare proverbium manavit ,ingressus manica, collari tandem egreditur" de eo qui ad familiaritatem admissus maiora sibi in dies sumit. ${ }^{1}$ )

Bei den Römern war noch in der Kaiserzeit eine adoptio in cubiculo pro toro geniali üblich, deren Vorgang wir allerdings nicht näher kennen, der sich aber von dem der früher genannten Fälle nicht weit entfernt haben dürfte und jedenfalls im Grundgedanken damit übereinstimmt.

Plinius erzählt von der Adoption Traians durch Nerva folgendes:

Fecit hoc Nerva, nihil interesse arbitratus, genueris an elegeris: si perinde sine iudicio adoptentur liberi ac nascuntur, nisi tamen quod aequiore animo ferunt homines, quem princeps parum feliciter genuit, quam quem male elegit. Sedulo ergo vitavit hunc casum nec iudicium hominum sed deorum etiam consilium adsumsit. Itaque non tuo in cubiculo sed in templo, nec ante genia lem torum sed ante pulvinar Iovis optimi maximi adoptio peracta est. ${ }^{2}$ )

Aus dem Umstand, daß Nerva die Adoptionsform in cubiculo ante genialem torum bei der Adoption Traians durch eine höhere, durch eine adoptio in templo ante pulvinar Iovis optimi maximi ersetzte, darf mit Sicherheit geschlossen werden, daß erstere Adoptionsform als eine private neben den offiziellen öffentlichen Adoptionsarten noch in der Kaiserzeit bestanden hat.

Die symbolische Bedeutung dieser Adoptionsform war nun, sofern ein Mann adoptierte, die Nachahmung des Zeu-

1) Joh. Mariana, Historiae de rebus Hispaniae libri 30 , Lib. 8 cap. 9. Ausgabe Mainz 1605 S. 341 , Ausgabe Toleti 1592 S. 383 f. 2) Plinius, Panegyricus ad Traianum, cap. 8. 
gungsaktes, sofern eine Frau adoptierte, die Fiktion des Geburtsaktes. Diodorus Siculus sagt von der Juno ausdrück-

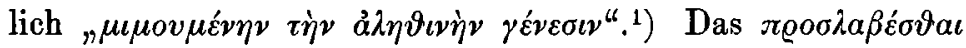

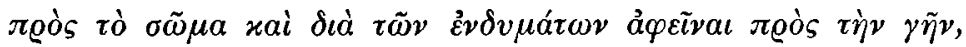
das nudo pectori suo astringere et sub proximo carnis suae indumento investire, das intra lineam interulam (= camisiam) nudum intrare, das diducere pallium et ulnis admovere, das traducere per stolae fluentes sinus, das acceptum amplissimi indusii manica, collari etiam indusii inserto additoque osculo in familiam transire, und schlieflich auch das adoptare in cubiculo ante genialem torum, hat durchaus denselben Grundgedanken, es will das Adoptivkind als leibliches Kind des Adoptierenden hinstellen.

Ursprünglich handelte es sich wohl nur um die Nachahmung der leiblichen Geburt, infolgedessen der Akt der Adoption nur von Frauen vorgenommen wurde. Im vorgenannten Beispiel adoptiert nicht Zeus den Herakles, sondern er wendet sich bittend an seine Gemahlin Hera, daßs sie den göttlichen Jüngling adoptiere. Erst später wurde der Adoptionsakt auch von Männern, eventuell also von beiden Adoptiveltern ${ }^{2}$ ), vorgenommen und mußte hier natürlich zu einer Symbolik des Zeugungsaktes werden.

Ebenso wie bei den Römern hinsichtlich der rechtlichen Voraussetzungen und der Wirkungen der Adoption der Satz galt „adoptio imitatur naturam", so können wir das zum Teil auch in bezug auf die Form der Eingehung derselben sagen. Nach Cicero ${ }^{3}$ ) soll die Annahme an Kindes Statt quam maxime reritatem suscipiendorum liberorum nachahmen. Tatsächlich war auch den Römern, wie wir gesehen, die Adoption in der Form der initatio naturae nicht unbekannt.

Diese symbolische Form der Adoption wurde nun herübergenommen, als man auch für die Legitimation einer besonderen symbolischen Form bedurfte: „Adoption und Legiti-

1) Vgl. auch Du Cange, Dissertations ou reflexions sur l'histoire de s. Louys du sire de Joinville, Diss. XXlI. Eberhard Otto, De iurisprudentia symbolica, Traiecti ad Rhenum 1730, exercitatio III, cap. 4 und 5 S. $271 \mathrm{ff} .{ }^{2}$ ) Vgl. die Adoption des Balduin auf S. 166 f. 3) Oratio pro domo 36 . 
mation haben ja beide den Zweck der Aufnahme in das Geschlecht, diese eines natürlichen, jene eines fremden Kindes, die Förmlichkeiten beider berühren sich daher. "1)

Der Legitimationsform durch Stellung der Kinder unter den Mantel der Mutter bzw. des Vaters oder beider Erzeuger liegt demnach ebenso wie der gleichen Adoptionsform der Gedanke einer Fiktion des Zeugungs- bzw. Geburtsaktes oder beider Akte zugrunde.

Ähnlich wie die genannten Adoptionsformen auch als Legitimationsformen benutzt wurden, so wurde auch die in den nordischen Ländern bei der Adoption übliche Kniesetzung (aettleiding) ${ }^{2}$ ) neben der Stellung des Kindes in sinu et sub pallio patris ${ }^{3}$ ) verwendet, um die Legitimität des vor Eingehung der Ehe gebornen Kindes anzuzeigen.")

Verwandt mit dieser Kniesetzung ist die Schoßsetzung, wie sie uns bei einer im Jahre 1317 in Trient vor dem Notar abgeschlossenen Ehe begegnet. Danach hält die Mutter ihr voreheliches Kind, das durch die Ehe legitimiert werden soll, während der Trauung in den Armen und auf dem Schoße. ${ }^{5}$ )

An eine symbolische Zeugung bzw. Geburt ist bei dieser Knie- und Schoßsetzung nicht zu denken, sondern das Kind sollte dadurch nur als zur Familie gehörig und als im Vollbesitz ehelicher Rechte stehend nach außen hin gekennzeichnet werden.

Eine weitere Legitimationsform bestand darin, daß die Kinder ebenfalls zur Trauung zugezogen, aber nicht unter

1) Grimm, Deutsche Rechtsaltertümer ${ }^{4}$ I. S. 638. - 2) Vgl. darüber Mathilde Wergeland, Aettleiding (Züricher Dissertation) München 1890. Grimm, Deutsche Rechtsaltertümer 4. Ausgabe von Heusler und Hübner Leipzig 1899, I S. 213 und 638. - $\left.{ }^{3}\right)$ S. $164 .-$ 4) Schlyter, Corpus iuris Sueo-Gothorum antiqui Vol. XIII S. 578. 5) Ficker, Ital. Forschungen IV, Nr. 505 S. 514 ff.: Ipsa domina Polla (Braut) semper retinendo in suis brachiis et gremio Franciscum filium dictorum coniugalium natum ante hanc desponsationem ex predictis d. Polla et Egeno; et ita predictus d. Egenus ipsum Franciscum infantem in sum filium legitimum recognovit et deinceps perpetuo habere intendit; .... et Franciscus eorum filius legitimus de vero matrimonio natus censeatur et iuridice approbetur et publice habeatur, teneatur ab omnibus et tractetur. 
das Pallium oder unter den Mantel gestellt wurden, sondern einfach vor den Eltern standen und so gewissermaßen unter das Buch zu stehen kamen, aus dem der zugewandte Priester die Konsensfragen, die Benediktionsformel und die verschiedenen Gebete las.

Der holländische Sachsenspiegel in der Groudaischen Ausgabe ${ }^{1}$ ), Artikel 58, sagt, daß unechte Kinder per subsequens matrimonium legitimiert werden, wenn sie bei der Trauung unter das Buch genommen werden: of si den outsten in der trouwen mede onder den boeke naem, so soude hi echtes echt hebben, ut in codice de naturalibus liberis 1 . si quis $[=1.10 \mathrm{C} . \mathrm{V}, 27]$.

Wir besitzen über diese Legitimationsform allerdings nur diese eine Quellenstelle, sie scheint aber doch verbreiteter gewesen $\mathrm{zu}$ sein, da die von dieser Zeremonie sogenannten Buchkinder doch öfter vorzukommen scheinen. ${ }^{2}$ )

An eine symbolische Zeugung bzw. symbolische Geburt ist in diesem Falle ebensowenig zu denken, wie bei der Schoß- und Kniesetzung, sondern es sollte einfach die abstrakte Wirkung der Ehe für die Kinder irgendwie äußerlich und öffentlich zum Ausdruck gebracht werden. Wir finden hier den reinen Ausdruck des Publizitätsprinzipes. Das Hauptgewicht lag in der Zuziehung der Kinder zur öffentlichen Trauung. Eine friesische Rechtsquelle bezeichnet auch die Trauung geradezu als „unter Buch und Stola zusammen geben (under bok ende stola gader jewen). ${ }^{3}$ )

1) Die alte Goudaische Ausgabe von 1479 neu herausgegeben von Grupen und Meermann, Frankfurt und Leipzig 1763. - 2) Haltaus, Glossarium Germanicum medii aevi. Spalte 191. Irrig bezieht Zöpfl, Grundsätze des allg. und deutschen Staatsrechtes * II S. 81 den Namen „Buchkinder" ohne jede Quellenangabe auf die per rescriptum legitimierten, "weil si häufig eine ausführliche Urkunde in forma libelli erhielten". - ${ }^{3}$ ) Hettema, Het Fivelingoer en Oldampster landregt, 18: Hwersa en fruwe anne mon nom and bi ther bern bi thach and nede se thi prester under bok ende stola nout gader jewen and tha word ther ther to herden nout spretzen, alsa se starf, wolde hi tha to erum hebba and to aft makia; sa was goud. (Auch bei Fockema Andreae, Bijdragen tot de nederlandsche rechtsgeschiedenis I S. 79f.) 